
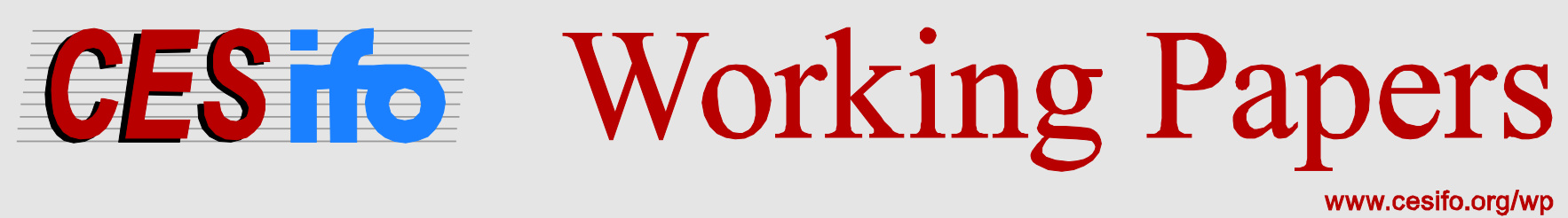

\title{
Sector Specific News Shocks in Aggregate and Sectoral Fluctuations
}

\author{
Christoph Görtz \\ John D. Tsoukalas
}

\author{
CESIFO WORKING PAPER NO. 4269 \\ CATEgory 6: Fiscal Policy, Macroeconomics AND GROWTH \\ JUNE 2013
}

Presented at CESifo Area Conference on Macro, Money \& International Finance, February 2013

An electronic version of the paper may be downloaded

- from the SSRN website:

- from the RePEc website:

- from the CESifo website:

WWW.SSRN.com

www.RePEc.org

www.CESifo-group.org/wp

\section{CESifo}




\title{
Sector Specific News Shocks in Aggregate and Sectoral Fluctuations
}

\begin{abstract}
Using a two-sector estimated DSGE model with a financial channel we show the sector where TFP news arrives matters for its propagation and quantitative importance. Anticipated increases in TFP expected to arrive in the consumption sector are expansionary while those in the investment sector are broadly contractionary. Our results indicate a significant role of TFP news shocks as a predictive force behind fluctuations. Consumption sector TFP news shocks generate both aggregate and sectoral co-movement and account for approximately, 31\%, 21\%, $43 \%, 29 \%$ in the variance of output, investment, hours worked, and consumption respectively in business cycle frequencies. The financial channel provides amplification to TFP news. We discuss the relationship of our findings with VAR based estimates of TFP news shocks.
\end{abstract}

JEL-Code: E200, E300.

Keywords: news, business cycles, DSGE, Bayesian estimation.

\author{
Christoph Görtz \\ University of Birmingham \\ Department of Economics \\ J.G. Smith Building, Edgbaston \\ UK - Birmingham, B15 2TT \\ c.g.gortz@bham.ac.uk
}

\author{
John D. Tsoukalas \\ University of Glasgow \\ Adam Smith Business School / Economics \\ 312 Adam Smith Building \\ UK - Glasgow, G12 8RT \\ john.tsoukalas@glasgow.ac.uk
}

First version: March 2011

This version: May 2013

This is a substantially revised version of an earlier draft, titled, 'News and Financial Intermediation in Aggregate and Sectoral Fluctuations'. We thank Harald Uhlig, Paul Mizen, Francesco Zanetti, Lilia Karnizova, Emilio Fernandez-Corugedo, Hashmat Khan and especially our discussant Kai Christoffel for useful comments and suggestions. We thank seminar participants at the Richmond Federal Reserve Bank, San Francisco Federal Reserve Bank, Bank of Finland/CEPR/Philadelphia Fed 2012 Conference (Bank of Finland), CESifo Area Conference on Macro, Money and International Finance 2013, Royal Economic Society 2012 Annual Conference (University of Cambridge), Canadian Economics Association 2012 Annual Conference (University of Calgary), Birmingham Econometrics and Macroeconomics 2012 Conference and University of Piraeus for helpful comments. We are grateful to Giorgio Primiceri for providing computer code and Simon Gilchrist for providing the excess bond premium series. All remaining errors are our own. 


\section{Introduction}

News shocks about future total factor productivity (TFP) have been proposed as a potentially important source of fluctuations (see Beaudry and Portier (2004), and Jaimovich and Rebelo (2009)). ${ }^{1}$ In an influential paper Beaudry and Portier (2006) confirm this proposition empirically, suggesting that a significant fraction of U.S business cycles is driven by anticipated disturbances. But recent empirical estimates, based on the DSGE methodology (see Fujiwara et al. (2011), Khan and Tsoukalas (2012), Schmitt-Grohe and Uribe (2012)), suggest otherwise, reporting that TFP news shocks play a very minor role in the business cycle, thereby questioning their relevance. In this paper, we take a fresh look at the importance and propagation of TFP news shocks using a two sector estimated DSGE model with financial intermediation and sector specific TFP. We argue that the sector where the TFP shock is anticipated is important for its propagation and quantitative importance.

Our estimated model suggests that sector specific TFP news shocks have very different dynamic implications for both real and nominal macroeconomic aggregates and asset prices. A positive, consumption sector TFP news shock is expansionary, causing a strong increase in investment and hours worked along with increases in output and consumption. At the same time, it is associated with increases in inflation, the real wage, price of capital and the relative price of investment. In addition to broad based co-movement, a consumption sector TFP news shock generates sectoral co-movement, a pervasive stylized fact of business cycles. By contrast, a positive, investment sector TFP news shock causes a significant decline in investment spending, inflation and the real wage, and suppresses the price of capital and the relative price of investment. Quantitatively, consumption sector TFP news shocks are estimated to be important drivers of the business cycle over the sample period 1990 to 2011. They account for approximately $31 \%, 21 \%, 43 \%, 29 \%$ of the variance in output, investment, hours worked and consumption respectively, in business cycle frequencies. They also account for significant shares of the variance in nominal variables, and approximately $40 \%$ of the variance in corporate bond spreads, a key financial indicator used in the analysis. These estimates are robust to a variety of checks, including, among others, incorporating news components in other, non-structural disturbances, considered for example in Khan and Tsoukalas (2012) and Schmitt-Grohe and Uribe (2012), or allowing for news in a common aggregate TFP process that affects both sectors symmetrically.

\footnotetext{
${ }^{1}$ Other recent theoretical work, includes, Beaudry and Portier (2007), Karnizova (2010), Gunn and Jorhi (2011), Gunn and Johri (2011), Kobayashi and Nutahara (2010), Den Haan and Kaltenbrunner (2009), Christiano et al. (2008), Walentin (2012), Chen and Song (2012).
} 
The two sectors in the model produce consumption and investment goods and the latter serve as an input to the production of the former. The model propagates consumption sector TFP news shocks via this sectoral channel that shifts the demand for capital goods. The consumption sector, following the anticipation of a future permanent increase in TFP, demands capital goods from the investment sector, and the latter responds by hiring more hours worked to satisfy demand, bidding up wages and the price of investment goods. The increase in the price of capital provides the market signal for that expansion in investment spending to take place. Financing of capital purchases is permitted by intermediaries which face constraints in their lending. The relaxation of these constraints via a higher price of capital in turn provide a source of financial amplification. It is worthwhile to highlight, this propagation satisfies the conditions emphasized in Beaudry and Portier (2004) for a TFP news shock to be expansionary, namely: (a) the future productivity improvement arrives in the consumption (not the capital goods) sector, (b) it creates current investment demand which, importantly, is met by an increase in hours worked. These conditions, especially (b), are not met following an investment specific TFP news shock because the latter does not stimulate total investment demand; current investment spending declines and agents instead wait for the improvement in TFP to materialize before they begin to invest. The expected future improvement in investment sector TFP implies installed capital is less valuable and as a result its price declines. These different dynamics in capital prices induced by the two types of news shocks - and the corresponding opposite movements in investment demand they generate - are key for the quantification of sector specific news shocks: financial amplification propagates consumption sector TFP news strongly since capital prices rise in response to this shock.

Our model features two departures from one sector estimated DSGE models. First, it builds on the tradition of multi-sector RBC frameworks as in, among others, Long and Plosser (1983), Horvath (1998), Horvath (2000), Hornstein and Praschnik (1997), Dupor (1999), Ramey and Shapiro (1998), and more recently Foerster et al. (2011) who provide evidence on the importance of sector specific TFP shocks. The real side of the model builds on the two sector RBC model of Huffman and Wynne (1999), combined with the nominal elements of the New Neoclassical Synthesis model of Goodfriend and King (1997) and real frictions proposed in Christiano et al. (2005), Smets and Wouters (2007). Second, it introduces a financial channel with financial intermediation constraints as in Gertler and Karadi (2011) and Gertler and Kiyotaki (2010). Recent evidence (see Adrian et al. (2010), Gilchrist and Zakrajsek (2012)) highlighting the important role of intermediaries - following a wave of financial innovation since the early 1990s - in affecting the flow of credit and determination of asset prices motivates this choice. ${ }^{2}$ Extending

\footnotetext{
${ }^{2}$ Recently, DSGE studies have considered financial factors in business cycle models,
} 
the model in this direction is a judicious way to proceed: It permits a parsimonious link between financial markets and the real economy. Importantly, it allows the model to extract potentially useful information about future economic developments, and consequently news shocks, from variation in the excess return to capital which we measure, for reasons explained below, from corporate bond spreads. In the model, the financial intermediary's decision to expand or contract lending is tightly linked to its equity capital, thereby creating a feedback loop between equity capital and capital prices. A higher price of capital generates gains in equity capital and sets in motion this dynamic feedback. This financial channel, when disciplined with information from corporate bond spreads and bank equity capital, provides a source of amplification to the propagation of sector specific TFP news. Importantly, however, the differences in the dynamic propagation of sector specific TFP news shocks highlighted above are robust to the presence (or absence) of the financial channel.

A key source of information in the analysis comes from corporate bond markets. New evidence in Gilchrist et al. (2009) and Gilchrist and Zakrajsek (2012) suggests that medium-to-long maturities, investment grade, corporate bond spreads, predict future movements in output, and employment, with a predictive power that substantially increases in the post 1990 s period. ${ }^{3}$ Further, Philippon (2009) argues that corporate bond spreads provide better signals about future company prospects than equity prices and validates this claim empirically. ${ }^{4}$ We therefore construct measures of non-financial, investment grade, firm level corporate bond spreads and match them to the sectors in the model. ${ }^{5}$ When we inform estimation with these measures we find them to contain a substantive amount of predictive information about business cycles and turn out to be key for identifying a quantitative important role of TFP news shocks. We further scrutinize our estimated TFP news shocks and compare them with an observable indicator of future (company level) earnings derived from the Institutional Brokers Estimate System

e.g. Christiano et al. (2010), Nolan and Thoenissen (2009), Christensen and Dib (2008), Jermann and Quadrini (2012) among others.

${ }^{3}$ The indicator constructed by Gilchrist et al. (2009) is shown to perform better, both statistically and economically, compared to other widely used financial indicators, such as, the Baa-Aaa spread or Commercial paper-T-bill spread across all three measures of economic activity they examine. Most recently, Faust et al. (2013) demonstrate the information from corporate bond spreads to dominate information from over 100 financial indicators, in a real time forecasting context.

${ }^{4}$ He shows a Tobin's $Q$ measure derived from corporate bond market spreads predicts, significantly better, compared to a conventional measure derived from equity prices, corporate investment. Proceeding in a similar fashion, Cummins et al. (2006), construct a measure of Tobin's $Q$ from analysts earnings forecasts and find that it has significant explanatory power for company investment.

${ }^{5}$ Other recent work utilizes information from financial markets. Christiano et al. (2010) and Christiano et al. (2012), use the Moody's Baa corporate bond spread, while Davis (2007) utilizes information from the yield curve, in estimated one sector DSGE models. In a VAR context, Kurmann and Otrok (2012) identify TFP news shocks as the main determinants behind movements in the slope of the yield curve. 
$(\mathrm{I} / \mathrm{B} / \mathrm{E} / \mathrm{S})$ analysts earnings forecasts. We find the latter to be significantly correlated with the TFP news shocks we recover from the model, suggesting our anticipated measure contains information that reflects news about future profitability or future fundamentals more generally.

Our paper contributes to the news shocks, and more broadly sources of business cycles literature. By departing from a one sector model, we highlight important differences in the propagation and importance of sectoral TFP news shocks as drivers of the business cycle. Recent work in Basu et al. (2010) measuring sector specific technical change, with annual industry data, also emphasizes the importance of investigating fluctuations from the lens of a multi sector model. ${ }^{6}$ We find it informative to discuss our results in relationship to VAR based and previous DSGE based estimates of TFP news shocks but also more generally in relation to sectoral TFP shocks. Earlier work, based on the DSGE methodology, has also identified news shocks as important drivers for business cycles (most notably Khan and Tsoukalas (2012), Schmitt-Grohe and Uribe (2012)). But the news sources identified therein lie in non-structural disturbances, such as wage markups and preference shocks that lack a clear micro-foundation, and TFP news shocks account for very small variance shares in the data, for example, less than $10 \%$ in the variance of output. ${ }^{7}$ By contrast, VAR based findings in Beaudry and Portier (2006), Beaudry and Lucke (2010), Barsky and Sims (2011), Forni et al. (2012), Leduc and Sill (2013) report that news about future fundamentals may be important drivers of business cycles especially in medium frequencies, beyond the very short run. ${ }^{8}$ Thus our finding that TFP news shocks are important in those frequencies are in broad agreement to those reported in VAR based studies. For example, the share of (consumption sector) TFP news shocks in the variance of output we estimate $(31 \%)$ is within the share reported in Barsky and Sims (2011) (between $24 \%$ to $42 \%$ ) in the same frequencies, though smaller than what reported in Beaudry and Portier (2006). ${ }^{9}$ Finally, we note our two sector

\footnotetext{
${ }^{6}$ Basu et al. (2010), using a growth accounting methodology document important differences in the macroeconomic effects of consumption vs. investment specific innovations to technology. They therefore conclude using an aggregate index of technology will likely yield inaccurate results, since this measure, by weighting together sectoral processes with different dynamic implications will be subject to specification error.

${ }^{7}$ To be more precise, Schmitt-Grohe and Uribe (2012) report that approximately half of the variance in consumption, over half of the variance in hours worked and $25 \%$ of the variance in output is accounted for by, anticipated wage mark-up and preference shocks. Similarly, Khan and Tsoukalas (2012), report, anticipated wage mark up shocks to explain the majority of the hours worked variance.

${ }^{8}$ It is worthwhile noting that differences in identification assumptions in the VAR studies mentioned above matter for the short run effects in response to TFP news.

${ }^{9}$ Nevertheless there still exist some differences in the short run effects of TFP news shocks between our findings and Barsky and Sims (2011), where it is shown that TFP news do not generate co-movement. However, since we are focusing on sector specific news, while Barsky and Sims (2011) identify news from a measure of aggregate TFP makes the comparison problematic, especially in light of our argument that sectoral news generate qualitatively different dynamics and aggregation may therefore induce a
} 
framework allows to test a restriction, conventionally employed in one sector estimated models, namely, that the relative price of investment reflects (one-to-one) only investment specific shocks, a by-product of assuming a perfectly competitive investment sector. Empirically, we show this restriction is not accurate in the short run: our results suggest that around $40 \%$ of the business cycle variation in the relative price of investment is accounted for by other disturbances, among others, sectoral price mark up shocks. Moreover, generalizing this restriction in our two sector model implies investment specific shocks play a non-negligible role over the sample period as documented in Section 5, in line with findings in Greenwood et al. (2000) and Fisher (2006). Thus our findings, provide, we believe, a more accurate view of fluctuations relative to one sector estimated models. ${ }^{10}$

The rest of the paper is organized as follows. Section 2 describes the model economy. Section 3 describes the estimation methodology, data, and discusses estimation results. Section 4 discusses the propagation of TFP news shocks while Section 5 quantifies the importance of different shocks as driving forces behind aggregate fluctuations. Section 6 provides a comparison of TFP news shocks with I/B/E/S analysts earnings forecasts. Section 7 concludes.

\section{The Two Sector Model}

The sectors in the model produce consumption and investment goods. The latter are used as capital inputs in each sectors' production process, while the former enter only into households utility functions. Appendix B provides details on how 2 digit industries are mapped into sectors using information from the 2005 Input-Output Tables.

The model includes households that consume, save in interest bearing deposits and supply labor on a monopolistically competitive labor market. Employment agencies aggregate different types of labor to a homogenous aggregate for intermediate goods production. A continuum of sector specific intermediate goods firms produce distinct investment and consumption goods using labor and capital services as inputs. Investment goods, after a transformation to capital, serve as an input to the production of consumption goods. These firms rent labor services from the employment agencies and rent capital services on

specification error. We do not use this measure of aggregate TFP in our analysis precisely for this reason.

${ }^{10}$ One sector estimated DSGE models we are aware of (see for example, among others, Khan and Tsoukalas (2012), Schmitt-Grohe and Uribe (2012), Justiniano et al. (2011)) report investment specific shocks are negligible sources of fluctuations. Instead they report a related but broader concept, namely, marginal efficiency of investment (MEI) shocks, are found to be important sources of fluctuations. Our analysis allows to decompose MEI shocks into investment TFP and financial shocks and as we show in Section 5, a significant fraction of MEI shocks can be interpreted as investment specific shocks, or investment sector TFP shocks. 
a perfectly competitive market from capital services producers; they are subject to sector specific Calvo contracts when setting prices. Physical capital producers use investment goods and existing capital to produce new sector specific capital goods. Financial intermediaries collect deposits from households and finance capital acquisitions by capital services producers. A monetary policy authority controls the nominal interest rate.

\subsection{Goods production}

\subsubsection{Intermediate and final goods production}

Intermediate goods in the consumption sector are produced by a monopolist according to the production function,

$$
C_{t}(i)=\max \left\{A_{t}\left(L_{C, t}(i)\right)^{1-a_{c}}\left(K_{C, t}(i)\right)^{a_{c}}-A_{t} V_{t}^{\frac{a_{c}}{1-a_{i}}} F_{C} ; 0\right\} .
$$

Intermediate goods in the investment sector are produced by a monopolist according to the production function,

$$
I_{t}(i)=\max \left\{V_{t}\left(L_{I, t}(i)\right)^{1-a_{i}}\left(K_{I, t}(i)\right)^{a_{i}}-V_{t}^{\frac{1}{1-a_{i}}} F_{I} ; 0\right\}
$$

where $K_{x, t}(i)$ and $L_{x, t}(i)$ denote the amount of capital services and labor services rented by firm $i$ in sector $x=C, I$ and $a_{c}, a_{i} \in(0,1)$ denote capital shares in production. Fixed costs of production, $F_{C}, F_{I}>0$, ensure that profits are zero along a non-stochastic balanced growth path and allow us to dispense with the entry and exit of intermediate good producers (Christiano et al. (2005)). ${ }^{11}$ The variable $A_{t}$ denotes the (non-stationary) level of TFP in the consumption sector and its growth rate, $z_{t}=\ln \left(\frac{A_{t}}{A_{t-1}}\right)$, follows the process,

$$
z_{t}=\left(1-\rho_{z}\right) g_{a}+\rho_{z} z_{t-1}+\varepsilon_{t}^{z}
$$

Similarly, $V_{t}$ is the (non-stationary) level of TFP in the investment sector and its growth rate, $v_{t}=\ln \left(\frac{V_{t}}{V_{t-1}}\right)$ follows the process,

$$
v_{t}=\left(1-\rho_{v}\right) g_{v}+\rho_{v} v_{t-1}+\varepsilon_{t}^{v}
$$

The parameters $g_{a}$ and $g_{v}$ are the steady state growth rates of the two TFP processes above and $\rho_{z}, \rho_{v} \in(0,1)$ determine their persistence. We introduce anticipated com-

\footnotetext{
${ }^{11}$ The fixed costs are assumed to grow at the same rate as output in the consumption and investment sector to ensure that they do not become asymptotically negligible.
} 
ponents in the TFP processes above and describe them in detail in Section 2.4. It is worthwhile noting, our concept of sector specific TFP is different from a usual convention, separating TFP to a neutral (affecting both sectors symmetrically) and investment specific processes. In terms of this convention, a consumption sector TFP is equivalent to neutral minus investment specific TFP. ${ }^{12}$ Later in the robustness checks, we introduce an aggregate common TFP process that affects both sectors equally.

The intermediate goods producers also make a pricing decision under Calvo (1983) contracts which, for space considerations, is described in Appendix C.

Final goods, $C_{t}$ and $I_{t}$, in the consumption and investment sector respectively, are produced by perfectly competitive firms combining a continuum $-C_{t}(i)$ and $I_{t}(i)-$ of intermediate goods, according to the technology,

$$
C_{t}=\left[\int_{0}^{1}\left(C_{t}(i)\right)^{\frac{1}{1+\lambda_{p, t}^{C}}} d i\right]^{1+\lambda_{p, t}^{C}}, \quad I_{t}=\left[\int_{0}^{1}\left(I_{t}(i)\right)^{\frac{1}{1+\lambda_{p, t}^{I}}} d i\right]^{1+\lambda_{p, t}^{I}}
$$

The elasticity $\lambda_{p, t}^{x}$ is the time varying price markup over marginal cost for intermediate firms. It is assumed to follow the exogenous stochastic process,

$$
\log \left(1+\lambda_{p, t}^{x}\right)=\left(1-\rho_{\lambda_{p}^{x}}\right) \log \left(1+\lambda_{p}^{x}\right)+\rho_{\lambda_{p}^{x}} \log \left(1+\lambda_{p, t-1}^{x}\right)+\varepsilon_{p, t}^{x}
$$

where $\rho_{\lambda_{p}^{x}} \in(0,1)$ and $\varepsilon_{p, t}^{x}$ is i.i.d. $N\left(0, \sigma_{\lambda_{p}^{x}}^{2}\right)$, with $x=C, I$. Shocks to $\lambda_{p, t}^{x}$ can be interpreted as mark-up (or cost-push) shocks. Moreover, prices of final goods are CES aggregates of intermediate prices, which are given in Appendix C.

\subsection{Households}

\subsubsection{Household's utility and budget constraint}

Households consist of two types of members, workers and bankers. At any point in time, there is a fraction $1-f$ that are workers and $f$ that are bankers. The workers supply (specialized) labor, indexed by $j$, and earn wages while bankers manage a financial intermediary. Both member types return their respective earnings back to the household. This set-up is identical to Gertler and Karadi (2011) except for the fact that workers have monopoly power in setting wages. The household maximizes the utility function,

$$
E_{0} \sum_{t=0}^{\infty} \beta^{t} b_{t}\left[\ln \left(C_{t}-h C_{t-1}\right)-\varphi \frac{\left(L_{C, t}(j)+L_{I, t}(j)\right)^{1+\nu}}{1+\nu}\right], \quad \beta \in(0,1), \quad \varphi>0, \quad \nu>0
$$

\footnotetext{
${ }^{12}$ Recent work in Basu et al. (2010), using a growth accounting methodology, estimate sector specific technical change and emphasize this distinction.
} 
where $E_{0}$ is the conditional expectation operator, $\beta$ is the discount factor and $h$ is the degree of (external) habit formation. The inverse Frisch labor supply elasticity is denoted by $\nu$ while $\varphi$ is a free parameter which allows to calibrate total labor supply in the steady state. ${ }^{13}$ The variable $b_{t}$ is a intertemporal preference shock, which affects both the marginal utility of consumption and the marginal disutility of labor. It is assumed to follow the stochastic process,

$$
\log b_{t}=\rho_{b} \log b_{t-1}+\varepsilon_{t}^{b}
$$

where $\rho_{b} \in(0,1)$ and $\varepsilon_{t}^{b}$ is $i . i . d N\left(0, \sigma_{b}^{2}\right)$.

The household's flow budget constraint (in consumption units) is,

$$
C_{t}+\frac{B_{t}}{P_{C, t}} \leq \frac{W_{t}(j)}{P_{C, t}}\left(L_{C, t}(j)+L_{I, t}(j)\right)+R_{t-1} \frac{B_{t-1}}{P_{C, t}}-\frac{T_{t}}{P_{C, t}}+\frac{\Psi_{t}(j)}{P_{C, t}}+\frac{\Pi_{t}}{P_{C, t}},
$$

where $B_{t}$ is holdings of bank deposits (which are risk free and equivalent to government bonds), $\Psi_{t}$ is the net cash flow from household's portfolio of state contingent securities, $T_{t}$ is lump-sum taxes, $R_{t}$ the (gross) nominal interest rate paid on deposits and $\Pi_{t}$ is the net (after a start-up fund given to new bankers' members of household) per-capita profit accruing to households from ownership of all firms (financial and non-financial). Notice above, the wage rate, $W_{t}$, is identical across sectors due to perfect labor mobility.

Wage setting. Each household $j \in[0,1]$ supplies sectoral specialized labor, $L_{x} t(j)$, $x=C, I$, monopolistically as in Erceg et al. (2000). A large number of competitive "employment agencies" aggregate this specialized labor into a homogenous labor input which is sold to intermediate goods producers in a competitive market. The wage decision details are described in Appendix C.

\subsection{Capital goods production}

Capital services producers. There is a perfectly competitive sector with capital services producers that transform physical capital to capital services. At the end of period $t$ capital services producers in sector $x=C, I$, purchase sector specific physical capital $\bar{K}_{C, t}$ or $\bar{K}_{I, t}$ from physical capital producers (described below) at price $Q_{C, t}$ or $Q_{I, t}$. The sector specific prices of capital are expressed in consumption units and are defined, for sector $x$, as the ratio, $Q_{x, t}=\frac{\Phi_{x, t}}{\Lambda_{t}}$, where $\Lambda_{t}, \Phi_{x, t}$, are the lagrange multipliers on the households' budget constraint, and capital accumulation constraint respectively. These sector specific prices are equivalent to (sector specific) Tobin's marginal $Q$. At the beginning of the next

\footnotetext{
${ }^{13}$ Consumption is not indexed by $(j)$ because the existence of state contingent securities ensures that in equilibrium, consumption and asset holdings are the same for all households.
} 
period, capital services producers set the utilization rate of capital. The utilization rate, $u_{x, t}$, transforms physical capital into capital services according to

$$
K_{x, t}=u_{x, t} \xi_{x, t}^{K} \bar{K}_{x, t-1}, \quad x=C, I
$$

Capital services producers incur costs when setting utilization, which are denoted by $a_{x}\left(u_{x, t}\right)$ per unit of capital. This function has the properties that in the steady state $u=1, a_{x}(1)=0$ and $\chi_{x} \equiv \frac{a_{x}^{\prime \prime}(1)}{a_{x}^{\prime}(1)}$, denotes the cost elasticity. They rent capital services in perfectly competitive markets to intermediate goods produces and earn a rental rate equal to $R_{x, t}^{K} / P_{C, t}$ per unit of capital.

In the transformation above, we allow for a capital quality shock (as in Gertler and Karadi (2011)), $\xi_{x, t}^{K}$, and assume it evolves according to

$$
\log \xi_{x, t}^{K}=\rho_{\xi^{K}, x} \log \xi_{x, t-1}^{K}+\varepsilon_{x, t}^{\xi^{K}}, \quad x=C, I,
$$

where $\rho_{\xi^{K}, x} \in(0,1)$ and $\varepsilon_{x, t}^{\xi^{K}}$ is $i . i . d N\left(0, \sigma_{\xi^{K}}^{2}\right)$. This disturbance shifts the demand for capital and directly affects its value - equivalently the value of assets held by intermediaries since they provide finance for capital acquisitions. For this reason we interpret it as a financial shock. ${ }^{14}$

These producers in period $t+1$ in sector $x=C, I$ solve,

$$
\max _{u_{x, t+1}}\left[\frac{R_{x, t+1}^{K}}{P_{C, t+1}} u_{x, t+1} \xi_{x, t+1}^{K} \bar{K}_{x, t}-a_{x}\left(u_{x, t+1}\right) \xi_{x, t+1}^{K} \bar{K}_{x, t} A_{t+1} V_{t+1}^{\frac{a_{c}-1}{1-a_{i}}}\right] .
$$

Further, they sell the un-depreciated component (with $\delta_{x}$ denoting the sectoral depreciation rate) of capital at the end of period $t+1$ at price $Q_{x, t+1}$ to physical capital producers. Hence, total receipts of capital services producers in period $t+1$ are equal to,

$$
\frac{R_{x, t+1}^{K}}{P_{C, t+1}} u_{x, t+1} \xi_{x, t+1}^{K} \bar{K}_{x, t}-a_{x}\left(u_{x, t+1}\right) \xi_{x, t+1}^{K} \bar{K}_{x, t} A_{t+1} V_{t+1}^{\frac{a_{c}-1}{1-a_{i}}}+\left(1-\delta_{x}\right) Q_{x, t+1} \xi_{x, t+1}^{K} \bar{K}_{x, t}
$$

which can be expressed as,

$$
R_{x, t+1}^{B} Q_{x, t} \bar{K}_{x, t} \quad x=C, I
$$

\footnotetext{
${ }^{14}$ Recently this type of exogenous variation to the value of capital has enjoyed increasing popularity in macroeconomic models. Other studies that include this type of shock include for example Gourio (2012), Sannikov and Brunnermeier (2010), Gertler and Kiyotaki (2010) and Gertler et al. (2011).
} 
with

$$
R_{x, t+1}^{B}=\frac{\frac{R_{x, t+1}^{K}}{P_{x, t+1}} \xi_{x, t+1}^{K} u_{x, t+1}+Q_{x, t+1} \xi_{x, t+1}^{K}\left(1-\delta_{x}\right)-a_{x}\left(u_{x, t+1}\right) \xi_{x, t+1}^{K} A_{t+1} V_{t+1}^{\frac{a_{c}-1}{1-a_{i}}}}{Q_{x, t}}
$$

where $R_{x, t+1}^{B}$ is the real rate of return on capital. Since these agents finance their purchase of capital at the end of each period with funds from financial intermediaries (to be described below), $R_{x, t+1}^{B}$ is also the sector specific stochastic return earned by financial intermediaries.

Physical capital production. Capital producers in sector $x=C, I$ use a fraction of investment goods from final goods producers and undepreciated capital stock from capital services producers (as described above) to produce new capital goods, subject to investment adjustment costs as proposed by Christiano et al. (2005). Solving their optimization problem yields a standard capital accumulation equation, ${ }^{15}$

$$
\bar{K}_{x, t}=\left(1-\delta_{x}\right) \xi_{x, t}^{K} \bar{K}_{x, t-1}+\left(1-S\left(\frac{I_{x, t}}{I_{x, t-1}}\right)\right) I_{x, t}, \quad x=C, I
$$

\subsection{News shocks}

We introduce a richer information structure with respect to the sectoral TFP processes. To facilitate illustration we re-write the sector specific (growth) TFP processes,

$$
\begin{aligned}
& z_{t}=\left(1-\rho_{z}\right) g_{a}+\rho_{z} z_{t-1}+\varepsilon_{t}^{z}, \\
& v_{t}=\left(1-\rho_{v}\right) g_{v}+\rho_{v} v_{t-1}+\varepsilon_{t}^{v},
\end{aligned}
$$

Specifically, we assume the respective sectoral innovation consists of two components,

$$
\varepsilon_{t}^{z}=\varepsilon_{t, 0}^{z}+\varepsilon_{t, \text { news }}^{z}, \quad \varepsilon_{t}^{v}=\varepsilon_{t, 0}^{v}+\varepsilon_{t, \text { news }}^{v}
$$

where the first component, $\varepsilon_{t, 0}^{x}$, is unanticipated and the second component, $\varepsilon_{t, n e w s}^{x}$, $x=z, v$ is anticipated or news. For example, Alexopoulos (2011) and Ramey (2011)

\footnotetext{
${ }^{15}$ Sector specific capital implies that installed capital is immobile between sectors. Our assumption of sector specific capital is motivated by evidence in Ramey and Shapiro (2001) who report significant costs of reallocating capital across sectors. Two sector models with sector specific capital include, among others, Boldrin et al. (2001), Ireland and Schuh (2008), Huffman and Wynne (1999) and Papanikolaou (2011). Limited factor mobility is shown to be able to correct many counterfactual predictions of one sector models with respect to both aggregate quantities and asset returns. For example, Boldrin et al. (2001) show it can rationalize the equity premium puzzle, co-movement of sectoral inputs over the business cycle, the inverted leading indicator property of interest rates.
} 
document, using a variety of sources from US data, people receive information (or news) in advance of the actual realization of technology and government spending innovations. ${ }^{16}$ News can be anticipated several quarters ahead so that,

$$
\varepsilon_{t, \text { news }}^{x} \equiv \sum_{h=1}^{H} \varepsilon_{t-h, h}^{x}, \quad x=z, v
$$

where $\varepsilon_{t-h, h}^{x}, x=z, v$ is advanced information (or news) received by agents in period $t-h$ (equivalently $h$ periods ahead) about the innovation that affects sectoral TFP in period $t . H$ is the maximum horizon over which agents can receive advance information (anticipation horizon). It is assumed that the anticipated and unanticipated components for sector $x=C, I$ and horizon $h=0,1, \ldots, H$ are i.i.d. with $N\left(0, \sigma_{z, t-h}^{2}\right), N\left(0, \sigma_{v, t-h}^{2}\right)$ and uncorrelated across sector, horizon and time. Note the process above also allows for revisions in expectations. In other words, information received $t-h$ periods in advance can later be revised by updated information received at $t-h+1, \ldots t-1$, or by the unanticipated component, $\varepsilon_{t, 0}^{v}, \varepsilon_{t, 0}^{z}$ at time $t$. This implies news received at any anticipation horizon may only be partially (or fail to) materialize. To clarify this information structure, suppose we consider a one-quarter ahead news horizon for consumption sector TFP growth, so $H=1$ and $\varepsilon_{t}^{z}=\varepsilon_{t, 0}^{z}+\varepsilon_{t-1,1}^{z}$. Now, in period $t$, rational agents can form expectations about one period ahead TFP growth process as follows,

$$
\begin{aligned}
z_{t} & =\left(1-\rho_{z}\right) g_{a}+\rho_{z} z_{t-1}+\varepsilon_{t, 0}^{z}+\varepsilon_{t-1,1}^{z} \\
z_{t+1} & =\left(1-\rho_{z}\right) g_{a}+\rho_{z} z_{t}+\varepsilon_{t+1,0}^{z}+\varepsilon_{t, 1}^{z} \\
z_{t+1} & =\left(1-\rho_{z}\right) g_{a}+\rho_{z}\left(\left(1-\rho_{z}\right) g_{a}+\rho_{z} z_{t-1}+\varepsilon_{t, 0}^{z}+\varepsilon_{t-1,1}^{z}\right)+\varepsilon_{t+1,0}^{z}+\varepsilon_{t, 1}^{z} \\
E_{t}\left[z_{t+1}\right] & =\left(1-\rho_{z}\right) g_{a}\left(1+\rho_{z}\right)+\rho_{z}^{2} z_{t-1}+\rho_{z} \varepsilon_{t, 0}^{z}+\rho_{z} \varepsilon_{t-1,1}^{z}+\varepsilon_{t, 1}^{z} .
\end{aligned}
$$

\subsection{Financial sector}

Financial intermediaries use deposits from households and their own equity capital to finance the acquisitions of capital by capital services producers. We interpret the financial sector as a single intermediary with two independent branches, each specializing in providing financing to one sector only, where the probability of lending specialization is equal across sectors and independent across time. The implementation of financial intermediaries in our two sector model is based on the framework developed in Gertler and Karadi (2011) in a standard one sector model, so we only briefly describe it here (Appendix C provides all the equations). The workings of the financial sector can be described with

\footnotetext{
${ }^{16}$ News shocks are introduced in a similar way as for example in Davis (2007), Schmitt-Grohe and Uribe (2012), Khan and Tsoukalas (2012) and Fujiwara et al. (2011).
} 
three key equations. The balance sheet identity, the demand for assets that links equity capital with the value of assets, and finally, the evolution of equity capital. We describe them in turn. The balance sheet (in nominal terms) of a branch that lends in sector $x=C, I$, is,

$$
Q_{x, t} P_{C, t} S_{x, t}=N_{x, t} P_{C, t}+B_{x, t}, \quad x=C, I,
$$

where $S_{x, t}$ denotes the quantity of financial claims on capital services producers held by the intermediary and $Q_{x, t}$ denotes the price per unit of claim. The variable $N_{x, t}$ denotes equity capital (or wealth) at the end of period $t, B_{x, t}$ are households deposits and $P_{C, t}$ is the consumption sector price level.

Financial intermediaries are limited from infinitely borrowing household funds by a moral hazard/costly enforcement problem. Bankers, at the beginning of each period, can choose to divert a fraction $\lambda_{B}$ of available funds and transfer it back to the household. Depositors can force and recover a fraction $1-\lambda_{B}$ of assets. Note that the fraction, $\lambda_{B}$, which bankers can divert is the same across sectors, to guarantee that the household is indifferent of deposit allocation.

Intermediaries maximize expected terminal wealth, i.e. the discounted sum of future equity capital. The moral hazard/costly enforcement problem introduces an endogenous leverage constraint, limiting the bank's ability to acquire assets. This is formalized in the equation that determines demand for assets,

$$
Q_{x, t} S_{x, t}=\varrho_{x, t} N_{x, t}
$$

In the equation above, the value of assets which the intermediary can acquire depends on equity capital, $N_{x, t}$, scaled by the leverage ratio, $\varrho_{x, t}$. The leverage ratio (bank's intermediated assets to equity) is a function of the marginal gains of expanding assets (holding equity constant), expanding equity (holding assets constant), and the gain from diverting assets.

We now describe the evolution of equity capital. In each period a fraction of intermediaries exits exogenously with an exogenous i.i.d. constant probability of exit. Those who do exit, are replaced by new ones who in turn face the same probability of survival, $\theta_{B}$. Total wealth of intermediaries is the sum of equity capital of existing, $N_{x, t}^{e}$, and new ones, $N_{x, t}^{n}$,

$$
N_{x, t}=N_{x, t}^{e}+N_{x, t}^{n}
$$

The law of motion for the equity capital of existing intermediaries for $x=C, I$, is given 
by,

$$
N_{x, t}^{e}=\theta_{B}\left[\left(R_{x, t}^{B} \pi_{C, t}-R_{t-1}\right) \varrho_{x, t-1}+R_{t-1}\right] \frac{N_{x, t-1}}{\pi_{C, t}}, \quad 0<\theta_{B}<1
$$

where, $R_{x, t}^{B} \pi_{C, t}-R_{t-1}$ denotes the ex-post (nominal) excess return on assets and $R_{x, t}^{B}$ is the return to capital given by equation (2). $\pi_{C, t}$ is inflation in the consumption sector.

New intermediaries receive startup funds from households equal to a small fraction, $0<\varpi<1$, of the value of assets held by the existing ones in their final operating period (equal to $\left.\left(1-\theta_{B}\right) Q_{x, t} S_{x, t}\right)$. Therefore, new intermediaries begin with, $N_{x, t}^{n}=\varpi Q_{x, t} S_{x, t}$,

Combining (6) with the above leads to the law of motion for total equity capital,

$$
N_{x, t}=\left(\theta_{B}\left[\left(R_{x, t}^{B} \pi_{C, t}-R_{t-1}\right) \varrho_{x, t-1}+R_{t-1}\right] \frac{N_{x, t-1}}{\pi_{C, t}}+\varpi Q_{x, t} S_{x, t}\right),
$$

It is useful to define the expected (nominal) excess return (or risk premium) on assets earned by banks in sector $x=C, I$, as,

$$
R_{x, t}^{S}=R_{x, t+1}^{B} \pi_{C, t+1}-R_{t}
$$

The presence of the financial intermediation constraint in equation (5), implies a nonnegative excess return (equivalently wedge between the expected return on capital and the risk free interest rate), which varies over time with the equity capital of intermediaries.

Financing capital acquisitions by capital services producers. Capital services producers in sector $x=C, I$, acquire physical capital $\bar{K}_{x, t}$ at the end of period $t$, and sell the capital on the open market again at the end of period $t+1$. This acquisition of capital is financed by intermediaries. The funds to buy capital are produced by issuance of $S_{C, t}$ or $S_{I, t}$ claims equal to the number of units of physical capital acquired, $\bar{K}_{C, t}$ or $\bar{K}_{I, t}$, priced at $Q_{C, t}$ and $Q_{I, t}$ respectively. Then, by arbitrage the following constraint holds,

$$
Q_{x, t} \bar{K}_{x, t}=Q_{x, t} S_{x, t}
$$

where the left-hand side stands for the value of physical capital acquired and the righthand side denotes the value of claims against this capital. We assume - in line with Gertler and Karadi (2011) - there are no frictions in the process of intermediation between non-financial firms and banks. Notice the assumptions above imply financial intermediaries carry all the risk when lending to capital services producers. Using the assumptions in Gertler and Karadi (2011) we can interpret these claims as one period state-contingent bonds which allows interpreting the risk premium defined in equation 
(7) as a corporate bond spread.

\subsection{Monetary policy and market clearing}

The nominal interest rate $R_{t}$, set by the monetary authority follows a feedback rule,

$$
\frac{R_{t}}{R}=\left(\frac{R_{t-1}}{R}\right)^{\rho_{R}}\left[\left(\frac{\pi_{c, t}}{\pi_{c}}\right)^{\phi_{\pi}}\left(\frac{Y_{t}}{Y_{t-1}}\right)^{\phi_{\Delta Y}}\right]^{1-\rho_{R}} \eta_{m p, t}, \quad \rho_{R} \in(0,1), \phi_{\pi}>0, \phi_{\Delta Y}>0
$$

where $R$ is the steady state (gross) nominal interest rate and $\left(Y_{t} / Y_{t-1}\right)$ is the gross growth rate in real GDP. The interest rate responds to deviations of consumption sector inflation from its target level, and real GDP growth and is subject to a monetary policy IID shock $\eta_{m p, t}$. The policy rule above allows for inertia in the policy rate, captured by the parameter $\rho_{R}$.

The resource constraint in the consumption sector is,

$$
C_{t}+\left(a\left(u_{C, t}\right) \xi_{C, t}^{K} \bar{K}_{C, t-1}+a\left(u_{I, t}\right) \xi_{I, t}^{K} \bar{K}_{I, t-1}\right) \frac{A_{t} V_{t}^{\frac{a_{c}}{1-a_{i}}}}{V_{t}^{\frac{1}{1-a_{i}}}}=A_{t} L_{c, t}^{1-a_{c}} K_{c, t}^{a_{c}}-A_{t} V_{t}^{\frac{a_{c}}{1-a_{i}}} F_{C}
$$

The resource constraint in the investment sector is,

$$
I_{I, t}+I_{C, t}=V_{t} L_{I, t}^{1-a_{i}} K_{I, t}^{a_{i}}-V_{t}^{\frac{1}{1-a_{i}}} F_{I}
$$

Hours worked are aggregated as,

$$
L_{t}=L_{I, t}+L_{C, t}
$$

Output (GDP in consumption units) is defined as,

$$
Y_{t}=C_{t}+\frac{P_{I, t}}{P_{C, t}} I_{t}+e_{t}
$$

where $e_{t}$ denotes GDP measurement error. We assume that this measurement error in GDP evolves according to,

$$
\log e_{t}=\left(1-\rho_{e}\right) \log e+\rho_{e} \log e_{t-1}+\varepsilon_{t}^{e},
$$

where $\rho_{e} \in(0,1)$ and $\varepsilon_{t}^{e}$ is $i . i . d . N\left(0, \sigma_{e}^{2}\right)$. This measurement error is introduced in order to capture movements in GDP which can arise for example from government spending. We abstract from these in the model, motivated by recent evidence in Justiniano et al. (2010) that assigns a very minor role of government spending shocks as a driving force 
of the business cycle.

\section{Data and Methodology}

We estimate the model using quarterly U.S. data (1990 Q2 - 2011 Q1) on eleven real, nominal and financial market variables. Our financial observables consist of sectoral (non-financial) corporate bond spreads and a publicly available measure of intermediaries' equity capital reported by the Federal Financial Institutions Examination Council. We only use sector specific spreads for corporate bonds issued by non-financial companies that are actively traded in the secondary market. The average rating range/duration in our sample is $\mathrm{A}$ - to $\mathrm{BBB}+/ 7.5$ years, $\mathrm{A}$ - to $\mathrm{BBB}+/ 7$ years, in the consumption, investment sector respectively. Thus, our bond spreads series are classified as investment grade. ${ }^{17}$ The vector of observables we use in the estimation is given as,

$$
\mathbf{Y}_{t}=\left[\Delta \log Y_{t}, \Delta \log C_{t}, \Delta \log I_{t}, \Delta \log W_{t}, \pi_{C, t}, \pi_{I, t}, \log L_{t}, R_{t}, R_{C, t}^{S}, R_{I, t}^{S}, \Delta \log N_{t}\right]
$$

where $\Delta$ denotes the first-difference operator and we demean the data prior to estimation. In the vector above, $Y_{t}, C_{t}, I_{t}, W_{t}, \pi_{C, t}, \pi_{I, t}, L_{t}, R_{t}, R_{C, t}^{S}, R_{I, t}^{S}, N_{t}$, denote, output, consumption, investment, real wage, consumption sector inflation, investment sector inflation, hours worked, nominal interest rate, consumption sector bond spread, investment sector bond spread and bank equity respectively. Appendix B describes the data sources and methods in detail.

We use the Bayesian methodology to estimate the model parameters. The posterior distribution of parameters is evaluated numerically using the random walk MetropolisHastings algorithm. We simulate the posterior using a sample of 500,000 draws and (after dropping the first $20 \%$ of the draws) report the mean, and the 10 and 90 percentiles of the posterior distribution of the estimated parameters. We use two tests to check for identification of the model parameters. First, a test of (local) parameter identifiability as proposed by Iskrev (2010) the results of which suggest all parameters we estimate are identifiable in a neighborhood of our estimates. ${ }^{18}$ Nevertheless because this test

\footnotetext{
${ }^{17}$ This information is provided by Datastream. In line with Gilchrist and Zakrajsek (2012) we only consider durations longer than one and shorter than 30 years. We also drop all corporate spreads below 10 and above 5000 basis points to ensure that our time series are not driven by a small number of extreme observations. To arrive at the corporate spread series for the consumption and investment sector, we aggregate the spreads of 1213 and 4168 bonds respectively and take the arithmetic average. The extremely limited availability of corporate spread data for the 1980s is a factor that restricts the sample for the estimation.

${ }^{18}$ This test evaluates the Jacobian of the vector containing all parameters (including the parameters describing the exogenous processes) which determine the first two moments of the data. When evaluated at the posterior mean of our parameter estimates this Jacobian matrix has full column rank-equal to
} 
is a yes/no proposition it cannot precisely scrutinize for weak identifiability. For this reason we adopt an indicator of Bayesian learning proposed by Koop et al. (2012), namely the "Bayesian learning rate indicator", which given the focus on asymptotics gives an indication of the informativeness of the data. This indicator examines the rate at which the posterior precision of parameters gets updated with the sample size. For identified parameters the posterior precision increases at rate $\mathrm{T}$ (with $\mathrm{T}$ denoting the sample size). The indicator suggests no evidence of weak identification: we measure this by taking the product of posterior variances with $\mathrm{T}$ and examine if it converges to a constant for all parameters, which we find that it does, suggesting the posterior precision of parameters is updated at the same rate as T. ${ }^{19}$

Prior distributions. A number of parameters are calibrated and hence held fixed during estimation. These are described in the Appendix in Table 8. They are parameters we believe are difficult to identify, since they define steady state objects. For the parameters we estimate we use prior distributions that conform to the assumptions in Justiniano et al. (2010), Khan and Tsoukalas (2012). The first five columns in Table 1 list the parameters and the assumptions on the prior distributions.

We consider four and eight quarter ahead sector specific TFP news in the consumption and investment sector. This choice is guided by the desire to economize on the state space and consequently on parameters to be estimated while being flexible enough such that the news process is able to accommodate revisions in expectations. Similar news horizons are considered by Christiano et al. (2012), Schmitt-Grohe and Uribe (2012) and Khan and Tsoukalas (2012). Finally, all standard deviations of the contemporaneous and news shocks are assumed to be distributed as an inverse Gamma distribution with a standard deviation of 2.0. The prior means assumed for the TFP news components are in line with Khan and Tsoukalas (2012) and Schmitt-Grohe and Uribe (2012) and imply that the sum of the variance of news components is at most one half of the variance of the corresponding unanticipated component.

Posterior distributions. Table 1 reports the posterior mean and the $10 \%$ to $90 \%$ probability interval of estimated parameters. Overall, the estimates are broadly consistent with earlier studies using one sector models, e.g. Smets and Wouters (2007),

the number of parameters to be estimated. This implies that any chosen vector of parameters around our estimates will give rise to an auto-covariance function that is different than that implied by our estimates. All estimations are done using DYNARE (see Adjemian et al. (2011)), http://www.dynare.org. We calculate convergence diagnostics in order to check and ensure the stability of the posterior distributions of parameters as described in Brooks and Gelman (1998).

${ }^{19}$ To implement this test we generate a large sample of simulated data from the model equal to 30,000 observations. We then estimate the model on samples of increasing size which we set to $T=$ $50,100,1,000,10,000,20,000,25,000,30,000$, and compute the posterior variance of parameters for these consecutive samples. Finally, we check the rate at which these variances are declining in comparison to the sample size. In the interest of space we do not report the results, but are available upon request. 
Khan and Tsoukalas (2012) and Justiniano et al. (2010), and we do not discuss them in detail. The standard deviations for the sectoral TFP shocks - unanticipated and newsare quite precisely estimated. The standard deviations for the TFP news components (consumption sector) are estimated to be around or slightly above their unanticipated components, especially for the 8 quarter ahead component. Combined with a relatively high autoregressive parameter, this estimate suggests, consumption sector TFP news shocks may be potentially important in accounting for economic fluctuations.

\section{The Propagation of Consumption Sector TFP News Shocks}

In this section, we discuss the model's responses to a consumption sector TFP news shock. This will shed light on the reasons for their important role in accounting for fluctuations we document in the next section.

Figure 1 shows the impulse responses (IRFs) to an anticipated (two year ahead) positive, consumption sector TFP shock. This type of news shock is expansionary. All the broad and sectoral aggregates, namely, consumption, investment, and hours worked rise along with output in anticipation of the future improvement in TFP. We can gain more intuition for the expansionary nature of the news shock by looking at the labor market and the market for capital goods. First, note that the real wage and equilibrium hours both rise on impact, implying an increase in labor demand. Given the preference specification we utilize, which is of the King et al. (1988) type, the positive TFP news shock implies a negative wealth effect on labor supply. However, this negative wealth effect is dominated by a strong expansion of labor demand and a rightward shift in labor supply and equilibrium hours rise. The key mechanisms that cause the expansion of sectoral labor demand and labor supply are the presence of countercyclical price and wage mark-ups, discussed in more detail below.

The two sector structure of the model - the fact that consumption sector uses investment sector output as an input-propagates the shock to the investment sector. The anticipation that future productivity of capital will be permanently higher in the consumption sector creates demand for capital goods produced by the investment sector. The relative price of investment and the price of consumption sector capital both increase in anticipation of the future improvement in TFP. The price of investment sector capital increases as well: more input use, including capital will have to be employed by the investment sector in order to satisfy higher demand for investment goods from the consumption sector. Thus, both hours worked and investment goods allocated to the 
investment sector rise. This latter effect is therefore a consequence of the sectoral link of the model. Moreover, higher capital prices boost bank equity as the value of assets in the intermediaries portfolio rises, causing intermediaries to expand financing. Sectoral bond spreads decline in response to the expected improvement in TFP, consistent with the time path of capital prices. Thus, the sectoral bond spreads signal the future improvement in TFP. The sectoral bond spread in the model corresponds to the expected excess return to capital (wedge between expected return to capital and risk free rate). The expected return to capital (between time $t, t+1$ ) declines (as capital prices are expected to fall) and the risk free rate rises to produce the decline in the corporate bond spreads shown in the Figure. It is also interesting to note that both sectoral inflation rates and the nominal interest rate rise in response to this type of TFP news shock. The reaction of the nominal interest rate following the surge in consumption sector inflation is consistent with a conventional view of monetary policy (see e.g. Bernanke and Gertler (2000)), according to which it acts as a stabilizing force that dampens expectation driven cycles.

\subsection{Inspecting the mechanism}

We discuss several features of the model to gain a better understanding of those channels that are important for the results. The discussion is organized around two dimensions, namely co-movement and amplification. As we show below, countercyclical mark-ups are a key channel for co-movement, but the quantitative importance of TFP news rests on financial amplification. In this section we also support our claim that the two sectoral TFP news shocks generate different dynamics, namely that consumption TFP news are expansionary, but investment TFP news are not.

Financial intermediation and amplification. To investigate the impact of the financial intermediation channel, we compare the IRFs from a model with and a model without financial intermediation, shown in Figure 2. The IRFs shown in solid lines are from the baseline with the financial channel. The IRFs shown in circled lines are from an estimated model without the financial channel (Table 5 in the Appendix reports the estimated parameters from this model). We show the responses to a positive (eight quarter ahead) consumption sector TFP news shock.

A noteworthy feature is that in both model versions, a consumption sector TFP news shock generates aggregate and sectoral comovement. Thus, financial intermediation does not qualitatively affect the business cycle co-movement properties for this type of news shock. Fundamentally, in both model versions, this type of TFP news shock shifts the demand for capital outward: good news creates the need to build more capital to be allocated in the consumption sector when positive TFP materializes. This stimulates 
investment demand so (in principle) capital prices can rise as shown in the figure. ${ }^{20}$ This is a key difference to the prediction of a standard RBC model, as shown for example in Jaimovich and Rebelo (2009), where for co-movement to obtain in response to an aggregate TFP news shock, there must be a decline in the price of capital. ${ }^{21}$ This prediction is hard to reconcile with empirical evidence however, where various measures (e.g. stock market indices) of the price of capital are procyclical. Financial intermediation amplifies the responses to the TFP news shock, by causing the prices of capital to rise more strongly. Essentially, due to the leverage constraint, equation (5), the gains in intermediaries' equity caused by higher capital prices, create additional demand for assets, bidding up capital prices further in comparison to the version without such a financial channel. So, if a decline in the price of capital where to take place this amplification could not occur. Further, the stronger rise in capital prices support more financing and thus more investment spending. This amplification is important for the significance of TFP news shocks as drivers of business cycles we find in this paper. However as we show in the next section the presence of this channel alone will not suffice. Informing the estimation with corporate bond spreads and equity capital is essential for the quantitative role of TFP news shocks we estimate.

Co-movement and nominal rigidities. These frictions are important for the comovement properties of the consumption sector TFP news shock. Nominal (price and wage) rigidities give rise to endogenous countercyclical price and wage mark ups. A positive, consumption sector TFP news shock is associated with a fall in both sectoral price mark ups (i.e. the wedge between the marginal product of labor and the real wage), since firms cannot fully adjust prices to higher demand, shifting sectoral labor demand to the right. At the same time, the same shock is associated with a fall in the wage mark up (i.e. the wedge between the marginal rate of substitution and the real wage) causing a rightward shift of the labor supply. Both of these forces, act to counteract and dominate the negative wealth effect on labor supply due to the expected improvement in productivity and equilibrium hours rise. ${ }^{22}$ The properties of the model

\footnotetext{
${ }^{20} \mathrm{~A}$ notable difference however is that, in the model without a financial sector, nominal rigidities are key frictions for the rise in capital prices, consistent with the analysis in Kobayashi and Nutahara (2010), and Christiano et al. (2008), based on one sector calibrated models. When we shut down nominal price (in the consumption sector) and wage rigidities we obtain a decline in the consumption sector capital price. In the absence of countercyclical price and wage mark-ups, the negative wealth effect on labor supply dominates and hours worked - along with consumption-in the consumption sector decline sharply, despite the stimulation of investment demand which is met by a sharp increase in hours worked allocated to the investment sector. There is thus substitution of consumption into the future and this can be supported by a decline in the consumption sector capital price today relative to the future.

${ }^{21}$ In Jaimovich and Rebelo (2009), one of the key mechanisms which permits co-movement is a strong rise in utilization. However, at the same time this rise in utilization increases the depreciation rate of capital and hence decreases the value of installed capital.

${ }^{22}$ There is at the same time a rise in utilization rates (not shown in the Figure) that shifts the labor
} 
where nominal rigidities are minimized, are shown in Figure $3 .^{23}$ The specification where nominal (price and wage) rigidities are (nearly) eliminated has a noticeable effect on the propagation of the news shock. First, co-movement does not obtain: Consumption now declines, caused by a decline in hours worked employed in that sector, suggesting that the behavior of mark-ups is important for sectoral hours comovement, consistent with the analysis in DiCecio (2009). Second, the IRFs highlight that the (near) absence of nominal rigidities significantly affect the magnitude of the responses, especially for investment and hours. Moreover, the impact of the countercyclical price mark-ups, compared to countercyclical wage mark-ups, is far more important for co-movement (see IRFs in circled lines). This demonstrates that, countercyclical price mark-ups alone, with the shift in labor demand they generate, work to counteract the negative wealth effect on labor supply. We can observe that the elimination of wage rigidities does not change the response of consumption and hours worked in the consumption sector qualitativelythey both continue to increase, though less strongly, compared to the baseline. ${ }^{24}$

Investment Sector TFP News Shocks. Figure 4 shows model responses to an anticipated (two year ahead), positive, investment sector TFP shock. We show two sets of IRFs: (a) from the baseline model and (b) from a model estimated without financial frictions (estimated parameter values reported in Table 5, Appendix A). Note that this type of favorable news shock does not create a broad based expansion in either model version. In the baseline model (solid line) with financial frictions, investment declines in anticipation of the future improvement in TFP, driven by the decline in hours worked in the production of investment goods. Examining the IRFs to the same size news shock (estimated volatility from the baseline) when we shut off the financial channel (circled lines) shows the contraction in real macroeconomic aggregates to be broad based: output, consumption, and hours worked, in addition to investment, all decline. Moreover, all sectoral aggregates decline in response to the positive news. Thus, an expected improvement in investment specific TFP causes a broad based contraction today, followed by a

demand curve. However the utilization boost is of secondary importance since utilization is estimated to be relatively inelastic.

${ }^{23}$ The Figure plots a set of IRFs where both price and wage rigidities are nearly eliminated and a set of IRFs where only wage rigidities are nearly eliminated. The first set is generated from the baseline model where we have set the steady state mark-ups, namely, $\lambda_{p}=\lambda_{w}=0.01$, indexation parameters, $\iota_{p_{C}}=\iota_{p_{I}}=\iota_{w}=0.01$, and Calvo probabilities for prices and wages, $\xi_{C}=\xi_{I}=\xi_{w}=0.01$. The second set is generated from the baseline model where we have set the steady state wage mark-up, namely, $\lambda_{w}=0.01$, indexation parameter, $\iota_{w}=0.01$, and calvo probability for wages, $\xi_{w}=0.01$.

${ }^{24}$ We have also examined the sensitivity to variations in real rigidity parameters. Specifically, investment adjustment cost (IAC), habit persistence, utilization elasticity parameters, with all other parameters set to their estimated values. An interesting finding, is that, qualitatively, these parameters do not matter for the co-movement properties of consumption sector TFP news, though of course matter quantitatively. Under all parametrizations we examine, the consumption sector TFP news shock is expansionary. We do not show the IRFs for all different perturbations here in the interest of space, but they are available upon request. 
rebound in activity when the shock materializes. Also note, this shock causes a decline in the relative price of investment (delayed in the model without financial frictions) and declines in sectoral capital prices. The price of capital falls since the expected improvement in investment sector TFP implies that installed capital is less valuable. Overall, this type of news shock generates qualitatively different dynamic responses in comparison to a consumption TFP news shock. Fundamentally, the reason why this shock is not expansionary is that it does not generate an increase in investment demand (supported by higher employment), in contrast to the consumption sector TFP news. This difference is reflected in the opposing movement in capital prices, which rise under a consumption sector TFP news shock but fall under a news shock of the investment specific type. An increase in investment demand with an associated rise in hours is one of the conditions emphasized in Beaudry and Portier (2004) for an expected improvement in productivity to generate an expansion today, and this intuition goes through in this model as well. The difference in this model is in the mechanism used to generate the expansion in labor demand, that is, mainly through the presence of countercyclical mark-ups which permit a rise in hours worked.

\section{$5 \quad$ Variance Decompositions}

In this section we document the relative contribution and importance of various disturbances in accounting for fluctuations in the data. We discuss results from a decomposition at the frequency domain, focussing on business cycle frequencies. ${ }^{25}$ Table 2 reports our findings.

News shocks. TFP news shocks (consumption sector) account for 30.6\%, 29.1\%, $20.8 \%, 43.2 \%$ of the variance in output, consumption, investment and hours worked respectively, with the majority of these shares accounted for by the two year anticipation horizon. Moreover, they account for a significant fraction in the variance of both corporate bond spread series, approximately 40\%, suggesting a significant amount of variation in the latter may reflect future fundamentals. They also account for over $50 \%$ in the variance of the nominal interest rate, and between, approximately, $25 \%$ to $36 \%$ of the variance in the sectoral inflation rates. Investment sector TFP news components account for significantly smaller variance shares in all observables, namely, less than $10 \%$ (except the variance share in the real wage, approximately 17\%), in line with the analysis in Section 4. Taken together, both sectoral TFP news shocks account for significant shares in the variance of the real macroeconomic aggregates, accounting for approximately, $37 \%$, $30 \%, 31 \%, 50 \%$ of the variance in output, consumption, investment and hours worked

\footnotetext{
${ }^{25}$ We also report an unconditional decomposition in Appendix A.3 (Table 6)
} 
respectively. The findings on the overall importance of TFP news shocks are broadly in line with recent VAR based findings. For example, Barsky and Sims (2011), report TFP news shocks to account for between $24 \%$ to $43 \%$ (see Table 1 from their 7 -variable VAR) in the variance of output in business cycle frequencies beyond the very short run, while Beaudry and Portier (2006) report the same share of TFP news to be around $50 \%$. These shares are reasonably close to our estimated variance share of output accounted for by TFP news shocks. Leduc and Sill (2013), using a "news about unemployment" concept from surveys, find it is consistent with a broad based expansion in activity and accounts for a significant fraction of the variance in employment, also consistent with our findings. ${ }^{26}$

The importance of consumption sector TFP news shocks. Why do consumption sector TFP news shocks become so important in accounting for the variation in the data, in the presence of multiple sources of disturbances? Relative to other disturbances, they generate the right type of co-movements between aggregate quantities and prices (see section 4 for an exposition of the transmission). More specifically, (a) procyclical movements in quantities, (b) countercyclical movements in corporate bond spreads and a set of cross correlations of the latter with real macro aggregates in line with those in the data. An illustration of the facts above can be confirmed by examining Figure 5. The Figure presents dynamic correlations among several key variables pertaining to facts (a) and (b) above, in the data (solid line), model with all shocks active (line with '+'), model with the dominant TFP news shock only active (and all other shocks set to zero-line with circles). The dynamic correlations implied by the TFP news only driven model are very similar to the correlations generated by the model with all shocks active. Moreover, in some dimensions the correlations implied by TFP news (e.g. see subplots (1,3) — output growth with hours, $(2,2)$ - output growth with C sector spread, $(3,1)$-investment growth with C sector spread, (3,2) - sectoral bond spreads, (3,3)-hours worked) are extremely well aligned to the empirical ones, highlight their importance for the ability of the model to match them so closely.

Its important to note when we estimate the baseline model without financial observables, the quantitative importance of TFP news shocks declines significantly. We report a comparison of the variance shares in observables from the baseline and the same model estimated without incorporating financial observables in Table 3. In the latter model, the contribution of TFP news shocks is quite limited, explaining less than $10 \%$ of the variation

\footnotetext{
${ }^{26}$ We note, most VAR based studies use an aggregate measure of TFP to help in the identification of news shocks, based on a quarterly approximation of the annual one constructed by Basu et al. (2006). We do not incorporate this measure of TFP in our analysis precisely because in related work (Basu et al. (2010)) these same authors argue that it is subject to specification error when it aggregates two qualitatively different sectoral processes inducing very different dynamics, which is what we find in this paper.
} 
in the data (except the real wage). For example, the contribution of consumption sector TFP news shocks in the variance of output declines from approximately $31 \%$ in the baseline with financial information included, to less than $4 \%$ in the estimated model without financial observables. ${ }^{27}$ Thus, when the spectrum of correlations between real aggregates with corporate bond spreads does not discipline estimation, the role of TFP news shocks is substantially reduced. We conclude, including information from the corporate bond market is essential for identifying a substantial quantitative role of TFP news shocks. ${ }^{28}$ Recent work by Philippon (2009) makes a very related point. He shows one can derive a measure of future productivity fundamentals from corporate bond spreads, namely the "bond market's $Q$ " that contains superior information, relative to a conventional measure from the stock market, for explaining and predicting U.S. corporate investment growth.

Sector specific TFP shocks. Table 2 suggests unanticipated investment sector TFP or equivalently investment specific shocks are also sizable drivers of fluctuations, especially for investment, broadly consistent with earlier findings in Greenwood et al. (2000), Fisher (2006) and Justiniano et al. (2010). They account for approximately, 19\% of output, $38 \%$ of investment and $16 \%$ of hours worked variation. ${ }^{29}$ Moreover, unanticipated consumption sector TFP shocks also account for approximately between $20 \%$ and $25 \%$ in the variance of output and consumption. Taken together these sector specific TFP shocks account for a relatively large fraction of the variance in the data. Because the estimated importance of investment specific shocks we find stands in sharp contrast to findings in recent one sector estimated DSGE studies (e.g. Khan and Tsoukalas (2012), Schmitt-Grohe and Uribe (2012), Christiano et al. (2012)), reporting these shocks to be negligible sources of fluctuations, we provide a brief explanation. We focus on the expression for the relative price of investment given as,

$$
\frac{P_{I, t}}{P_{C, t}}=\frac{\operatorname{mark}_{\operatorname{up}}}{\operatorname{mark} \operatorname{up}_{C, t}} \frac{1-a_{c}}{1-a_{i}} \frac{A_{t}}{V_{t}}\left(\frac{K_{I, t}}{L_{I, t}}\right)^{-a_{i}}\left(\frac{K_{C, t}}{L_{C, t}}\right)^{a_{c}}
$$

where, $a_{c}, a_{i}$ are capital shares in consumption, and investment sector respectively. $V_{t}, A_{t}$, is TFP in the investment and consumption sector respectively, and $\frac{K_{x, t}}{L_{x, t}}, x=I, C$

\footnotetext{
${ }^{27}$ In the estimated model without financial observables, we find that, in addition to the unanticipated investment sector TFP, the capital quality shock that hits the investment sector becomes quite important in accounting for the variation in the data. Both of these shocks affect the capital accumulation equation and can thus be, following Justiniano et al. (2010), broadly defined as investment shocks. Their combined contribution, which is over half of the variance in the main macroeconomic aggregates, is in line with findings from their study.

${ }^{28}$ Recent work by Christiano et al. (2012) also emphasizes the importance of financial information for shock identification.

${ }^{29}$ The IRFs following an unanticipated shock of this type are presented in the Appendix (see Figure 7), and are qualitatively similar to those generated from a one sector model as in Justiniano et al. (2010).
} 
the capital-labor ratio in sector $x$. mark up $\mathrm{u}_{x, t}$ is the price mark-up or inverse of the real marginal cost in sector $x$. $V_{t}$ corresponds to the investment specific shock. Notice how the relative price of investment can be driven - at least in the short run - by, (a) mark up shocks, via their impact on the sectoral price-cost mark ups, (b) sector specific TFP and, (c) differences in capital labor ratios across sectors (due to the sector specific nature of capital in the model). The fact that (c) above affects the relative price of investment implies that all shocks can in principle affect this price. In a special case of our model with: (i) perfectly competitive product markets, (ii) identical production functions (factor intensities) in both sectors and (iii) full factor mobility, the expression above simplifies to, $\frac{P_{I, t}}{P_{C, t}}=\frac{A_{t}}{V_{t}} \cdot{ }^{30}$ In this case the model admits a one sector representation (e.g. Greenwood et al. (2000)). Further, one can readily redefine the investment sector TFP process as $V_{t}=A_{t} V_{t}^{*}$, where in this formulation $A_{t}$ denotes sector neutral TFP, while $V_{t}^{*}$ denotes investment specific TFP. Under this equivalent formulation the expression above becomes, $\frac{P_{I, t}}{P_{C, t}}=\left(V_{t}^{*}\right)^{-1}$, a commonly used restriction in one sector estimated DSGE models. Thus, under assumptions (i)-(iii), one can identify the investment specific technology shock from the relative price of investment alone. But as demonstrated, this tight restriction, is not necessarily valid in a more elaborate two sector model with an imperfectly competitive investment sector and slow capital mobility across sectors, like ours. In the more general framework we consider, variation in the relative price of investment reflects not only investment specific shocks but also (in principle) other shocks. This is illustrated in Table 2 where investment sector TFP shocks explain around $60 \%$ of the variation in the relative price. The remaining $40 \%$ is accounted for by, mainly, consumption sector TFP and price mark up shocks.

The variance shares accounted for by investment sector TFP shocks are smaller compared to, for example, Justiniano et al. (2010). Note however, that in the latter study - in addition to a different sample period - the concept of investment shocks is broader, in that they can include both investment sector TFP as well as, for example, financial shocks affecting the transformation of investment to capital. An advantage of our two sector model is that we can explore a finer decomposition between investment specific shocks and financial type shocks. In the estimation, we allow for capital quality shocks, which directly affect the sectoral capital accumulation equation (see equation (3)). ${ }^{31}$ A positive shock of this type has the property that it raises the price of capital and thus causes a revaluation of assets in the banks' portfolios, leading to gains in bank equity and expan-

\footnotetext{
${ }^{30} \mathrm{~A}$ slightly different and simpler formulation of a two sector model, where investment producers buy final goods and convert them to investment would effectively deliver this restriction (see Justiniano et al. (2011)). This is the approach followed by most one sector New Keynesian models.

${ }^{31}$ These shocks have been recently considered by Gertler and Karadi (2011), Gertler and Kiyotaki (2010) and Gourio (2012) in calibrated one sector models.
} 
sion in lending allowing an interpretation as a financial shock. Table 2 suggests the role of the capital quality shocks is fairly limited, accounting for less than $10 \%$ in the majority of macroeconomic real and nominal series (except consumption), but nevertheless account for shares close to $20 \%$ in two out of the three financial observables, consistent with the interpretation we adopt for these shocks.

Overall, sector specific TFP shocks, unanticipated and news, account for the majority of the forecast error variance in the data. Specifically, they account for approximately, $75 \%, 57 \%, 73 \%, 72 \%$, of the variance in output, consumption, investment and hours worked (see Column 2 in Table 2). They also account for the majority of the variation in the financial observables as well as nominal interest rate, inflation rates and the real wage.

Robustness. Finally, we undertake several additional robustness exercises to assess the sensitivity of our results, focusing on the quantitative importance of TFP news shocks, along four dimensions. First, we allow for a common aggregate TFP shock, as a source of broad based co-movement, that affects symmetrically both sectors. Second, we vary the assumptions on prior distributions of shocks in the model, and prior weights assigned on news shocks. Third, we exclude the most recent "Great Recession" period, namely, observations from 2008Q1 to 2011Q1, from the estimation sample, addressing a concern that the importance of news shocks may be driven by this most recent volatile period, as well as potential misspecification of the monetary policy rule when the policy rate approaches the zero lower bound. Fourth, we add news components in the non-structural disturbances of the model as in Khan and Tsoukalas (2012) and Schmitt-Grohe and Uribe (2012). These robustness checks are reported in Appendix A.1. Briefly, we find, in line with our baseline results, consumption sector TFP news shocks continue to be significant drivers of business cycles along all perturbations described above.

\section{TFP news and company earnings expectations}

To what extent do estimated TFP news shocks from the model reflect future fundamentals? We examine this issue by focusing on Institutional Brokers' Estimate System $(\mathrm{I} / \mathrm{B} / \mathrm{E} / \mathrm{S})$, analysts earnings forecasts. The I/B/E/S database provides company earnings forecasts for the majority of the companies in our sample of corporate bond issuers. We focus on the "long term growth" median earnings forecast which provides a projection of the trend growth rate in companies net income in a three to five year horizon. This forecast ignores current business cycle conditions and is therefore thought to provide a good measure of future fundamentals. Cummins et al. (2006) for example, encode the information from this forecast in a Tobin's $Q$ measure and show this alternative measure 
of future fundamentals to be a sufficient statistic for corporate investment. ${ }^{32}$ Figure 6 plots TFP news shocks from the model against the long term earnings forecast. Both series exhibit strong co-movement (correlation equal to 0.45 , significant at the $1 \%$ significance level), with positive values of TFP news shocks associated with a higher earnings forecast and both series correctly anticipating the last two recessions.

This evidence therefore suggests, our TFP news shocks reflect similar information to cash flow or profitability news encoded in the analysts earnings forecasts, corroborating our claim that the estimated TFP news shocks capture future fundamentals. ${ }^{33}$ A reasonable conjecture we explore in current work might be that firms in the consumption sector expand into new markets (by adding for example new products and services); they add capacity to their existing operations by buying it from the investment sector to serve these new markets. This expansion is expected to enhance their profitability and it is signalled in the forecast produced by analysts.

\section{Conclusions}

In this paper we have estimated a two sector model with a financial channel and sector specific TFP news shocks. We have shown sector specific TFP news shocks generate qualitatively different dynamics in both real and nominal aggregates as well as asset prices. Consumption sector TFP news shocks are expansionary, in contrast to investment specific TFP news which are contractionary. The former generate aggregate and sectoral co-movement in real macroeconomic aggregates, with countercyclical movements in corporate bond spreads consistent with the data. Further, they play a substantial role in the business cycle. In terms of real aggregates, they account for around $30 \%$ of the variance in consumption and output, $21 \%$ of the variance in investment and $43 \%$ of the variance in hours worked. They also account for important variance shares in nominal variables and corporate bond spreads, a key source of information we use to inform the estimation. The financial channel, via procyclical movements in the price of capital, propagates these shocks very strongly. The finding that TFP news shocks are important drivers of fluctuations is broadly consistent with recent evidence from VAR based identi-

\footnotetext{
${ }^{32}$ Cummins et al. (2006), show this measure to drive out cash flow from estimated equations on investment and $Q$ on firm level panel data sets from the U.S.

${ }^{33}$ Because a significant amount of information for the identification of TFP news shocks is contained in the corporate bond spread series we find it informative to investigate an alternative interpretation. Gilchrist and Zakrajsek (2012) argue that innovations in corporate bond spreads are, to a certain extent, driven by the excess bond premium (EBP), an indicator of disruptions in the supply of credit that may be orthogonal to corporate fundamentals. It is important to report that the correlation between our estimated TFP news shocks and the EBP is equal to -0.10 and insignificant at any level, suggesting our news concept is not related to credit supply factors.
} 
fication (e.g. Beaudry and Portier (2006), Beaudry and Lucke (2010), Barsky and Sims (2011), Forni et al. (2012), Leduc and Sill (2013)), especially in frequencies beyond the very short run. Overall, our findings have implications for research on expectations driven cycles, and more generally, sources of business cycles, suggesting incorporating sectoral heterogeneity may be important for a better understanding of the nature and sources of fluctuations.

\section{References}

Adjemian, S., Bastani, H., Juillard, M., Mihoubi, F., Perendia, G., Ratto, M., and Villemot, S. (2011). Dynare: Reference manual, version 4. Dynare Working Papers, 1.

Adrian, T., Moench, E., and Shin, H. S. (2010). Financial intermediation asset prices and macroeconomic fundamentals. Federal Reserve Bank of New York Staff Report, (422).

Alexopoulos, M. (2011). Read all about it! What happens following a technology shock? American Economic Review, (101):1144-79.

Barsky, R. B. and Sims, E. R. (2011). News shocks and business cycles. Journal of Monetary Economics, 58(3):273-289.

Basu, S., Fernald, J., J., F., and M., K. (2010). Sector specific technical change. Mimeo.

Basu, S., Fernald, J., and Kimpball, M. (2006). Are technology improvements contractionary? American Economic Review, 96(5):1418-1448.

Beaudry, P. and Lucke, B. (2010). Letting different views about business cycles compete. In NBER Macroeconomics Annual 2009, Volume 24, NBER Chapters, pages 413-455. National Bureau of Economic Research, Inc.

Beaudry, P. and Portier, F. (2004). An exploration into Pigou's theory of cycles. Journal of Monetary Economics, 51(6):1183-1216.

Beaudry, P. and Portier, F. (2006). News, stock prices and economic fluctuations. The American Economic Review, 96(4):1293-1307.

Beaudry, P. and Portier, F. (2007). When can changes in expectations cause business cycle fluctuations in neo-classical settings? Journal of Economic Theory, 135:458-477.

Bernanke, B. and Gertler, M. (2000). Monetary policy and asset price volatility. Working Papers 7559, NBER.

Boldrin, M., Christiano, L. J., and Fisher, J. D. M. (2001). Habit persistence, asset returns, and the business cycle. American Economic Review, 91(1):149-166.

Brooks, S. P. and Gelman, A. (1998). General methods for monitoring convergence of iterative simulations. Journal of Computational and Graphical Statistics, 7(4):434-455. 
Calvo, G. A. (1983). Staggered prices in a utility-maximizing framework. Journal of Monetary Economics, 12(3):383-398.

Caplin, A. and Leahy, J. (1997). Aggregation and optimization with state-dependent pricing. Econometrica, 65(3):601-626.

Chen, K. and Song, Z. (2012). Financial frictions on capital allocation: A transmission mechanism of tfp fluctuations. mimeo.

Christensen, I. and Dib, A. (2008). The financial accelerator in an estimated New Keynesian model. Review of Economic Dynamics, 11(1):155-178.

Christiano, L., Motto, R., and Rostagno, M. (2008). Monetary policy and stock market boom-bust cycles. Working Paper Series 955, European Central Bank.

Christiano, L., Motto, R., and Rostagno, M. (2010). Financial factors in economic fluctuations. Working Paper Series 1192, European Central Bank.

Christiano, L., Motto, R., and Rostagno, M. (2012). Risk shocks. Working paper series, Northwestern University.

Christiano, L. J., Eichenbaum, M., and Evans, C. L. (2005). Nominal rigidities and the dynamic effects of a shock to monetary policy. Journal of Political Economy, 113(1):145 .

Cummins, J., Hassett, K., and Oliner, S. (2006). Investment behavior, observable expectations, and internal funds. American Economic Review, (96):796-810.

Davis, J. (2007). News and the term structure in general equilibrium. Manuscript, Northwestern University.

Den Haan, W. J. and Kaltenbrunner, G. (2009). Anticipated growth and business cycles in matching models. Journal of Monetary Economics, 56(3):309-327.

DiCecio, R. (2009). Sticky wages and sectoral labor comovement. Journal of Economic Dynamics and Control, 33(3):538 - 553.

Dupor, B. (1999). Aggregation and irrelevance in multi-sector models. Journal of Monetary Economics, 43(1):391-409.

Erceg, C. J., Henderson, D. W., and Levin, A. T. (2000). Optimal monetary policy with staggered wage and price contracts. Journal of Monetary Economics, 46(2):281-313.

Faust, J., Gilchrist, S., Wright, J., and Zakrajsek, E. (2013). Credit spreads as predictors of real-time economic activity: A bayesian model-averaging approach. Review of Economics and Statistics, fortcoming.

Fisher, J. D. M. (2006). The dynamic effects of neutral and investment-specific technology shocks. Journal of Political Economy, 114(3):413-451. 
Foerster, A., Sarte, P.-D., and Watson, M. (2011). Sectoral versus aggregate shocks: A structural factor analysis of industrial production. Journal of Political Economy, 119(1):1-38.

Forni, M., Gambetti, L., and Sala, L. (2012). No news in business ccycles. mimeo.

Fujiwara, I., Hirose, Y., and Shintani, M. (2011). Can news be a major source of aggregate fluctuations? A Bayesian DSGE approach. Journal of Money, Credit and Banking, 43(1):1-29.

Gertler, M. and Karadi, P. (2011). A model of unconventional monetary policy. Journal of Monetary Economics, 58(1):17 - 34 .

Gertler, M., Kiyotaki, N., and Queralto, A. (2011). Financial crises, bank risk exposure and government financial policy. Princeton University Mimeo.

Gertler, M. L. and Kiyotaki, N. (2010). Financial intermediation and credit policy in business cycle analysis. In Friedman, B. M. and Woodford, M., editors, Handbook of Monetary Economics, volume 3, chapter 11, pages 547-599. Elsevier, 1 edition.

Gilchrist, S., Yankov, V., and Zakrajsek, E. (2009). Credit market shocks and economic fluctuations: Evidence from corporate bond and stock markets. Journal of Monetary Economics, 56:471-493.

Gilchrist, S. and Zakrajsek, E. (2012). Credit spreads and business cycle fluctuations. American Economic Review, 102(4):1692-1720.

Goodfriend, M. and King, R. (1997). The new neoclassical synthesis and the role of monetary policy. NBER Macroeconomics Annual, 12:231-383.

Görtz, C. and Tsoukalas, J. (2012). Learning, capital-embodied technology and aggregate fluctuations. Review of Economic Dyamics, forthcoming.

Gourio, F. (2012). Disaster risk and business cycles. American Economic Review, forthcoming.

Greenwood, J., Hercowitz, Z., and Krusell, P. (2000). The role of investment specific technological change in the business cycle. European Economic Review, 44:91-115.

Gunn, C. and Johri, A. (2011). News and knowledge capital. Review of Economic Dynamics, 14(1):92-101.

Gunn, C. and Jorhi, A. (2011). News, intermediation efficiency and expectations-driven boom-bust cycles. Mimeo, McMaster University.

Hornstein, A. and Praschnik, J. (1997). Intermediate inputs and sectoral comovement in the business cycle. Journal of Monetary Economics, 40(3):573-595.

Horvath, M. (1998). Cyclicality and sectoral linkages: Aggregate fluctuations from independent sectoral shocks. Review of Economic Dynamics, 1(4):781-808. 
Horvath, M. (2000). Sectoral shocks and aggregate fluctuations. Journal of Monetary Economics, 45(1):69-106.

Huffman, G. W. and Wynne, M. A. (1999). The role of intratemporal adjustment costs in a multisector economy. Journal of Monetary Economics, 43(2):317-350.

Ireland, P. N. and Schuh, S. (2008). Productivity and us macroeconomic performance: Interpreting the past and predicting the future with a two-sector real business cycle model. Review of Economic Dynamics, 11(3):473 - 492.

Iskrev, N. (2010). Local identification in DSGE models. Journal of Monetary Economics, $57(2): 189-202$.

Jaimovich, N. and Rebelo, S. (2009). Can news about the future drive the business cycle? American Economic Review, 99(4):1097-1118.

Jermann, U. and Quadrini, V. (2012). Macroeconomic effects of financial shocks. American Economic Review, 102(1):238-71.

Justiniano, A., Primiceri, G. E., and Tambalotti, A. (2010). Investment shocks and business cycles. Journal of Monetary Economics, 57(2):132-145.

Justiniano, A., Primiceri, G. E., and Tambalotti, A. (2011). Investment shocks and the relative price of investment. Review of Economic Dynamics, 14(1):101 - 121.

Karnizova, L. (2010). The spirit of capitalism and expectation-driven business cycles. Journal of Monetary Economics, 57(6):739 - 752.

Khan, H. and Tsoukalas, J. (2012). The quantitative importance of news shocks in estimated DSGE models. Journal of Money Credit and Banking, forthcoming.

King, R. G., Plosser, C., and Rebelo, S. T. (1988). Production, growth, and business cycles: I the basic neoclassical model. Journal of Monetary Economics, 21:195-232.

Kobayashi, K. and Nutahara, K. (2010). Nominal rigidities, news-driven business cycles, and monetary policy. The B.E. Journal of Macroeconomics, 10(1).

Koop, G., Pesaran, H., and Smith, R. (2012). On identification of bayesian dsge models. mimeo.

Kurmann, A. and Otrok, C. (2012). News shocks and the slope of the term structure of interest rates. Technical report.

Leduc, S. and Sill, K. (2013). Expectations and economic fluctuations: An analysis using survey data. Review of Economics and Statistics, forthcoming.

Long, John B, J. and Plosser, C. I. (1983). Real business cycles. Journal of Political Economy, 91(1):39-69.

Mankiw, N. Gregory and Reis, Ricardo (2002). Sticky Information versus Sticky Prices: A Proposal to Replace the New Keynesian Phillips Curve. The Quarterly Journal of Economics, 117(4):1295-1328. 
Nolan, C. and Thoenissen, C. (2009). Financial shocks and the US business cycle. Journal of Monetary Economics, 56(4):596-604.

Papanikolaou, D. (2011). Investment shocks and asset prices. Journal of Political Economy, 119(4):639 - 685 .

Philippon, T. (2009). The bond market's q. Quarterly Journal of Economics, 124:10111056.

Ramey, V. (2011). Identifying government spending shocks: It's all in the timing. Quarterly Journal of Economics, February.

Ramey, V. and Shapiro, M. D. (1998). Costly capital reallocation and the effects of government spending. Carnegie Rochester Conference Series on Public Policy, 48:114594.

Ramey, V. and Shapiro, M. D. (2001). Displaced capital: A study of aerospace plant closings. Journal of Political Economy, 109:959-992.

Sannikov, Y. and Brunnermeier, M. K. (2010). A macroeconomic model with a financial sector. Technical report.

Schmitt-Grohe, S. and Uribe, M. (2012). What's news in business cycles? Econometrica, forthcoming.

Smets, F. and Wouters, R. (2007). Shocks and frictions in US business cycles: A Bayesian DSGE approach. American Economic Review, 97(3):586-606.

Walentin, K. (2012). Expectation driven business cycles with limited enforcement. Riksbank Working Paper No. 229.

Walsh, C. E. (1993). What caused the 1990-1991 recession? Economic Review, pages 33-48. 
Table 1: Prior and Posterior Distributions

\begin{tabular}{|c|c|c|c|c|c|c|c|}
\hline \multirow[t]{2}{*}{ Parameter } & \multirow[t]{2}{*}{ Description } & \multicolumn{3}{|c|}{ Prior Distribution } & \multicolumn{3}{|c|}{ Posterior Distribution } \\
\hline & & Distribution & Mean & Std. dev. & Mean & $10 \%$ & $90 \%$ \\
\hline$h$ & Consumption habit & Beta & 0.50 & 0.10 & 0.6275 & 0.5599 & 0.6949 \\
\hline$\nu$ & Inverse labour supply elasticity & Gamma & 2.00 & 0.75 & 0.8718 & 0.2447 & 1.4893 \\
\hline$\xi_{w}$ & Wage Calvo probability & Beta & 0.66 & 0.10 & 0.6599 & 0.6196 & 0.7003 \\
\hline$\xi_{C}$ & C-sector price Calvo probability & Beta & 0.66 & 0.10 & 0.7785 & 0.7465 & 0.8132 \\
\hline$\xi_{I}$ & I-sector price Calvo probability & Beta & 0.66 & 0.10 & 0.7058 & 0.6334 & 0.7773 \\
\hline$\iota_{w}$ & Wage indexation & Beta & 0.50 & 0.15 & 0.1306 & 0.0581 & 0.2034 \\
\hline$\iota_{p_{C}}$ & C-sector price indexation & Beta & 0.50 & 0.15 & 0.0726 & 0.0281 & 0.1139 \\
\hline$\iota_{p_{I}}$ & I-sector price indexation & Beta & 0.50 & 0.15 & 0.3033 & 0.1348 & 0.4702 \\
\hline$\chi_{I}$ & I-sector utilization & Gamma & 5.00 & 1.00 & 4.9975 & 3.3997 & 6.6080 \\
\hline$\chi_{C}$ & C-sector utilization & Gamma & 5.00 & 1.00 & 4.6983 & 3.0598 & 6.3562 \\
\hline$\kappa$ & Investment adj. cost & Gamma & 4.00 & 1.00 & 2.2881 & 1.7747 & 2.7620 \\
\hline$\phi_{\pi}$ & Taylor rule inflation & Normal & 1.70 & 0.30 & 1.5864 & 1.3976 & 1.7665 \\
\hline$\rho_{R}$ & Taylor rule inertia & Beta & 0.60 & 0.20 & 0.8434 & 0.8191 & 0.8681 \\
\hline \multirow[t]{2}{*}{$\phi_{d X}$} & Taylor rule output growth & Normal & 0.25 & 0.10 & 0.6822 & 0.5706 & 0.7921 \\
\hline & Shocks: Persistence & & & & & & \\
\hline$\rho_{z}$ & C-sector TFP & Beta & 0.40 & 0.20 & 0.7498 & 0.6973 & 0.801 \\
\hline$\rho_{v}$ & I-sector TFP & Beta & 0.40 & 0.20 & 0.1415 & 0.0455 & 0.2328 \\
\hline$\rho_{b}$ & Preference & Beta & 0.60 & 0.20 & 0.9136 & 0.8762 & 0.9542 \\
\hline$\rho_{e}$ & GDP measurement error & Beta & 0.60 & 0.20 & 0.9826 & 0.9664 & 0.9993 \\
\hline$\rho_{\lambda_{p}^{C}}$ & C-sector price markup & Beta & 0.60 & 0.20 & 0.0539 & 0.0145 & 0.0919 \\
\hline$\rho_{\lambda_{p}^{I}}^{p}$ & I-sector price markup & Beta & 0.60 & 0.20 & 0.8871 & 0.8442 & 0.9337 \\
\hline$\rho_{\lambda_{w}}^{p}$ & Wage markup & Beta & 0.60 & 0.20 & 0.0523 & 0.0087 & 0.0945 \\
\hline$\rho_{\xi^{K}, C}$ & C-sector capital quality & Beta & 0.60 & 0.20 & 0.8437 & 0.8133 & 0.8765 \\
\hline \multirow[t]{2}{*}{$\rho_{\xi^{K}, I}$} & I-sector capital quality & Beta & 0.60 & 0.20 & 0.0862 & 0.0215 & 0.1471 \\
\hline & Shocks: Volatilities & & & & & & \\
\hline$\sigma_{z}$ & C-sector TFP & Inv Gamma & 0.50 & 2 & 0.1721 & 0.1288 & 0.2147 \\
\hline$\sigma_{z}^{4}$ & C-sector TFP. $4 \mathrm{Q}$ ahead news & Inv Gamma & $0.5 / \sqrt{2}$ & 2 & 0.1174 & 0.0839 & 0.1521 \\
\hline$\sigma_{z}^{z}$ & C-sector TFP. 8Q ahead news & Inv Gamma & $0.5 / \sqrt{2}$ & 2 & 0.2014 & 0.1544 & 0.2470 \\
\hline$\sigma_{v}$ & I-sector TFP & Inv Gamma & 0.50 & 2 & 1.8718 & 1.5932 & 2.1517 \\
\hline$\sigma_{v}^{4}$ & I-sector TFP. 4Q ahead news & Inv Gamma & $0.5 / \sqrt{2}$ & 2 & 0.2959 & 0.1090 & 0.4712 \\
\hline$\sigma_{v}^{8}$ & I-sector TFP. 8Q ahead news & Inv Gamma & $0.5 / \sqrt{2}$ & 2 & 0.7001 & 0.5282 & 0.8661 \\
\hline$\sigma_{b}$ & Preference & Inv Gamma & 0.10 & 2 & 1.4524 & 1.1644 & 1.7339 \\
\hline$\sigma_{e}$ & GDP measurement error & Inv Gamma & 0.50 & 2 & 0.5102 & 0.4357 & 0.5794 \\
\hline$\sigma_{m p}$ & Monetary policy & Inv Gamma & 0.10 & 2 & 0.1204 & 0.1023 & 0.1386 \\
\hline$\sigma_{\lambda_{p}^{C}}$ & C-sector price markup & Inv Gamma & 0.10 & 2 & 0.6045 & 0.5184 & 0.6839 \\
\hline$\sigma_{\lambda_{p}^{I}}^{I}$ & I-sector price markup & Inv Gamma & 0.10 & 2 & 0.2282 & 0.1647 & 0.2863 \\
\hline$\sigma_{\lambda_{w}}^{p}$ & Wage markup & Inv Gamma & 0.10 & 2 & 0.3689 & 0.3100 & 0.4274 \\
\hline$\sigma_{\xi^{K}, C}$ & C-sector capital quality & Inv Gamma & 0.50 & 2 & 0.3118 & 0.2237 & 0.3948 \\
\hline$\sigma_{\xi^{K}, I}$ & I-sector capital quality & Inv Gamma & 0.50 & 2 & 2.4029 & 2.0458 & 2.7600 \\
\hline
\end{tabular}




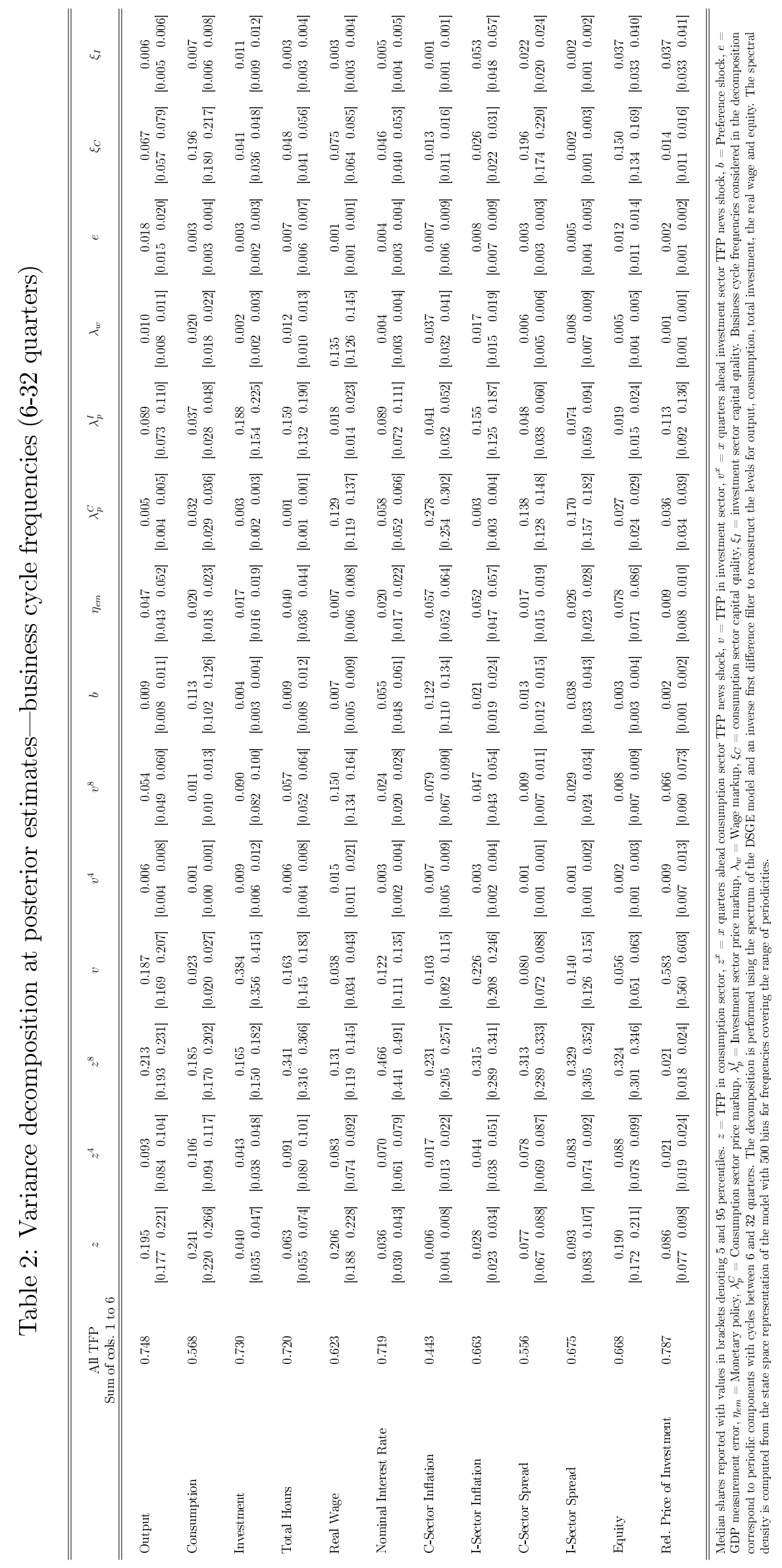




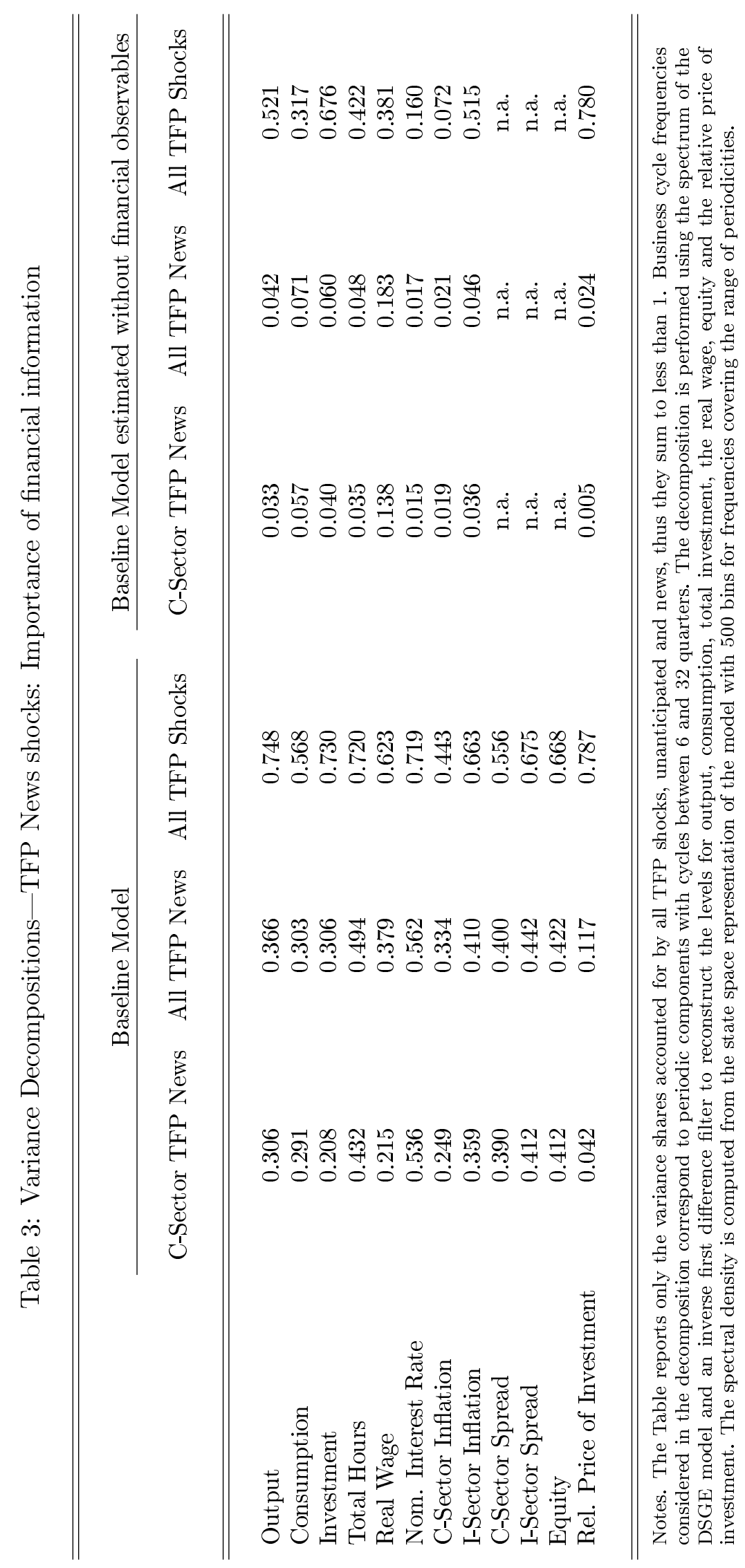



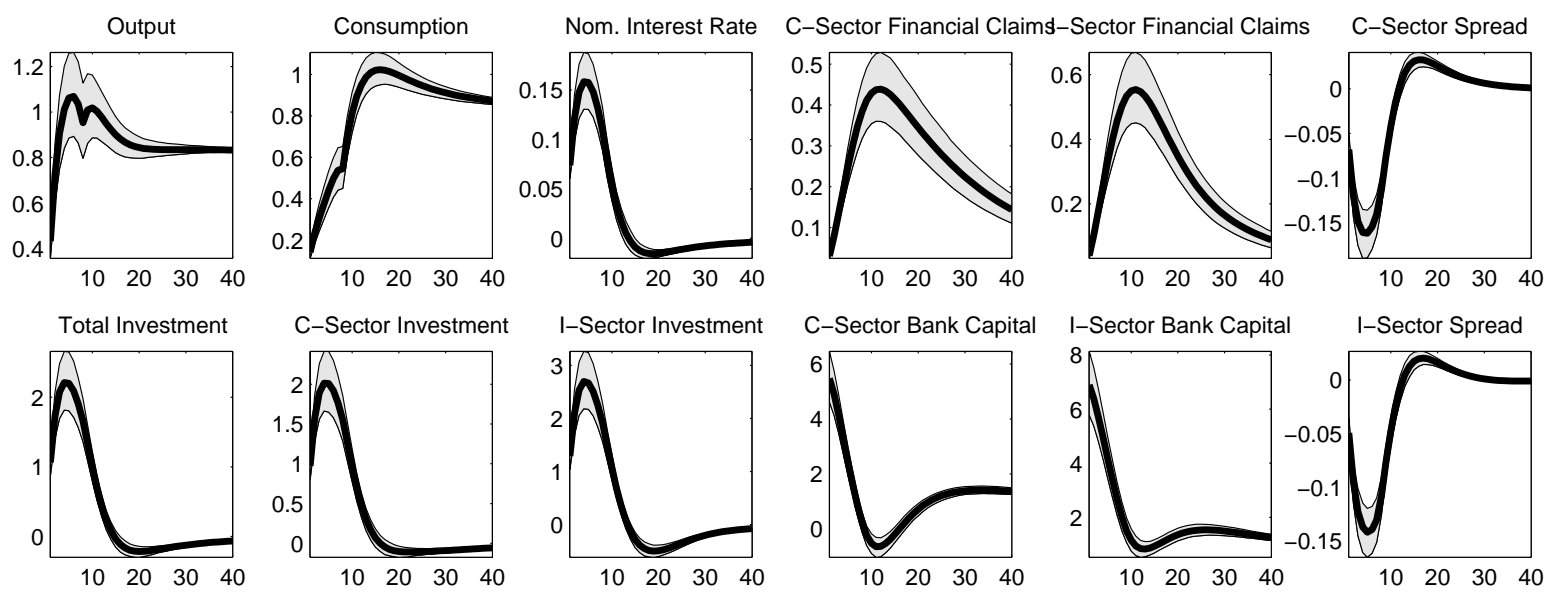

C-Sector Bank Capital
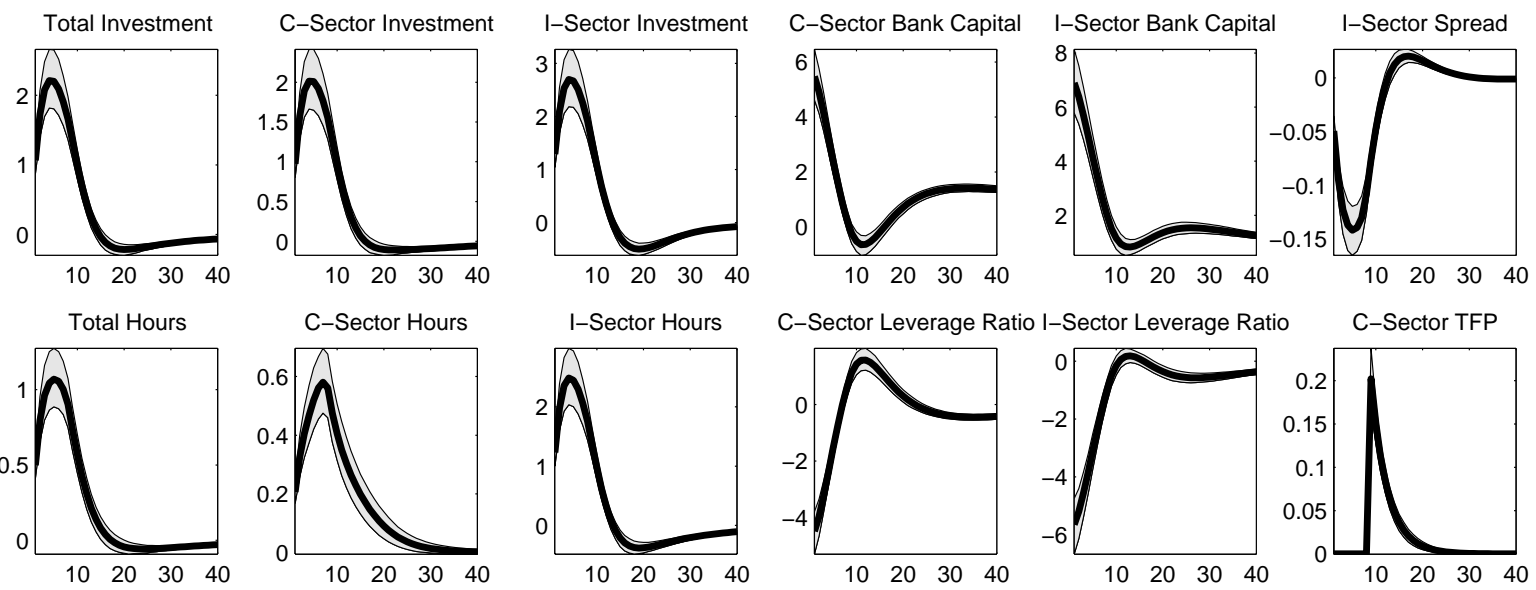

C-Sector Inflation
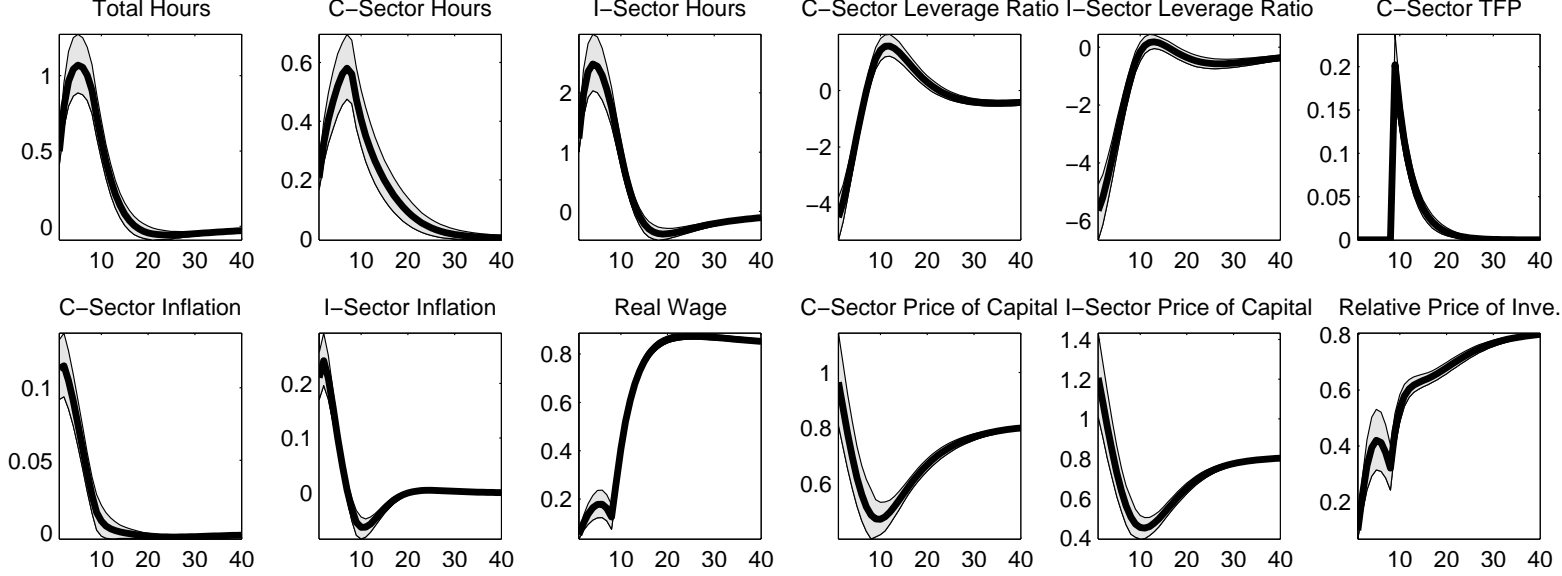

Figure 1: IRFs to a one std. deviation TFP news shock (anticipated 8 quarters ahead) in the consumption sector. Median responses with $90 \%$ confidence bands in shaded areas. 

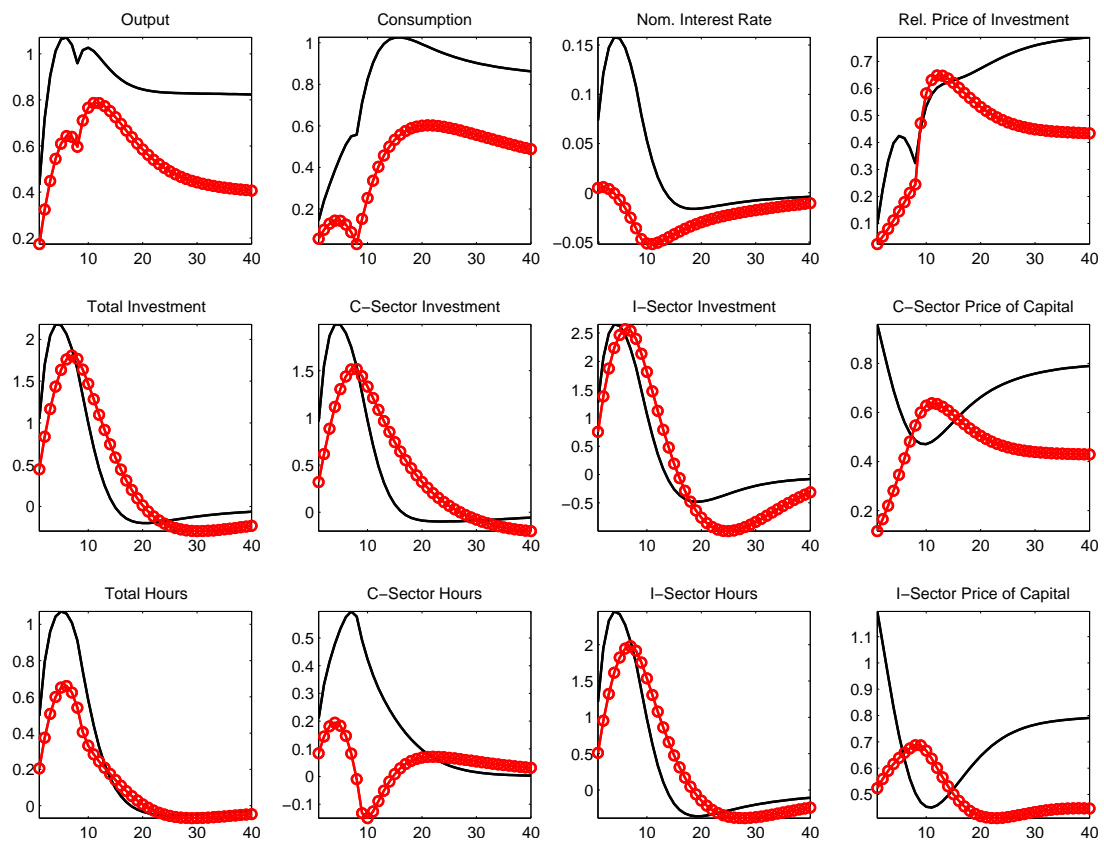

Figure 2: Responses to a one std. deviation TFP news shock (anticipated 8 quarters ahead) in the consumption sector. Baseline model with financial intermediation (black solid line), and estimated model without financial intermediation (red line with circles).
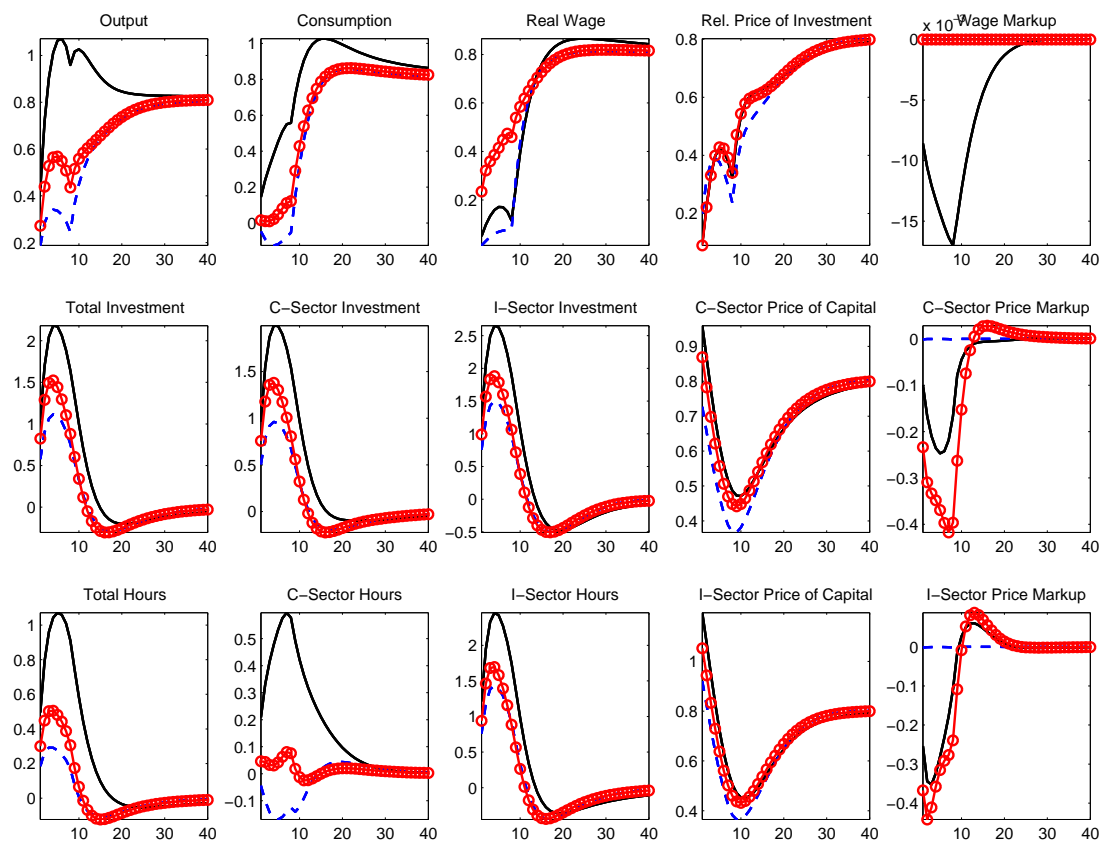

Figure 3: Responses to a one std. deviation TFP news shock (anticipated 8 quarters ahead) in the consumption sector. Baseline model (black solid line) vs. model without wage and price rigidities (blue dashed line) vs. model without wage rigidities (red line with circles). 

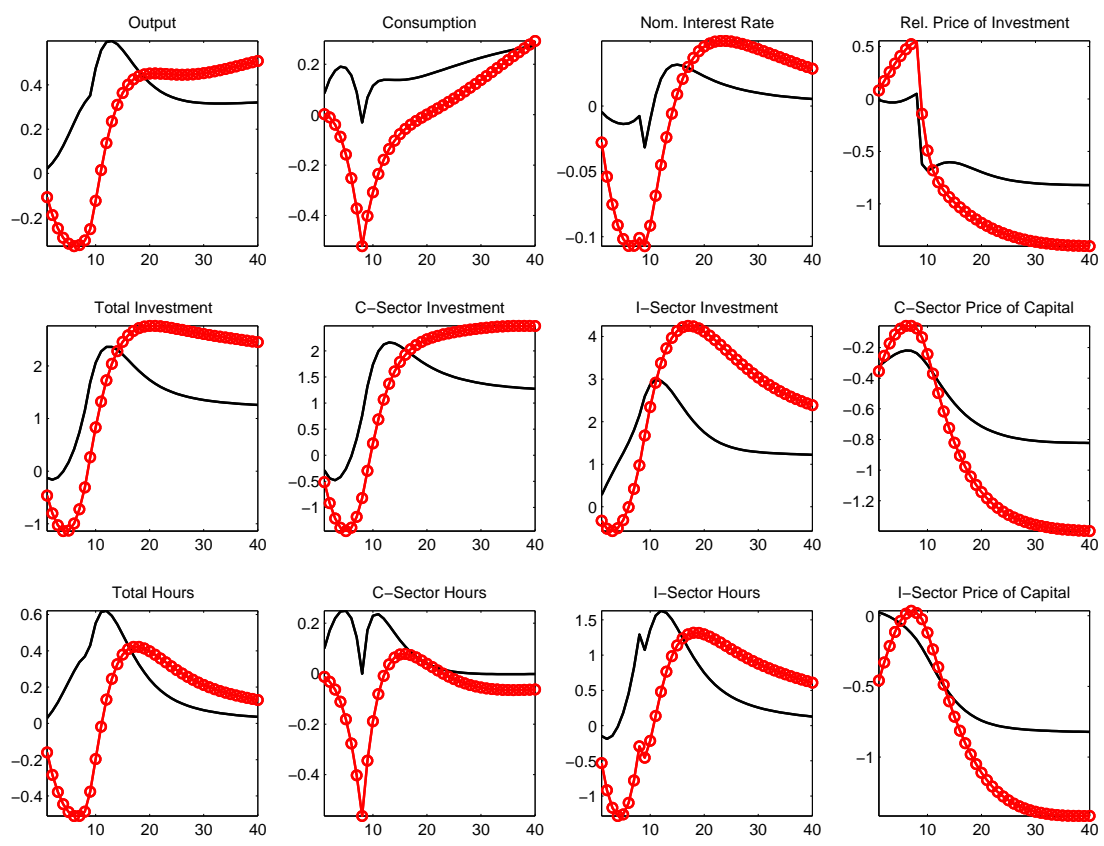

Figure 4: Responses to a one std. deviation TFP news shock (anticipated 8 quarters ahead) in the investment sector. Baseline model with financial intermediation (black solid line), and estimated model without financial intermediation (red line with circles).
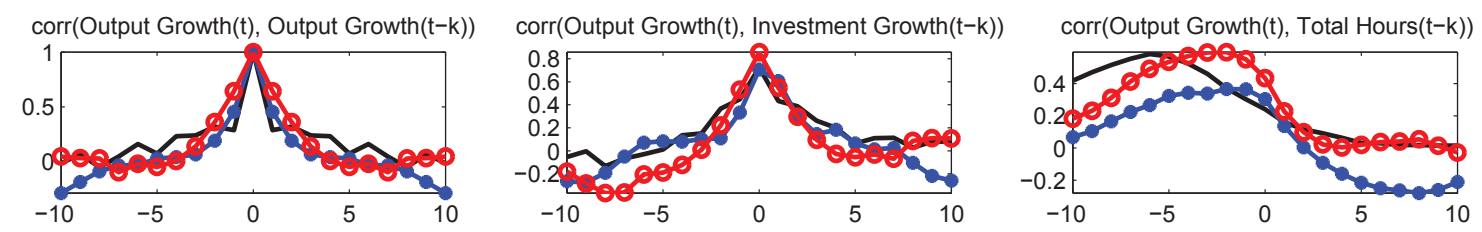

corr(Output Growth(t), Nom. Interest Rate(t-k))
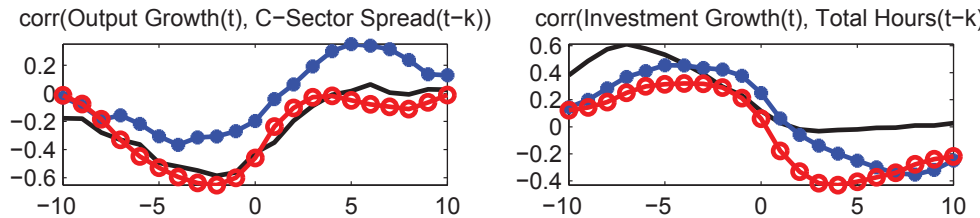

corr(Investment Growth(t), C-Sector Spread(t-k))corr(I-Sector Spread(t), C-Sector Spread(t-k))
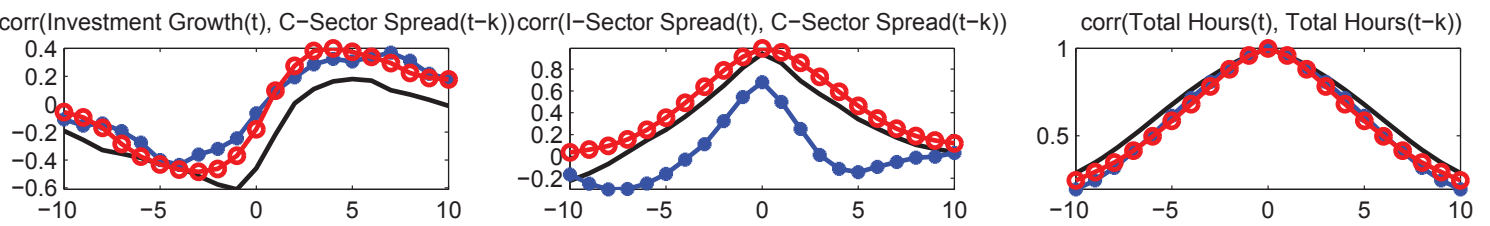

Figure 5: Dynamic correlations between key variables in the data (solid black line), implied by the baseline model with all shocks (blue line with stars) and the model with the eight quarter ahead consumption sector TFP news shock only (red line with circles). 


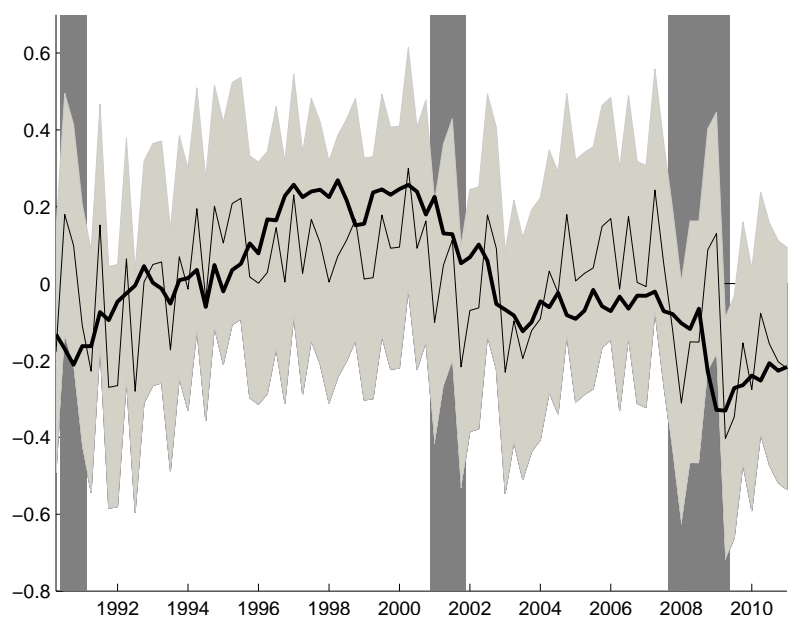

Figure 6: Eight quarter ahead consumption sector TFP news shock (thin line) and I/B/E/S long-term forecast for earnings per share (thick line). Light grey areas indicate two standard deviation confidence bands of the shock series. Dark grey bars show NBER dated recessions. 


\section{Appendix (For online publication)}

\section{A Additional Results, Tables and Figures}

\section{A.1 Robustness checks}

As explained in the main text we undertake several robustness checks to assess the sensitivity of our results, focusing on the importance of TFP news shocks. To this end, we have estimated five different specifications. Our first specification removes observations from the most recent "Great recession" period (2008Q1 to 2011Q1) addressing a potential concern that the volatility and disruption in financial markets following the Lehman collapse may be, at least partly, driving the important role of TFP news shocks in fluctuations, as well as potential misspecification of the monetary policy rule when the policy rate approaches the zero lower bound. The second specification introduces smaller prior means for the standard deviations for all TFP news shocks, assuming that the sum of the variances of all TFP news components is only one third of the variance of the respective unanticipated TFP component vs. one half assumed in the baseline. The third specification, assumes Gamma distributions for all shocks in the model, allowing for a non-zero probability mass at zero for the standard deviations of news shocks. The fourth specification, introduces a common stationary aggregate TFP process with unanticipated and news components. The last specification, adds news components in all exogenous processes of the model (except monetary policy shock) including a common aggregate TFP component, as in Khan and Tsoukalas (2012) and Schmitt-Grohe and Uribe (2012). The common TFP process is assumed to follow,

$$
f_{t}=\left(1-\rho_{f}\right) f+\rho_{f} f_{t-1}+\varepsilon_{t}^{f}, \quad \text { with } \quad \varepsilon_{t}^{f}=\varepsilon_{t, 0}^{f}+\varepsilon_{t-4,4}^{f}+\varepsilon_{t-8,8}^{f} .
$$

Here, each component is assumed, $N\left(0, \sigma_{f, t-h}^{2}\right), h=0,4,8$, uncorrelated across horizon and time, and the parameter $\rho_{f} \in(0,1)$ determines the persistence of the process. This aggregate TFP shock is a natural candidate in generating broad based and sectoral comovement so its interesting to check whether the importance of consumption sector TFP news shocks in accounting for the variance in the data is robust in this specification.

With the common aggregate TFP process the sectoral production functions become,

$$
\begin{gathered}
C_{t}(i)=\max \left\{A_{t} f_{t}\left(L_{C, t}(i)\right)^{1-a_{c}}\left(K_{C, t}(i)\right)^{a_{c}}-A_{t} V_{t}^{\frac{a_{c}}{1-a_{i}}} F_{C} ; 0\right\} . \\
I_{t}(i)=\max \left\{V_{t} f_{t}\left(L_{I, t}(i)\right)^{1-a_{i}}\left(K_{I, t}(i)\right)^{a_{i}}-V_{t}^{\frac{1}{1-a_{i}}} F_{I} ; 0\right\},
\end{gathered}
$$


In the estimated specification with the aggregate TFP shock, we indeed find that an aggregate TFP news shock induces qualitatively similar dynamics - and thus co-movement - to a consumption sector TFP news shock with the notable exception of hours worked. While hours worked rise on impact, they nevertheless decline significantly at the time when the positive aggregate TFP shock materializes. ${ }^{34}$ This is grossly at odds with the empirical autocorrelations of hours worked in the data, which are strongly autocorrelated even at very long lags (extending even at 10 lags, see Figure 5). A positive common TFP news shock at the four quarter horizon would instead generate counterfactual negative autocorrelations of hours worked at lags and leads beyond 1 and 2. Moreover, the variance shares explained by the aggregate TFP news components are very small and never exceed five percent in any observable. Including news components in non-structural disturbances is motivated by evidence in Khan and Tsoukalas (2012) and Schmitt-Grohe and Uribe (2012), who report, in estimated one sector models, news components in non-structural disturbances, most notably, wage mark-ups, preference, marginal efficiency of investment to dominate TFP news shocks, which are found to be very minor as sources of business cycles. Therefore, it is also interesting scrutinizing whether our baseline result is robust in this specification. Table 4 suggests our finding about the importance of TFP news shocks is robust across all of these different experiments, including when news components are allowed to affect the non-structural disturbances.

\footnotetext{
${ }^{34}$ The IRFs are not shown but are available upon request.
} 

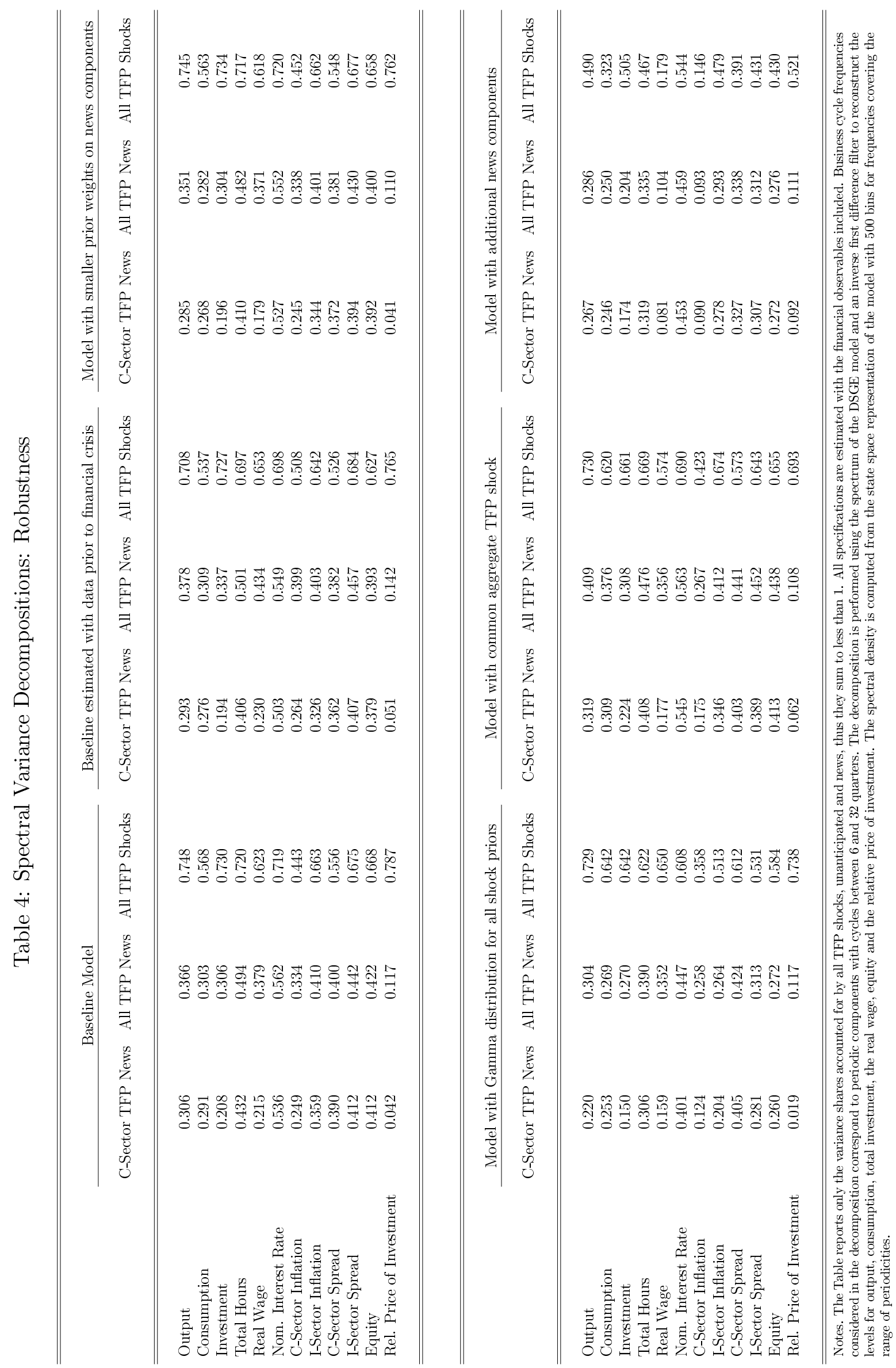


\section{A.2 Investment Specific Shocks}

The Figure below plots model responses to an unanticipated investment specific shock.
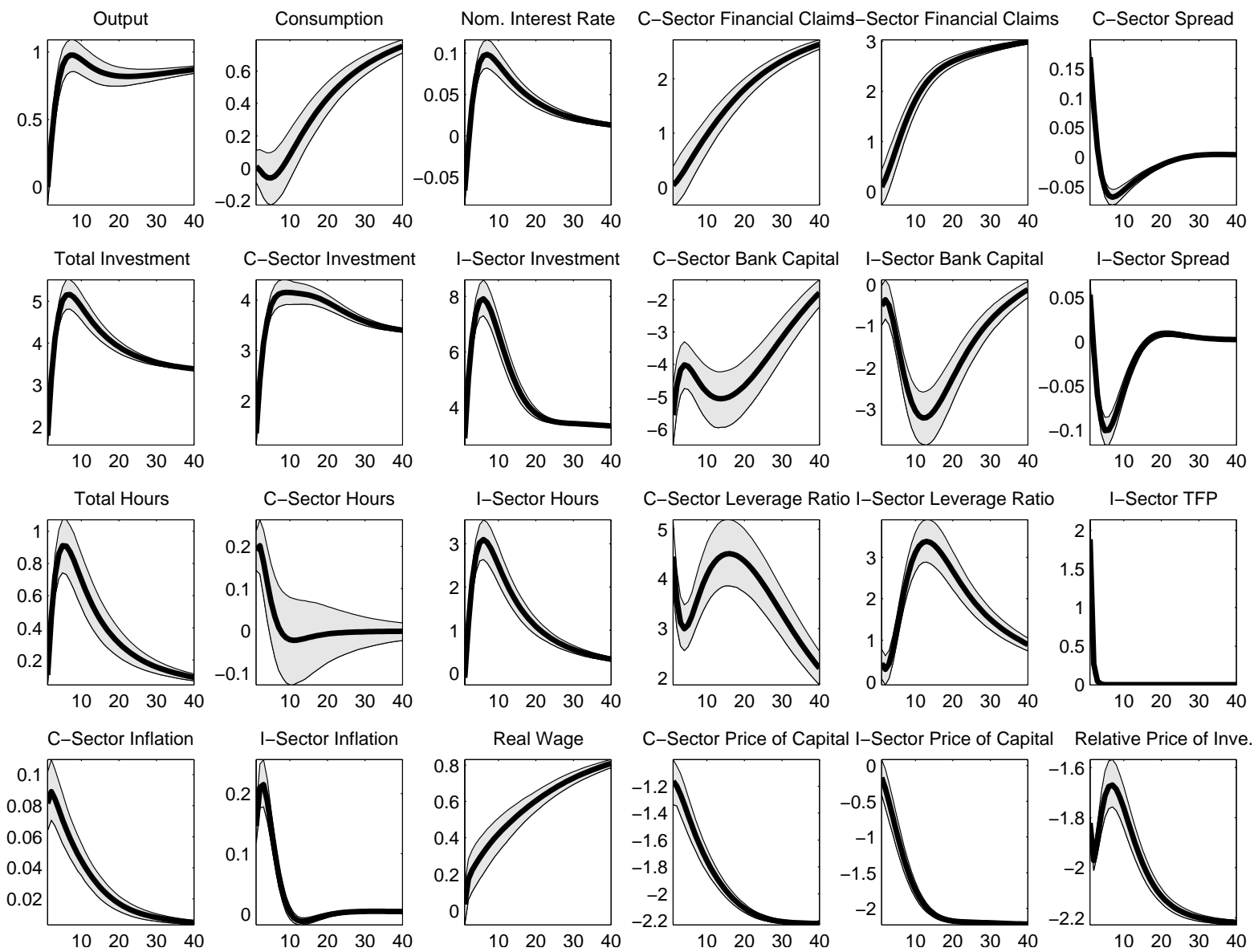

Figure 7: Responses to a one std. deviation unanticipated TFP shock in the investment sector.

\section{A.3 Additional Tables}

Table 5 reports the estimated parameter values from the model without financial intermediation. Table 6 reports an unconditional variance decomposition of the observables used in the baseline estimation. 
Table 5: Prior and Posterior Distributions - Model without Financial Sector and Financial Observables

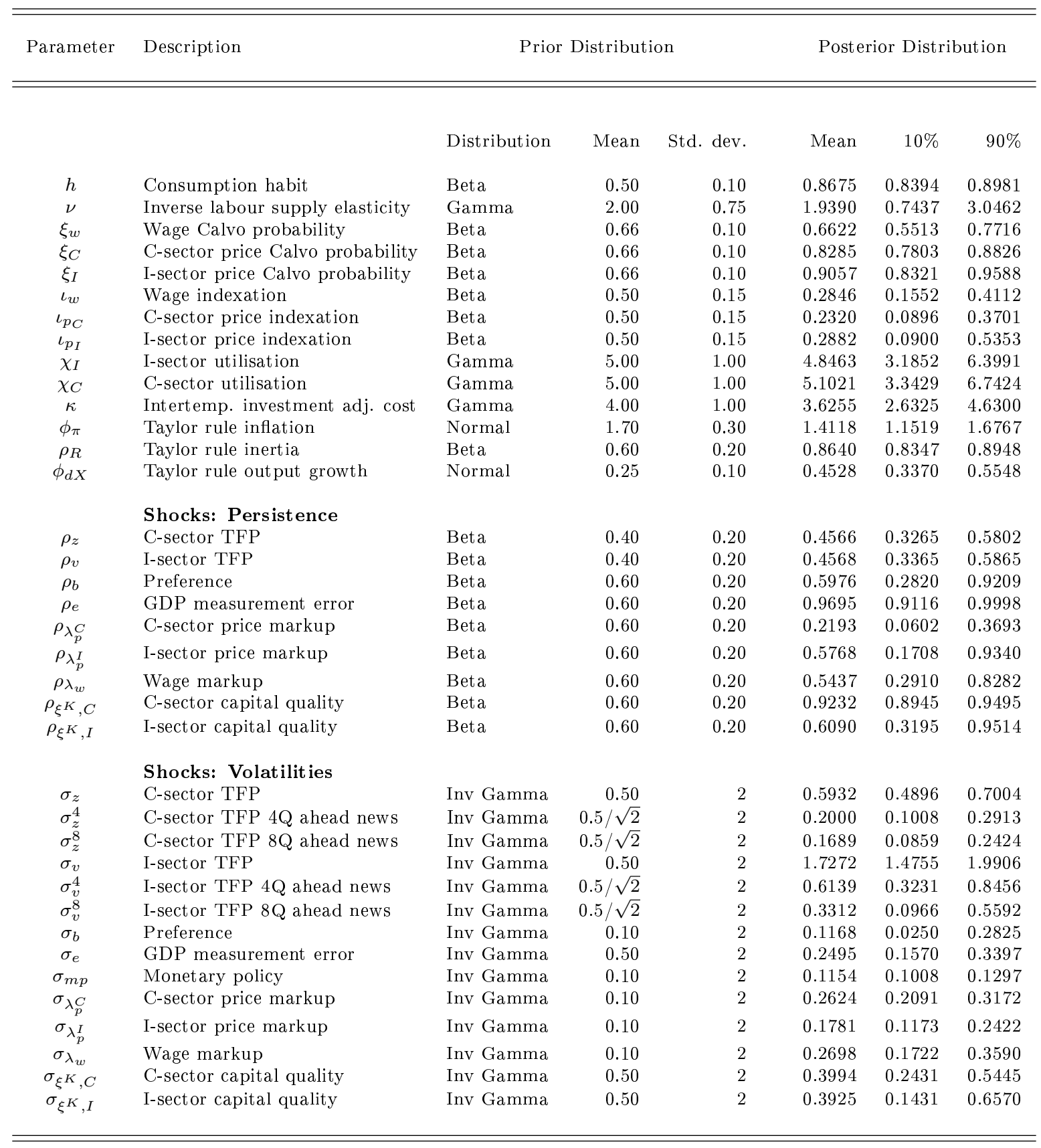




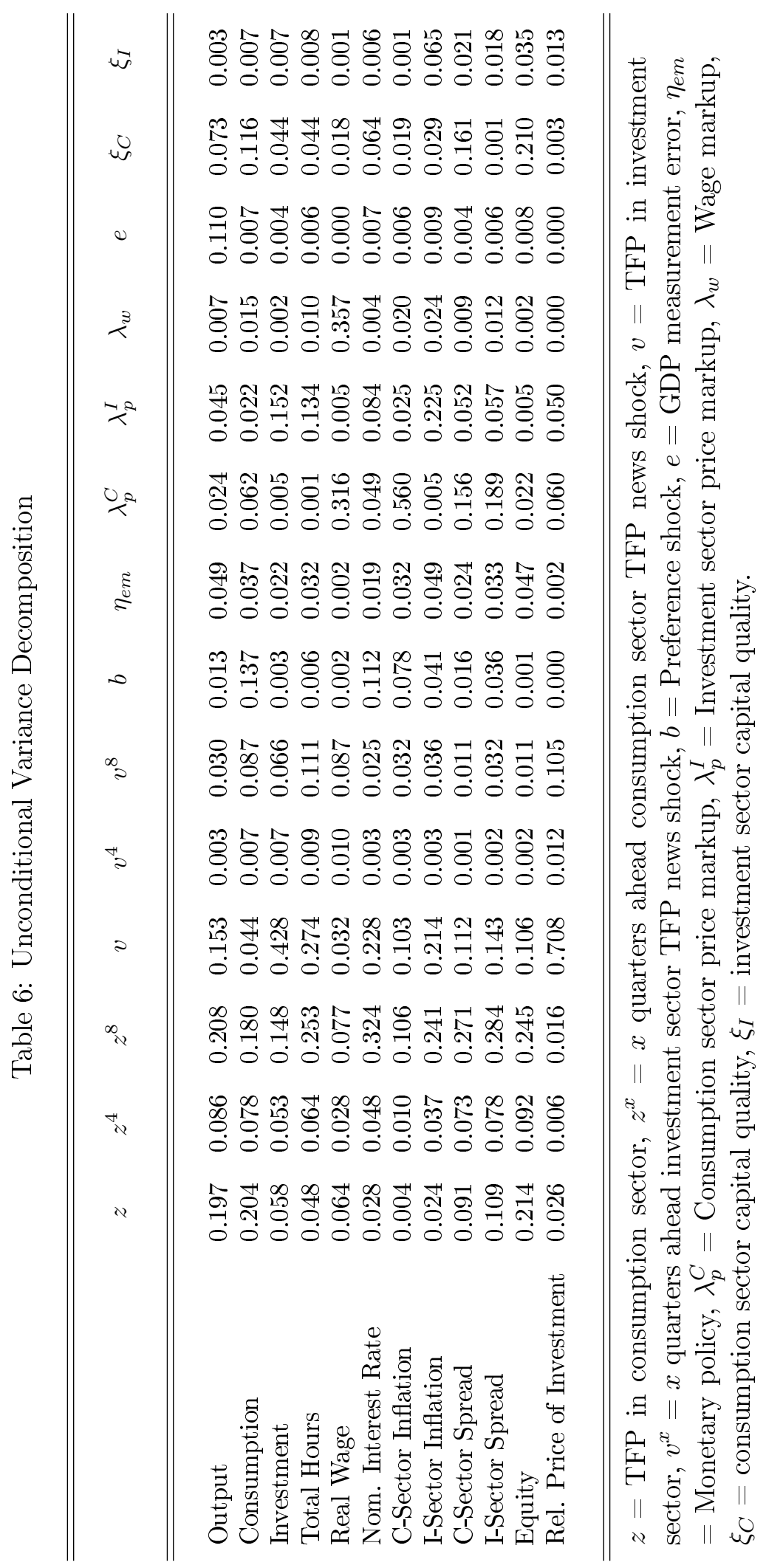




\section{A.4 A Historical Perspective and the 2008 Recession}

Given the quantitative importance of news shocks as driving forces behind fluctuations, we attempt to disentangle the impact of TFP news and unanticipated shocks on the in-sample variation of GDP and investment growth by performing a historical decomposition. This exercise can also reveal the importance of shocks during different time periods. Figure 8 depicts the results of this exercise. It shows the decomposition of output and investment growth into news and all other shocks.

The decomposition shows that news shocks account for a large fraction of the recessions in 2001 (2001Q1 - 2001Q4) and 2008 (2007Q4 - 2009Q2). They account for the majority of the drop in GDP growth and a large share of the decline in investment growth during the 2008 recession. By contrast, news shocks contribute very little to the downturn of GDP and investment in the early 1990s (1990Q3 - 1991Q1) recession, which according to this exercise is driven by unfavorable investment sector TFP shocks. This finding is in line with the general assessment of the reasons for these recessions: while movements in fundamentals are mainly found to be responsible for the recession in the early 1990s (see for example Walsh (1993)), the recent literature on news shocks entertains the idea that expectation shifts (e.g. due to correction of overoptimistic beliefs about asset prices) may have played a much bigger role in the last two recessions.

It is apparent from this decomposition that news shocks not only have a strong negative impact during the aforementioned recessions, but also slow down the subsequent recoveries. This is especially clear in the aftermath of the 2001 recession where we have a complete set of observations on the recovery and expansion phase. Unfavorable news continue to arrive well after the official end of the recession. A similar pattern can be observed after the recent recession, but in this case a longer sample size would be desirable to be able to draw a more complete picture. The slow reversion of news shock's impact on GDP and investment growth at the trough of the cycle is consistent with a literature that finds agent's forecast accuracy to be positively correlated with output. ${ }^{35}$

\section{B Data Sources and Time Series Construction}

Table 7 provides an overview of the data used to construct the observables. All the data transformations we have made in order to construct the dataset used for the estimation of the model are described in detail below.

Sectoral definition. To allocate a sector to the consumption or investment category, we used the 2005 Input-Output tables. The Input-Output tables track the flows of

\footnotetext{
${ }^{35}$ See for example Görtz and Tsoukalas (2012).
} 

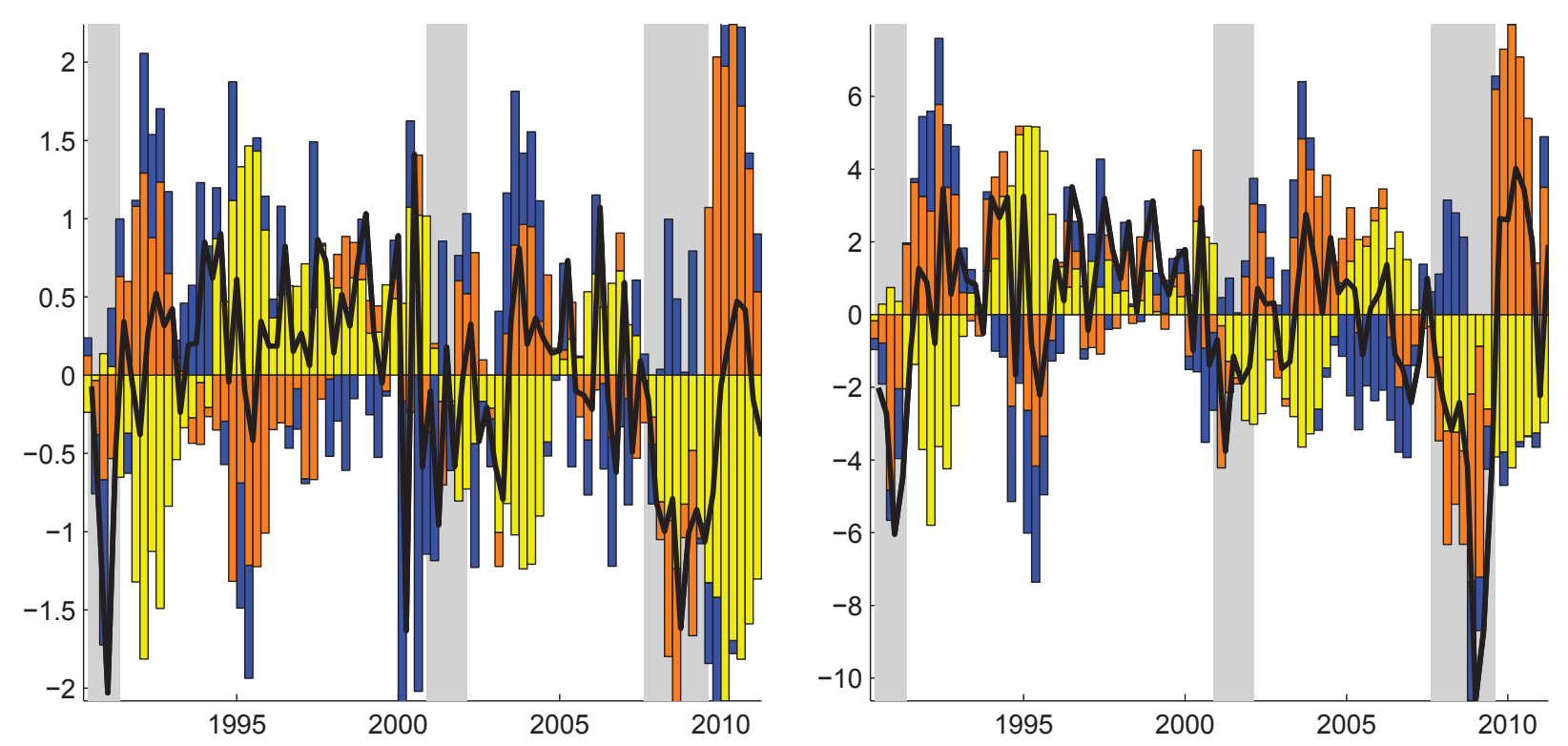

Figure 8: Historical decomposition of the growth rate of GDP (left) and investment (right) into TFP news shocks (yellow), unanticipated TFP shocks (orange) and all other shocks (blue). The grey bars denote NBER dated recessions.

goods and services across industries and record the final use of each industry's output into three broad categories: consumption, investment and intermediate uses (as well as net exports and government). First, we determine how much of a 2-digit industry's final output goes to consumption as opposed to investment or intermediate uses. Then we adopt the following criterion: if the majority of an industry's final output is allocated to final consumption demand it is classified as a consumption sector; otherwise, if the majority of an industry's output is allocated to investment or intermediate demand, it is classified as an investment sector. Using this criterion, mining, utilities, transportation and warehousing, information, manufacturing, construction and wholesale trade industries are classified as the investment sector and retail trade, finance, insurance, real estate, rental and leasing, professional and business services, educational services, health care and social assistance, arts, entertainment, recreation, accommodation and food services and other services except government are classified as the consumption sector. ${ }^{36}$

Real and nominal variables. Consumption (in current prices) is defined as the sum of personal consumption expenditures on services and personal consumption expenditures on non-durable goods. The times series for real consumption is constructed as follows. First, we compute the shares of services and non-durable goods in total (current price) consumption. Then, total real consumption growth is obtained as the chained

\footnotetext{
${ }^{36}$ We have checked whether there is any migration of 2-digit industries across sectors for our sample. The only industry which changes classification (from consumption to investment) during the sample is "information" which for the majority of the sample can be classified as investment and we classify it as such.
} 
weighted (using the nominal shares above) growth rate of real services and growth rate of real non-durable goods. Using the growth rate of real consumption we construct a series for real consumption using 2005 as the base year. The consumption deflator is calculated as the ratio of nominal over real consumption. Inflation of consumer prices is the growth rate of the consumption deflator. Analogously, we construct a time series for the investment deflator using series for (current price) personal consumption expenditures on durable goods and gross private domestic investment and chain weight to arrive at the real aggregate. The relative price of investment is the ratio of the investment deflator and the consumption deflator. Real output is GDP expressed in consumption units by dividing current price GDP with the consumption deflator.

The hourly wage is defined as total compensation per hour. Dividing this series by the consumption deflator yields the real wage rate. Hours worked is given by hours of all persons in the non-farm business sector. All series described above as well as the equity capital series (described below) are expressed in per capita terms using the the series of non-institutional population, ages 16 and over. The nominal interest rate is the effective federal funds rate. We use the monthly average per quarter of this series and divide it by four to account for the quarterly frequency of the model. The time series for hours is in logs. Moreover, all series used in estimation (including the financial time series described below) are expressed in deviations from their sample average.

Financial variables. Data for sectoral credit spreads are not directly available. However, Reuters' Datastream provides U.S. credit spreads for companies which we map into the two sectors using The North American Industry Classification System (NAICS). ${ }^{37} \mathrm{~A}$ credit spread is defined as the difference between a company's corporate bond yield and the yield of a US Treasury bond with an identical maturity. In constructing credit spreads we only consider non-financial corporations and only bonds traded in the secondary market. In line with Gilchrist and Zakrajsek (2012) we make the following adjustments to the credit spread data we construct: using ratings from Standard \& Poor's and Moody's, we exclude all bonds which are below investment grade as well as the bonds for which ratings are unavailable. We further exclude all spreads with a duration below one and above 30 years and exclude all credit spreads below 10 and above 5000 basis points to ensure that the time series are not driven by a small number of extreme observations. The series for the sectoral credit spreads are constructed by taking the average over all

\footnotetext{
${ }^{37}$ We use the 2005 NAICS codes. The investment sector is defined to consist of companies in mining, utilities, transportation and warehousing, information, manufacturing, construction and wholesale trade industries (NAICS codes 21222331323342484951 (except 491)). The consumption sector consists of companies in retail trade, finance, insurance, real estate, rental and leasing, professional and business services, educational services, health care and social assistance,arts, entertainment, recreation, accommodation and food services and other services except government (NAICS codes 67114445525354 $555681)$.
} 
Table 7: Time Series used to construct the observables and steady state relationships

\begin{tabular}{llll}
\hline \hline Time Series Description & & & \\
& & Units & Source \\
\hline \hline & & & \\
Gross domestic product & CP, SA, billion $\$$ & GDP & BEA \\
Gross Private Domestic Investment & CP, SA, billion $\$$ & GPDI & BEA \\
Real Gross Private Domestic Investment & CVM, SA, billion $\$$ & GPDIC1 & BEA \\
Personal Consumption Exp.: Durable Goods & CP, SA, billion $\$$ & PCDG & BEA \\
Real Personal Consumption Exp.: Durable Goods & CVM, SA, billion $\$$ & PCDGCC96 & BEA \\
Personal Consumption Expenditures: Services & CP, SA, billion $\$$ & PCESV & BEA \\
Real Personal Consumption Expenditures: Services & CVM, SA, billion $\$$ & PCESVC96 & BEA \\
Personal Consumption Exp.: Nondurable Goods & CP, SA, billion $\$$ & PCND & BEA \\
Real Personal Consumption Exp.: Nondurable Goods & CVM, SA, billion $\$$ & PCNDGC96 & BEA \\
Civilian Noninstitutional Population & NSA, 1000s & CNP160V & BLS \\
Nonfarm Business Sector: Compensation Per Hour & SA, Index 2005=100 & COMPNFB & BLS \\
Nonfarm Business Sector: Hours of All Persons & SA, Index 2005=100 & HOANBS & BLS \\
Effective Federal Funds Rate & NSA, percent & FEDFUNDS & BG \\
Total Equity & NSA & EQTA & IEC \\
Total Assets & NSA & H.8 & FRB \\
All Employees & SA & B-1 & BLS \\
Average Weekly Hours & SA & & BLS \\
& & & \\
\hline \hline
\end{tabular}

$\mathrm{CP}=$ current prices, CVM = chained volume measures (2005 Dollars), $\mathrm{SA}=$ seasonally adjusted, NSA $=$ not seasonally adjusted. BEA = U.S. Department of Commerce: Bureau of Economic Analysis, BLS = U.S. Department of Labor: Bureau of Labor Statistics and BG = Board of Governors of the Federal Reserve System, IEC = Federal Financial Institutions Examination Council, FRB = Federal Reserve Board.

company level spreads available in a certain quarter. These two series are transformed from basis points into percent and divided by four to guarantee that they are consistent with the quarterly frequency of our model. After these adjustments the dataset (1990Q22011Q1) contains 5381 bonds of which 1213 are classified to be issued by companies in the consumption sector and 4168 issued by companies in the investment sector. This is equivalent to 35413 observations in the consumption and 115286 observations in the investment sector over the entire sample. The average duration is 30 quarters (consumption sector) and 28 quarters (investment sector) with an average rating for both sectoral bond issues between $\mathrm{BBB}+$ and $\mathrm{A}-$. The total number of firms in our sample is equal to 1696, where 516 firms belong to the consumption sector and 1180 firms belong to the investment sector. The correlation between the two sectoral spread series is equal to 0.83 .

Steady state financial parameters. The steady state leverage ratio of financial intermediaries in the model - which helps to pin down the parameters $\varpi$ and $\lambda_{B}$ - is calculated by taking the sample average of the inverse of total equity over adjusted assets of all insured US commercial banks available from the Federal Financial Institutions Examination Council. The same body reports a series of equity over total assets. We multiply this ratio with total assets in order to get total equity for the U.S. banking 
sector that we use in estimation. Total assets includes consumer loans and holdings of government bonds which we want to exclude from total assets to be consistent with the model concept. Thus, to arrive at an estimate for adjusted assets we subtract consumer, real estate loans and holdings of government and government guaranteed bonds (such as government sponsored institutions) from total assets of all insured U.S. commercial banks.

Calibration. Table 8 describes the parameters we hold fixed during the estimation. We set the quarterly depreciation rate to be equal across sectors, $\delta_{C}=\delta_{I}=0.025$. From the steady state restriction $\beta=\pi_{C} / R$, we set $\beta=0.9974$. The shares of capital in the production functions, $a_{C}$ and $a_{I}$, are assumed equal across sectors and fixed at 0.3. The steady state values for the ratio of nominal investment to consumption is calibrated to be consistent with the average value in the data. The steady state sectoral inflation rates are set to the sample averages and the sectoral steady state mark-ups are assumed to be equal to $15 \%$. We also calibrate the steady state (deterministic) growth of TFP in the consumption/investment sectors in line with the sample average growth rates of output in the two sectors. This yields $g_{a}=0.141 \%$ and $g_{v}=0.434 \%$ per quarter. There are three parameters specific to financial intermediation. The parameter $\theta_{B}$, which determines the banker's average life span does not have a direct empirical counterpart and is fixed at 0.96 , very similar to the value used by Gertler and Kiyotaki (2010) and Gertler and Karadi (2011). This value implies an average survival time of bankers of slightly over six years. The parameters $\varpi$ and $\lambda_{B}$ are fixed at values which guarantee that the steady state risk premium (the average of spreads across the two sectors) and the steady state leverage ratio matches their empirical counterparts. The average of the consumption sector and investment sector credit spreads are each equal to 50 basis points in the sample. The average leverage ratio in the data is computed from the ratio of assets (excluding loans to consumers, real estate and holdings of government bonds) to equity for all U.S. insured commercial banks and is equal to 5.47. This value is considerably smaller compared to the ratio of total assets to equity, which is equal to 11.52 . 
Table 8: Calibrated Parameters

Parameter Value Description

\begin{tabular}{lll}
\hline \hline$\delta_{C}$ & 0.025 & Consumption sector capital depreciation \\
$\delta_{I}$ & 0.025 & Investment sector capital depreciation \\
$a_{c}$ & 0.3 & Consumption sector share of capital \\
$a_{I}$ & 0.3 & Investment sector share of capital \\
$\beta$ & 0.9974 & Discount factor \\
$\pi_{C}$ & 0.6722 & SS consumption sector quarterly inflation (percent) \\
$\pi_{I}$ & 0.0245 & SS investment sector quarterly inflation (percent) \\
$\lambda_{p}$ & 0.15 & Steady state price markup \\
$\lambda_{w}$ & 0.15 & Steady state wage markup \\
$g_{a}$ & 0.141 & SS C-sector TFP growth (percent quarterly) \\
$g_{v}$ & 0.434 & SS I-sector TFP growth (percent quarterly) \\
$p_{i} \frac{i}{c}$ & 0.399 & SS investment / consumption \\
$\theta_{B}$ & 0.96 & Fraction of bankers that survive \\
$\varpi$ & 0.0021 & Share of assets transferred to new bankers \\
$\lambda_{B}$ & 0.69 & Fraction of funds bankers can divert \\
$\varrho$ & 5.47 & SS leverage ratio \\
$R^{B}-R$ & 0.5 & SS risk premium (percent quarterly) \\
& & \\
\hline \hline
\end{tabular}

\section{Model Details and Derivations}

We provide the model details and derivations required for solution and estimation of the model. We begin with the pricing and wage decisions of firms and households, the financial sector followed by the normalization of the model to render it stationary, the description of the steady state and the log-linearized model equations.

\section{C.1 Intermediate and Final Goods Producers}

Intermediate producers pricing decision. A constant fraction $\xi_{p, x}$ of intermediate firms in sector $x=C, I$ cannot choose their price optimally in period $t$ but reset their price - as in Calvo (1983) — according to the indexation rule,

$$
\begin{aligned}
& P_{C, t}(i)=P_{C, t-1}(i) \pi_{C, t-1}^{\iota_{p}} \pi_{C}^{1-\iota_{p}}, \\
& P_{I, t}(i)=P_{I, t-1}(i) \pi_{I, t-1}^{\iota_{I}} \pi_{I}^{1-\iota_{I}}\left[\left(\frac{A_{t}}{A_{t-1}}\right)^{-1}\left(\frac{V_{t}}{V_{t-1}}\right)^{\frac{1-a_{C}}{1-a_{i}}}\right]^{\iota_{p_{I}}},
\end{aligned}
$$

where $\pi_{C, t} \equiv \frac{P_{C, t}}{P_{C, t-1}}$ and $\pi_{I, t} \equiv \frac{P_{I, t}}{P_{I, t-1}}\left(\frac{A_{t}}{A_{t-1}}\right)^{-1}\left(\frac{V_{t}}{V_{t-1}}\right)^{\frac{1-a_{C}}{1-a_{i}}}$ is gross inflation in the two sectors and $\pi_{C}, \pi_{I}$ denote steady state values. The factor that appears in the investment sector expression adjusts for investment specific progress. 
The remaining fraction of firms, $\left(1-\xi_{p, x}\right)$, in sector $x=C, I$ can adjust the price in period $t$. These firms choose their price optimally by maximizing the present discounted value of future profits.

The resulting aggregate price index in the consumption sector is,

$$
P_{C, t}=\left[\left(1-\xi_{p, C}\right) \tilde{P}_{C, t}^{\frac{1}{\lambda_{p, t}^{C}}}+\xi_{p, C}\left(\left(\frac{\pi_{C, t-1}}{\pi}\right)^{\iota_{p}} \pi_{C}^{1-\iota_{p}} P_{C, t-1}\right)^{\frac{1}{\lambda_{p, t}^{C}}}\right]^{\lambda_{p, t}^{C}}
$$

The aggregate price index in the investment sector is,

$$
P_{I, t}=\left[\left(1-\xi_{p, I}\right) \tilde{P}_{I, t}^{\frac{1}{\lambda_{p, t}^{I}}}+\xi_{p, I}\left(P_{I, t-1}\left(\frac{\pi_{I, t-1}}{\pi}\right)^{\iota_{p_{I}}} \pi_{I}^{1-\iota_{p}}\left[\left(\frac{A_{t}}{A_{t-1}}\right)^{-1}\left(\frac{V_{t}}{V_{t-1}}\right)^{\frac{1-a_{c}}{1-a_{i}}}\right]^{\iota_{p_{I}}}\right)^{\frac{1}{\lambda_{p, t}^{I}}}\right]^{\lambda_{p, t}^{I}} .
$$

Final goods producers. Profit maximization and the zero profit condition for final good firms imply that sectoral prices of the final goods, $P_{C, t}$ and $P_{I, t}$, are CES aggregates of the prices of intermediate goods in the respective sector, $P_{C, t}(i)$ and $P_{I, t}(i)$,

$$
P_{C, t}=\left[\int_{0}^{1} P_{C, t}(i)^{\frac{1}{\lambda_{p, t}^{C}}} d i\right]^{\lambda_{p, t}^{C}}, \quad P_{I, t}=\left[\int_{0}^{1} P_{I, t}(i)^{\frac{1}{\lambda_{p, t}^{I}}} d i\right]^{\lambda_{p, t}^{I}} .
$$

\section{C.1.1 Household's wage setting}

Each household $j \in[0,1]$ supplies specialized labor, $L_{t}(j)$, monopolistically as in Erceg et al. (2000). A large number of competitive "employment agencies" aggregate this specialized labor into a homogenous labor input which is sold to intermediate goods producers in a competitive market. Aggregation is done according to the following function,

$$
L_{t}=\left[\int_{0}^{1} L_{t}(j)^{\frac{1}{1+\lambda_{w, t}}} d j\right]^{1+\lambda_{w, t}}
$$

The desired markup of wages over the household's marginal rate of substitution (or wage mark-up), $\lambda_{w, t}$, follows the exogenous stochastic process,

$$
\log \left(1+\lambda_{w, t}\right)=\left(1-\rho_{w}\right) \log \left(1+\lambda_{w}\right)+\rho_{w} \log \left(1+\lambda_{w, t-1}\right)+\varepsilon_{w, t}
$$

where $\rho_{w} \in(0,1)$ and $\varepsilon_{w, t}$ is i.i.d. $N\left(0, \sigma_{\lambda_{w}}^{2}\right)$.

Profit maximization by the perfectly competitive employment agencies implies the labor demand function,

$$
L_{t}(j)=\left(\frac{W_{t}(j)}{W_{t}}\right)^{-\frac{1+\lambda_{w, t}}{\lambda_{w, t}}} L_{t}
$$


where $W_{t}(j)$ is the wage received from employment agencies by the supplier of labor of type $j$, while the wage paid by intermediate firms for the homogenous labor input is,

$$
W_{t}=\left[\int_{0}^{1} W_{t}(j)^{\frac{1}{\lambda_{w, t}}} d j\right]^{\lambda_{w, t}}
$$

Following Erceg et al. (2000), in each period, a fraction $\xi_{w}$ of the households cannot freely adjust its wage but follows the indexation rule,

$$
W_{t+1}(j)=W_{t}(j)\left(\pi_{c, t} e^{z_{t}+\frac{a_{c}}{1-a_{i}} v_{t}}\right)^{\iota_{w}}\left(\pi_{c} e^{g_{a}+\frac{a_{c}}{1-a_{i}} g_{v}}\right)^{1-\iota_{w}}
$$

The remaining fraction of households, $\left(1-\xi_{w}\right)$, chooses an optimal wage, $W_{t}(j)$, by maximizing, ${ }^{38}$

$$
E_{t}\left\{\sum_{s=0}^{\infty} \xi_{w}^{s} \beta^{s}\left[-b_{t+s} \varphi \frac{L_{t+s}(j)^{1+\nu}}{1+\nu}+\Lambda_{t+s} W_{t}(j) L_{t+s}(j)\right]\right\}
$$

subject to the labor demand function (C.1). The aggregate wage evolves according to,

$$
W_{t}=\left\{\left(1-\xi_{w}\right)\left(\tilde{W}_{t}\right)^{\frac{1}{\lambda_{w}}}+\xi_{w}\left[\left(\pi_{c} e^{g_{a}+\frac{a_{c}}{1-a_{i}} g_{v}}\right)^{1-\iota_{w}}\left(\pi_{c, t-1} e^{z_{t-1}+\frac{a_{c}}{1-a_{i}} v_{t-1}}\right)^{\iota_{w}} W_{t-1}\right]^{\frac{1}{\lambda_{w}}}\right\}^{\lambda_{w}},
$$

where $\tilde{W}_{t}$ is the optimally chosen wage.

\section{C.2 Physical capital producers}

Capital producers in sector $x=C, I$ use a fraction of investment goods from final goods producers and undepreciated capital stock from capital services producers (as described above) to produce new capital goods, subject to investment adjustment costs as proposed by Christiano et al. (2005). These new capital goods are then sold in perfectly competitive capital goods markets to capital services producers. The technology available for physical capital production is given as,

$$
O_{x, t}^{\prime}=O_{x, t}+\left(1-S\left(\frac{I_{x, t}}{I_{x, t-1}}\right)\right) I_{x, t}
$$

\footnotetext{
${ }^{38}$ All households that can reoptimize will choose the same wage. The probability to be able to adjust the wage, $\left(1-\xi_{w}\right)$, can be seen as a reduced-form representation of wage rigidities with a broader microfoundation; for example quadratic adjustment costs (Calvo (1983)), information frictions (Mankiw, N. Gregory and Reis, Ricardo (2002)) and contract costs (Caplin and Leahy (1997)).
} 
where $O_{x, t}$ denotes the amount of used capital at the end of period $t, O_{x, t}^{\prime}$ the new capital available for use at the beginning of period $t+1$. The investment adjustment cost function $S(\cdot)$ satisfies the following: $S(1)=S^{\prime}(1)=0$ and $S^{\prime \prime}(1)=\kappa>0$, where "'"s denote differentiation. The optimization problem of capital producers in sector $x=C, I$ is given as,

$$
\max _{I_{x, t}, O_{x, t}} E_{t} \sum_{t=0}^{\infty} \beta^{t} \Lambda_{t}\left\{Q_{x, t}\left[O_{x, t}+\left(1-S\left(\frac{I_{x, t}}{I_{x, t-1}}\right)\right) I_{x, t}\right]-Q_{x, t} O_{x, t}-\frac{P_{I, t}}{P_{C, t}} I_{x, t}\right\}
$$

where $Q_{x, t}$ denotes the price of capital (i.e. the value of installed capital in consumption units). The first order condition for investment goods is,

$$
\frac{P_{I, t}}{P_{C, t}}=Q_{x, t}\left[1-S\left(\frac{I_{x, t}}{I_{x, t-1}}\right)-S^{\prime}\left(\frac{I_{x, t}}{I_{x, t-1}}\right) \frac{I_{x, t}}{I_{x, t-1}}\right]+\beta E_{t} Q_{x, t+1} \frac{\Lambda_{t+1}}{\Lambda_{t}}\left[S^{\prime}\left(\frac{I_{x, t+1}}{I_{x, t}}\right)\left(\frac{I_{x, t+1}}{I_{x, t}}\right)^{2}\right] .
$$

From the capital producer's problem it is evident that any value of $O_{x, t}$ is profit maximizing. Let $\delta_{x} \in(0,1)$ denote the depreciation rate of capital and $\bar{K}_{x, t-1}$ the capital stock available at the beginning of period $t$ in sector $x=C, I$. Then setting $O_{x, t}=(1-\delta) \xi_{x, t}^{K} \bar{K}_{x, t-1}$ implies the available (sector specific) capital stock in sector $x$, evolves according to,

$$
\bar{K}_{x, t}=\left(1-\delta_{x}\right) \xi_{x, t}^{K} \bar{K}_{x, t-1}+\left(1-S\left(\frac{I_{x, t}}{I_{x, t-1}}\right)\right) I_{x, t}, \quad x=C, I,
$$

as described in the main text.

\section{C.3 Financial Intermediaries}

This section describes in detail how the setup of Gertler and Karadi (2011) is adapted for the two sector model and describes in detail how the equations for financial intermediaries in the main text are derived.

The balance sheet for the consumption or investment sector branch can be expressed as,

$$
P_{C, t} Q_{x, t} S_{x, t}=P_{C, t} N_{x, t}+B_{x, t}, \quad x=C, I,
$$

where $S_{x, t}$ denotes the quantity of financial claims held by the intermediary branch and $Q_{x, t}$ denotes the sector specific price of a claim. The variable $N_{x, t}$ represents the bank's wealth (or equity) at the end of period $t$ and $B_{x, t}$ are the deposits the intermediary branch 
obtains from households. The sector specific assets held by the financial intermediary pay the stochastic return $R_{x, t+1}^{B}$ in the next period. Intermediaries pay at $t+1$ the noncontingent real gross return $R_{t}$ to households for their deposits made at time $t$. Then, the intermediary branch wquity evolves over time as,

$$
\begin{aligned}
N_{x, t+1} P_{C, t+1} & =R_{x, t+1}^{B} \pi_{C, t+1} P_{C, t} Q_{x, t} S_{x, t}-R_{t} B_{x, t} \\
N_{x, t+1} \frac{P_{C, t+1}}{P_{C, t}} & =R_{x, t+1}^{B} \pi_{C, t+1} Q_{x, t} S_{x, t}-R_{t}\left(Q_{x, t} S_{x, t}-N_{x, t}\right) \\
N_{x, t+1} & =\left[\left(R_{x, t+1}^{B} \pi_{C, t+1}-R_{t}\right) Q_{x, t} S_{x, t}+R_{t} N_{x, t}\right] \frac{1}{\pi_{C, t+1}} .
\end{aligned}
$$

The premium, $R_{x, t+1}^{B} \pi_{C, t+1}-R_{t}$, as well as the quantity of assets, $Q_{x, t} S_{x, t}$, determines the growth in bank's equity above the riskless return. The bank will not fund any assets with a negative discounted premium. It follows that for the bank to operate in period $i$ the following inequality must hold,

$$
E_{t} \beta^{i} \Lambda_{t+1+i}^{B}\left(R_{x, t+1+i}^{B} \pi_{C, t+1+i}-R_{t+i}\right) \geq 0, \quad i \geq 0
$$

where $\beta^{i} \Lambda_{t+1+i}^{B}$ is the bank's stochastic discount factor, with,

$$
\Lambda_{t+1}^{B} \equiv \frac{\Lambda_{t+1}}{\Lambda_{t}}
$$

where $\Lambda_{t}$ is the Lagrange multiplier on the household's budget equation. Under perfect capital markets, arbitrage guarantees that the risk premium collapses to zero and the relation always holds with equality. However, under imperfect capital markets, credit constraints rooted in the bank's inability to obtain enough funds may lead to positive risk premia. As long as the above inequality holds, banks will keep building assets by borrowing additional funds from households. Accordingly, the intermediary branch objective is to maximize expected terminal wealth,

$$
\begin{aligned}
V_{x, t} & =\max E_{t} \sum_{i=0}\left(1-\theta_{B}\right) \theta_{B}^{i} \beta^{i} \Lambda_{t+1+i}^{B} N_{x, t+1+i} \\
& =\max E_{t} \sum_{i=0}\left(1-\theta_{B}\right) \theta_{B}^{i} \beta^{i} \Lambda_{t+1+i}^{B}\left[\left(R_{x, t+1+i}^{B} \pi_{C, t+1+i}-R_{t+i}\right) \frac{Q_{x, t+i} S_{x, t+i}}{\pi_{C, t+1+i}}+\frac{R_{t+i} N_{x, t+i}}{\pi_{C, t+1+i}}\right],
\end{aligned}
$$

where $\theta_{B} \in(0,1)$ is the fraction of bankers at $t$ that survive until period $t+1$.

Following the setup in Gertler and Kiyotaki (2010) and Gertler and Karadi (2011) the banks are limited from infinitely borrowing additional funds from households by a moral 
hazard/costly enforcement problem. On the one hand, the agent who works in the bank can choose, at the beginning of each period, to divert the fraction $\lambda_{B}$ of available funds and transfer it back to the household. On the other hand, depositors can force the bank into bankruptcy and recover a fraction $1-\lambda_{B}$ of assets. Note that the fraction, $\lambda_{B}$, which intermediaries can divert is the same across sectors to guarantee that the household is indifferent between lending funds between different branches.

Given this tradeoff, depositors will only lend funds to the intermediary when the latter's maximized expected terminal wealth is larger or equal to the the gain from diverting the fraction $\lambda_{B}$ of available funds. This incentive constraint can be formalized as,

$$
V_{x, t} \geq \lambda_{B} Q_{x, t} S_{x, t}, \quad 0<\lambda_{B}<1
$$

Using equation (C.3), the expression for $V_{x, t}$ can be written as the following first-order difference equation,

$$
V_{x, t}=\nu_{x, t} Q_{x, t} S_{x, t}+\eta_{x, t} N_{x, t}
$$

with,

$$
\begin{aligned}
& \nu_{x, t}=E_{t}\left\{\left(1-\theta_{B}\right) \Lambda_{t+1}^{B}\left(R_{x, t+1}^{B} \pi_{C, t+1}-R_{t}\right)+\theta_{B} \beta Z_{1, t+1}^{x} \nu_{x, t+1}\right\}, \\
& \eta_{x, t}=E_{t}\left\{\left(1-\theta_{B}\right) \Lambda_{t+1}^{B} R_{t}+\theta_{B} \beta Z_{2, t+1}^{x} \eta_{x, t+1}\right\}
\end{aligned}
$$

and,

$$
Z_{1, t+1+i}^{x} \equiv \frac{Q_{x, t+1+i} S_{x, t+1+i}}{Q_{x, t+i} S_{x, t+i}}, \quad Z_{2, t+1+i}^{x} \equiv \frac{N_{x, t+1+i}}{N_{x, t+i}}
$$

The variable $\nu_{x, t}$ can be interpreted as the expected discounted marginal gain of expanding assets $Q_{x, t} S_{x, t}$ by one unit while holding wealth $N_{x, t}$ constant. The interpretation of $\eta_{x, t}$ is analogous: it is the expected discounted value of having an additional unit of wealth, $N_{x, t}$, holding the quantity of financial claims, $S_{x, t}$, constant. The gross growth rate in assets is denoted by $Z_{1, t+i}^{x}$ and the gross growth rate of net worth is denoted by $Z_{2, t+i}^{x}$.

Then, using the expression for $V_{x, t}$, we can express the intermediary's incentive constraint (C.4) as,

$$
\nu_{x, t} Q_{x, t} S_{x, t}+\eta_{x, t} N_{x, t} \geq \lambda_{B} Q_{x, t} S_{x, t}
$$

As indicated above, under perfect capital markets banks will expand borrowing until the 
risk premium collapses to zero which implies that in this case $\nu_{x, t}$ equals zero as well. Imperfect capital markets however, limit the possibilities for this kind of arbitrage because the intermediaries are constrained by their equity capital. If the incentive constraint binds it follows that,

$$
\begin{aligned}
Q_{x, t} S_{x, t} & =\frac{\eta_{x, t}}{\lambda_{B}-\nu_{x, t}} N_{x, t} \\
& =\varrho_{x, t} N_{x, t} .
\end{aligned}
$$

In this case, the quantity of assets which the intermediary can acquire depends on the equity capital, $N_{x, t}$, as well as the intermediary's leverage ratio, $\varrho_{x, t}$, limiting the bank's ability to acquire assets. This leverage ratio is the ratio of the bank's intermediated assets to equity. The bank's leverage ratio is limited to the point where its maximized expected terminal wealth equals the gains from diverting the fraction $\lambda_{B}$ from available funds. However, the constraint (C.5) binds only if $0<\nu_{x, t}<\lambda_{B}$ (given $N_{x, t}>0$ ). This inequality is always satisfied with our estimates.

Using the leverage ratio (C.5) we can express the evolution of the intermediary's wealth as,

$$
N_{x, t+1}=\left[\left(R_{x, t+1}^{B} \pi_{C, t+1}-R_{t}\right) \varrho_{x, t}+R_{t}\right] \frac{N_{x, t}}{\pi_{C, t+1}} .
$$

From this equation it also follows that,

$$
Z_{2, t+1}^{x}=\frac{N_{x, t+1}}{N_{x, t}}=\left[\left(R_{x, t+1}^{B} \pi_{C, t+1}-R_{t}\right) \varrho_{x, t}+R_{t}\right] \frac{1}{\pi_{C, t+1}}
$$

and,

$$
Z_{1, t+1}^{x}=\frac{Q_{x, t+1} S_{x, t+1}}{Q_{x, t} S_{x, t}}=\frac{\varrho_{x, t+1} N_{x, t+1}}{\varrho_{x, t} N_{x, t}}=\frac{\varrho_{x, t+1}}{\varrho_{x, t}} Z_{2, t+1}^{x} .
$$

Financial intermediaries which are forced into bankruptcy are replaced by new entrants. Therefore, total wealth of financial intermediaries is the sum of the net worth of existing, $N_{x, t}^{e}$, and new ones, $N_{x, t}^{n}$,

$$
N_{x, t}=N_{x, t}^{e}+N_{x, t}^{n}
$$

The fraction $\theta_{B}$ of bankers at $t-1$ which survive until $t$ is equal across branches. Then, 
the law of motion for existing bankers is given by,

$$
N_{x, t}^{e}=\theta_{B}\left[\left(R_{x, t}^{B} \pi_{C, t}-R_{t-1}\right) \varrho_{x, t-1}+R_{t-1}\right] \frac{N_{x, t-1}}{\pi_{C, t}}, \quad 0<\theta_{B}<1 .
$$

where a main source of variation is the ex-post excess return on assets, $R_{x, t}^{B} \pi_{C, t}-R_{t-1}$.

New banks receive startup funds from their respective household, equal to a small fraction of the value of assets held by the existing bankers in their final operating period. Given that the exit probability is $i . i . d$., the value of assets held by the existing bankers in their final operating period is given by $\left(1-\theta_{B}\right) Q_{x, t} S_{x, t}$. The transfer to new intermediaries is a fraction, $\varpi$, of this value, leading to the following formulation for new banker's wealth,

$$
N_{x, t}^{n}=\varpi Q_{x, t} S_{x, t}, \quad 0<\varpi<1 .
$$

Existing banker's net worth (C.6) and entering banker's net worth (C.7) lead to the law of motion for total net worth,

$$
N_{x, t}=\left(\theta_{B}\left[\left(R_{x, t}^{B} \pi_{C, t}-R_{t-1}\right) \varrho_{x, t-1}+R_{t-1}\right] \frac{N_{x, t-1}}{\pi_{C, t}}+\varpi Q_{x, t} S_{x, t}\right) .
$$

The excess return, $x=C, I$ can be defined as,

$$
R_{x, t}^{S}=R_{x, t+1}^{B} \pi_{C, t+1}-R_{t}
$$

Since $R_{t}, \lambda_{B}, \varpi$ and $\theta_{B}$ are equal across sectors, the institutional setup of the two representative banks in the two sectors is symmetric. Both branches hold deposits from households and buy assets from firms in the sector they provide specialized lending. Their performance differs because the demand for capital differs across sectors resulting in sector specific prices of capital, $Q_{x, t}$, and nominal rental rates for capital, $R_{x, t}^{K}$. Note that the institutional setup of banks does not depend on firm-specific factors. Gertler and Karadi (2011) show that this implies a setup with a continuum of banks is equivalent to a formulation with a representative bank. Owing to the symmetry of the banks this also holds for our formulation of financial intermediaries in the two-sector setup.

\section{C.4 Stationary Economy}

The model includes two non-stationary TFP shocks, $A_{t}$ and $V_{t}$. This section shows how we normalize the model to render it stationary. Lower case variables denote normalized stationary variables. 
The model variables can be stationarized as follows:

$$
\begin{aligned}
& k_{x, t}=\frac{K_{x, t}}{V_{t}^{\frac{1}{1-a_{i}}}}, \quad \bar{k}_{x, t}=\frac{\bar{K}_{x, t}}{V_{t}^{\frac{1}{1-a_{i}}}}, \quad k_{t}=\frac{K_{t}}{V_{t}^{\frac{1}{1-a_{i}}}}, \\
& i_{x, t}=\frac{I_{x, t}}{V_{t}^{\frac{1}{1-a_{i}}}}, \quad i_{t}=\frac{I_{t}}{V_{t}^{\frac{1}{1-a_{i}}}}, \quad c_{t}=\frac{C_{t}}{A_{t} V_{t}^{\frac{a_{c}}{1-a_{i}}}}, \\
& r_{C, t}^{K}=\frac{R_{C, t}^{K}}{P_{C, t}} A_{t}^{-1} V_{t}^{\frac{1-a_{c}}{1-a_{i}}}, \quad r_{I, t}^{K}=\frac{R_{I, t}^{K}}{P_{C, t}} A_{t}^{-1} V_{t}^{\frac{1-a_{c}}{1-a_{i}}}, \quad w_{t}=\frac{W_{t}}{P_{C, t} A_{t} V_{t}^{\frac{a_{c}}{1-a_{i}}}} .
\end{aligned}
$$

From

$$
\begin{aligned}
\frac{P_{I, t}}{P_{C, t}} & =\frac{m c_{C, t}}{m c_{I, t}} \frac{1-a_{c}}{1-a_{i}} \frac{A_{t}}{V_{t}}\left(\frac{K_{I, t}}{L_{I, t}}\right)^{-a_{i}}\left(\frac{K_{C, t}}{L_{C, t}}\right)^{a_{c}} \\
& =\frac{m c_{C, t}}{m c_{I, t}} \frac{1-a_{c}}{1-a_{i}} A_{t} V_{t}^{\frac{a_{c}-1}{1-a_{i}}}\left(\frac{k_{I, t}}{L_{I, t}}\right)^{-a_{i}}\left(\frac{k_{C, t}}{L_{C, t}}\right)^{a_{c}},
\end{aligned}
$$

follows that,

$$
p_{i, t}=\frac{P_{I, t}}{P_{C, t}} A_{t}^{-1} V_{t}^{\frac{1-a_{c}}{1-a_{i}}} .
$$

and the multipliers are normalized as,

$$
\lambda_{t}=\Lambda_{t} A_{t} V_{t}^{\frac{a_{c}}{1-a_{i}}}, \quad \phi_{x, t}=\Phi_{x, t} V_{t}^{\frac{1}{1-a_{i}}}
$$

where $\Phi_{x, t}$ denotes the multiplier on the respective capital accumulation equation. Using the growth of investment, it follows that the prices of capital can be normalized as,

$$
q_{x, t}=Q_{x, t} A_{t}^{-1} V_{t}^{\frac{1-a_{c}}{1-a_{i}}} .
$$

with the price of capital in sector $x$, defined as,

$$
q_{x, t}=\phi_{x, t} / \lambda_{t}, \quad x=C, I .
$$

Using the growth of capital, it follows,

$$
s_{x, t}=\frac{S_{x, t}}{V_{t}^{\frac{1}{1-a_{i}}}} .
$$


Then, it follows from entering bankers wealth equation (C.7) that,

$$
n_{x, t}^{n}=N_{x, t}^{n} A_{t}^{-1} V_{t}^{\frac{-a_{c}}{1-a_{i}}}
$$

Total wealth, wealth of existing and entering bankers has to grow at the same rate,

$$
n_{x, t}^{e}=N_{x, t}^{e} A_{t}^{-1} V_{t}^{\frac{-a_{c}}{1-a_{i}}}, \quad n_{x, t}=N_{x, t} A_{t}^{-1} V_{t}^{\frac{-a_{c}}{1-a_{i}}} .
$$

\section{C.4.1 Intermediate goods producers}

Firm's production function in the consumption sector:

$$
c_{t}=L_{C, t}^{1-a_{c}} k_{C, t}^{a_{c}}-F_{C} .
$$

Firm's production function in the investment sector:

$$
i_{t}=L_{I, t}^{1-a_{i}} k_{I, t}^{a_{i}}-F_{I}
$$

Marginal costs in the consumption sector:

$$
m c_{C, t}=\left(1-a_{c}\right)^{a_{c}-1} a_{c}^{-a_{c}}\left(r_{C, t}^{K}\right)^{a_{c}} w_{t}^{1-a_{c}} .
$$

Marginal costs in the investment sector:

$$
m c_{I, t}=\left(1-a_{i}\right)^{a_{i}-1} a_{i}^{-a_{i}} w_{t}^{1-a_{i}}\left(r_{I, t}^{K}\right)^{a_{i}} p_{i, t}^{-1}, \quad \text { with } \quad p_{i, t}=\frac{P_{I, t}}{P_{C, t}} .
$$

Capital labour ratios in the two sectors:

$$
\frac{k_{C, t}}{L_{C, t}}=\frac{w_{t}}{r_{C, t}^{K}} \frac{a_{c}}{1-a_{c}}, \quad \frac{k_{I, t}}{L_{I, t}}=\frac{w_{t}}{r_{I, t}^{K}} \frac{a_{i}}{1-a_{i}} .
$$

\section{C.4.2 Firms' pricing decisions}

Price setting equation for firms that change their price in sector $x=C, I$ :

$$
0=E_{t}\left\{\sum_{s=0}^{\infty} \xi_{p, x}^{s} \beta^{s} \lambda_{t+s} \tilde{x}_{t+s}\left[\tilde{p}_{x, t} \tilde{\Pi}_{t, t+s}-\left(1+\lambda_{p, t+s}^{x}\right) m c_{x, t+s}\right]\right\},
$$


with

$$
\begin{aligned}
& \tilde{\Pi}_{t, t+s}=\prod_{k=1}^{s}\left[\left(\frac{\pi_{x, t+k-1}}{\pi_{x}}\right)^{\iota p_{x}}\left(\frac{\pi_{x, t+k}}{\pi_{x}}\right)^{-1}\right] \text { and } \tilde{x}_{t+s}=\left(\frac{\tilde{P}_{x, t}}{P_{x, t}} \tilde{\Pi}_{t, t+s}\right)^{-\frac{1+\lambda_{p, t+s}^{x}}{\lambda_{p, t+s}^{x}}} x_{t+s} \\
& \text { and } \frac{\tilde{P}_{x, t}}{P_{x, t}}=\tilde{p}_{x, t} .
\end{aligned}
$$

Aggregate price index in the consumption sector:

$$
1=\left[\left(1-\xi_{x, p}\right)\left(\tilde{p}_{x, t}\right)^{\frac{1}{\lambda_{p, t}^{x}}}+\xi_{x, p}\left[\left(\frac{\pi_{x, t-1}}{\pi_{x}}\right)^{\iota_{p}}\left(\frac{\pi_{x, t}}{\pi_{x}}\right)^{-1}\right]^{\frac{1}{\lambda_{p, t}^{x}}}\right]^{\lambda_{p, t}^{x}} .
$$

It further holds that

$$
\frac{\pi_{I, t}}{\pi_{C, t}}=\frac{p_{i, t}}{p_{i, t-1}}
$$

\section{C.4.3 Household's optimality conditions and wage setting}

Marginal utility of income:

$$
\lambda_{t}=\frac{b_{t}}{c_{t}-h c_{t-1}\left(\frac{A_{t-1}}{A_{t}}\right)\left(\frac{V_{t-1}}{V_{t}}\right)^{\frac{a_{c}}{1-a_{i}}}}-\beta h \frac{b_{t+1}}{c_{t+1}\left(\frac{A_{t+1}}{A_{t}}\right)\left(\frac{V_{t+1}}{V_{t}}\right)^{\frac{a_{c}}{1-a_{i}}}-h c_{t}} .
$$

Euler equation:

$$
\lambda_{t}=\beta E_{t} \lambda_{t+1}\left(\frac{A_{t}}{A_{t+1}}\right)\left(\frac{V_{t}}{V_{t+1}}\right)^{\frac{a_{c}}{1-a_{i}}} R_{t} \frac{1}{\pi_{c, t+1}} .
$$

Labor supply

$$
\lambda_{t} w_{t}=b_{t} \varphi\left(L_{C, t}+L_{I, t}\right)^{\nu}
$$

\section{C.4.4 Capital services}

Optimal capital utilization:

$$
r_{C, t}^{K}=a_{C}^{\prime}\left(u_{C, t}\right), \quad r_{I, t}^{K}=a_{I}^{\prime}\left(u_{I, t}\right) .
$$

Definition of capital services:

$$
k_{C, t}=u_{C, t} \xi_{C, t}^{K} \bar{k}_{C, t-1}\left(\frac{V_{t-1}}{V_{t}}\right)^{\frac{1}{1-a_{i}}}, \quad k_{I, t}=u_{I, t} \xi_{I, t}^{K} \bar{k}_{I, t-1}\left(\frac{V_{t-1}}{V_{t}}\right)^{\frac{1}{1-a_{i}}}
$$


Optimal choice of available capital in sector $x=C, I$ :

$\phi_{x, t}=\beta E_{t} \xi_{x, t+1}^{K}\left\{\lambda_{t+1}\left(\frac{V_{t}}{V_{t+1}}\right)^{\frac{1}{1-a_{i}}}\left(r_{x, t+1}^{K} u_{x, t+1}-a\left(u_{x, t+1}\right)\right)+(1-\delta) E_{t} \phi_{x, t+1}\left(\frac{V_{t}}{V_{t+1}}\right)^{\frac{1}{1-a_{i}}}\right\}$

\section{C.4.5 Physical capital producers}

Optimal choice of investment in sector $x=C, I$ :

$$
\begin{aligned}
\lambda_{t} p_{i, t}= & \phi_{x, t}\left[1-S\left(\frac{i_{x, t}}{i_{x, t-1}}\left(\frac{V_{t}}{V_{t-1}}\right)^{\frac{1}{1-a_{i}}}\right)-S^{\prime}\left(\frac{i_{x, t}}{i_{x, t-1}}\left(\frac{V_{t}}{V_{t-1}}\right)^{\frac{1}{1-a_{i}}}\right) \frac{i_{x, t}}{i_{x, t-1}}\left(\frac{V_{t}}{V_{t-1}}\right)^{\frac{1}{1-a_{i}}}\right] \\
& +\beta E_{t} \phi_{x, t+1}\left(\frac{V_{t}}{V_{t+1}}\right)^{\frac{1}{1-a_{i}}}\left[S^{\prime}\left(\frac{i_{x, t+1}}{i_{x, t}}\left(\frac{V_{t+1}}{V_{t}}\right)^{\frac{1}{1-a_{i}}}\right)\left(\frac{i_{x, t+1}}{i_{x, t}}\left(\frac{V_{t+1}}{V_{t}}\right)^{\frac{1}{1-a_{i}}}\right)^{2}\right] .
\end{aligned}
$$

Accumulation of capital in sector $x=C, I$ :

$$
\bar{k}_{x, t}=\left(1-\delta_{x}\right) \xi_{x, t}^{K} \bar{k}_{x, t-1}\left(\frac{V_{t-1}}{V_{t}}\right)^{\frac{1}{1-a_{i}}}+\left(1-S\left(\frac{i_{x, t}}{i_{x, t-1}}\left(\frac{V_{t}}{V_{t-1}}\right)^{\frac{1}{1-a_{i}}}\right)\right) i_{x, t}
$$

\section{C.4.6 Household's wage setting}

Household's wage setting:

$$
\begin{gathered}
E_{t} \sum_{s=0}^{\infty} \beta^{s} \xi_{w}^{s} \lambda_{t+s} \tilde{L}_{t+s}\left[\tilde{w}_{t} \tilde{\Pi}_{t, t+s}^{w}-\left(1+\lambda_{w, t+s}\right) b_{t+s} \varphi \frac{\tilde{L}_{t+s}^{\nu}}{\lambda_{t+s}}\right]=0, \\
\text { with } \\
\tilde{\Pi}_{t, t+s}^{w}=\prod_{k=1}^{s}\left[\left(\frac{\pi_{C, t+k-1} e^{a_{t+k-1}+\frac{a_{c}}{1-a_{i}} v_{t+k-1}}}{\pi_{c} e^{g_{a}+\frac{a_{c}}{1-a_{i}} g_{v}}}\right)^{\iota_{w}}\left(\frac{\pi_{C, t+k} e^{a_{t+k}+\frac{a_{c}}{1-a_{i}} v_{t+k}}}{\pi_{C} e^{g_{a}+\frac{a_{c}}{1-a_{i}} g_{v}}}\right)^{-1}\right] \\
\quad \text { and } \\
\tilde{L}_{t+s}=\left(\frac{\tilde{w}_{t} \tilde{\Pi}_{t, t+s}^{w}}{w_{t+s}}\right)^{-\frac{1+\lambda_{w, t+s}}{\lambda_{w, t+s}}} L_{t+s} .
\end{gathered}
$$

Wages evolve according to

$$
w_{t}=\left\{\left(1-\xi_{w}\right) \tilde{w}_{t}^{\frac{1}{\lambda_{w, t}}}+\xi_{w}\left[\left(\frac{\pi_{c, t-1} e^{a_{t-1}+\frac{a_{c}}{1-a_{i}} v_{t-1}}}{\pi_{c} e^{g_{a}+\frac{a_{c}}{1-a_{i}} g_{v}}}\right)^{l_{w}}\left(\frac{\pi_{c, t} e^{a_{t}+\frac{a_{c}}{1-a_{i}} v_{t}}}{\pi_{c} e^{g_{a}+\frac{a_{c}}{1-a_{i}} g_{v}}}\right)^{-1} w_{t-1}\right]^{\frac{1}{\lambda_{w, t}}}\right\}^{\lambda_{w, t}} .
$$




\section{C.4.7 Financial Intermediation}

The stationary stochastic discount factor can be expressed as,

$$
\lambda_{t+1}^{B}=\frac{\lambda_{t+1}}{\lambda_{t}}
$$

Then, one can derive expressions for $\nu_{x, t}$ and $\eta_{x, t}$,

$$
\begin{aligned}
& \nu_{x, t}=E_{t}\left\{\left(1-\theta_{B}\right) \lambda_{t+1}^{B} \frac{A_{t}}{A_{t+1}}\left(\frac{V_{t}}{V_{t+1}}\right)^{\frac{a_{c}}{1-a_{i}}}\left(R_{x, t+1}^{B} \pi_{C, t+1}-R_{t}\right)+\theta_{B} \beta z_{1, t+1}^{x} \nu_{x, t+1}\right\}, \\
& \eta_{x, t}=E_{t}\left\{\left(1-\theta_{B}\right) \lambda_{t+1}^{B} \frac{A_{t}}{A_{t+1}}\left(\frac{V_{t}}{V_{t+1}}\right)^{\frac{a_{c}}{1-a_{i}}} R_{t}+\theta_{B} \beta z_{2, t+1}^{x} \eta_{x, t+1}\right\},
\end{aligned}
$$

with

$$
z_{1, t+1+i}^{x} \equiv \frac{q_{x, t+1+i} s_{x, t+1+i}}{q_{x, t+i} s_{x, t+i}} \frac{A_{t+1}}{A_{t}}\left(\frac{V_{t+1}}{V_{t}}\right)^{\frac{a_{c}}{1-a_{i}}}, \quad z_{2, t+1+i}^{x} \equiv \frac{n_{x, t+1+i}}{n_{x, t+i}} \frac{A_{t+1}}{A_{t}}\left(\frac{V_{t+1}}{V_{t}}\right)^{\frac{a_{c}}{1-a_{i}}}
$$

It follows that if the bank's incentive constraint binds it can be expressed as,

$$
\begin{aligned}
& \nu_{x, t} q_{x, t} s_{x, t}+\eta_{x, t} n_{x, t}=\lambda_{B} q_{x, t} s_{x, t} \\
\Leftrightarrow & q_{x, t} s_{x, t}=\varrho_{x, t} n_{x, t},
\end{aligned}
$$

with the leverage ratio given as,

$$
\varrho_{x, t}=\frac{\eta_{x, t}}{\lambda_{B}-\nu_{x, t}}
$$

It further follows that:

$$
z_{2, t+1}^{x}=\frac{n_{x, t+1}}{n_{x, t}} \frac{A_{t+1}}{A_{t}}\left(\frac{V_{t+1}}{V_{t}}\right)^{\frac{a_{c}}{1-a_{i}}}=\left[\left(R_{x, t+1}^{B} \pi_{C, t+1}-R_{t}\right) \varrho_{x, t}+R_{t}\right] \frac{1}{\pi_{C, t+1}},
$$

and

$$
z_{1, t+1}^{x}=\frac{q_{x, t+1} s_{x, t+1}}{q_{x, t} s_{x, t}} \frac{A_{t+1}}{A_{t}}\left(\frac{V_{t+1}}{V_{t}}\right)^{\frac{a_{c}}{1-a_{i}}}=\frac{\varrho_{x, t+1} n_{x, t+1}}{\varrho_{x, t} n_{x, t}} \frac{A_{t+1}}{A_{t}}\left(\frac{V_{t+1}}{V_{t}}\right)^{\frac{a_{c}}{1-a_{i}}}=\frac{\varrho_{x, t+1}}{\varrho_{x, t}} z_{2, t+1}^{x} .
$$

The normalized equation for bank's wealth accumulation is,

$$
n_{x, t}=\left(\theta_{B}\left[\left(R_{x, t}^{B} \pi_{C, t}-R_{t-1}\right) \varrho_{x, t-1}+R_{t-1}\right] \frac{A_{t-1}}{A_{t}}\left(\frac{V_{t-1}}{V_{t}}\right)^{\frac{a_{c}}{1-a_{i}}} \frac{n_{x, t-1}}{\pi_{C, t}}+\varpi q_{x, t} s_{x, t}\right) .
$$


The borrow in advance constraint:

$$
\bar{k}_{x, t+1}=s_{x, t} .
$$

The leverage equation:

$$
q_{x, t} s_{x, t}=\varrho_{x, t} n_{x, t} .
$$

Bank's stochastic return on assets can be described in normalized variables as:

$$
R_{x, t+1}^{B}=\frac{r_{x, t+1}^{K} u_{x, t+1}+q_{x, t+1}\left(1-\delta_{x}\right)-a\left(u_{x, t+1}\right)}{q_{x, t}} \xi_{x, t+1}^{K} \frac{A_{t+1}}{A_{t}}\left(\frac{V_{t+1}}{V_{t}}\right)^{-\frac{1-a_{c}}{1-a_{i}}},
$$

knowing from the main model that

$$
r_{x, t}^{K}=\frac{R_{x, t}^{K}}{P_{x, t}} A_{t}^{-1} V_{t}^{\frac{1-a_{c}}{1-a_{i}}}
$$

\section{C.4.8 Monetary policy and market clearing}

Monetary policy rule:

$$
\frac{R_{t}}{R}=\left(\frac{R_{t-1}}{R}\right)^{\rho_{R}}\left[\left(\frac{\pi_{C, t}}{\pi_{C}}\right)^{\phi_{\pi}}\left(\frac{y_{t}}{y_{t-1}}\right)^{\phi_{\Delta Y}}\right]^{1-\rho_{R}} \eta_{m p, t}
$$

Resource constraint in the consumption sector:

$$
c_{t}+\left(a\left(u_{C, t}\right) \xi_{C, t}^{K} \bar{k}_{C, t-1}+a\left(u_{I, t}\right) \xi_{I, t}^{K} \bar{k}_{I, t-1}\right)\left(\frac{V_{t-1}}{V_{t}}\right)^{\frac{1}{1-a_{i}}}=L_{C, t}^{1-a_{c}} k_{C, t}^{a_{c}}-F_{C} .
$$

Resource constraint in the investment sector:

$$
i_{t}=L_{I, t}^{1-a_{i}} k_{I, t}^{a_{i}}-F_{I}
$$

Definition of GDP:

$$
y_{t}=c_{t}+p_{i, t} i_{t}+\left(1-\frac{1}{e_{t}}\right) y_{t}
$$

Moreover

$$
L_{t}=L_{I, t}+L_{C, t}, \quad i_{t}=i_{C, t}+i_{I, t} .
$$




\section{C.5 Steady State}

This section describes the model's steady state.

From the optimal choice of available capital (C.22) and the optimal choice of investment (C.23) in both sectors:

$$
\begin{aligned}
& r_{C}^{K}=\left(\frac{e^{\frac{1}{1-a_{i}} g_{v}}}{\beta}-\left(1-\delta_{C}\right)\right) p_{i}, \\
& r_{I}^{K}=\left(\frac{e^{\frac{1}{1-a_{i}} g_{v}}}{\beta}-\left(1-\delta_{I}\right)\right) p_{i} .
\end{aligned}
$$

From firm's price setting in both sectors (C.18),

$$
m c_{C}=\frac{1}{1+\lambda_{p}^{C}}, \quad m c_{I}=\frac{1}{1+\lambda_{p}^{I}} .
$$

Using equations (C.29) and imposing knowledge of the steady state expression for $r_{C}^{K}$ and $r_{I}^{K}$, one can derive expressions for the steady state wage from the equations that define marginal costs in the two sectors ((C.15) and (C.16)).

Consumption sector:

$$
w=\left(\frac{1}{1+\lambda_{p}^{C}}\left(1-a_{c}\right)^{1-a_{c}} a_{c}^{a_{c}}\left(r_{C}^{K}\right)^{-a_{c}}\right)^{\frac{1}{1-a_{c}}}
$$

Investment sector:

$$
w=\left(\frac{1}{1+\lambda_{p}^{I}}\left(1-a_{i}\right)^{1-a_{i}} a_{i}^{a_{i}}\left(r_{I}^{K}\right)^{-a_{i}} p_{i}\right)^{\frac{1}{1-a_{i}}}
$$

Since labour can move across sectors the steady state wage has to be the same in the consumption and investment sector. The equality is verified by $p_{i}$. An expression for $p_{i}$ 
can be found by setting (C.30) equal to (C.31):

$$
\begin{aligned}
& \left(\frac{1}{1+\lambda_{p}^{C}}\left(1-a_{c}\right)^{1-a_{c}} a_{c}^{a_{c}}\left(r_{C}^{K}\right)^{-a_{c}}\right)^{\frac{1}{1-a_{c}}}=\left(\frac{1}{1+\lambda_{p}^{I}}\left(1-a_{i}\right)^{1-a_{i}} a_{i}^{a_{i}}\left(r_{I}^{K}\right)^{-a_{i}} p_{i}\right)^{\frac{1}{1-a_{i}}} \\
\Leftrightarrow & \left(\frac{1}{1+\lambda_{p}^{C}}\left(1-a_{c}\right)^{1-a_{c}} a_{c}^{a_{c}}\left(\frac{e^{\frac{1}{1-a_{i}} g_{v}}}{\beta}-\left(1-\delta_{C}\right)\right)^{-a_{c}} p_{i}^{-a_{c}}\right)^{\frac{1}{1-a_{c}}} \\
= & \left(\frac{1}{1+\lambda_{p}^{I}}\left(1-a_{i}\right)^{1-a_{i}} a_{i}^{a_{i}}\left(\frac{e^{\frac{1}{1-a_{i}} g_{v}}}{\beta}-\left(1-\delta_{I}\right)\right)^{-a_{i}} p_{i}^{-a_{i}} p_{i}\right)^{\frac{1}{1-a_{i}}} \\
\Leftrightarrow & p_{i}=\frac{\frac{1}{1+\lambda_{p}^{C}}\left(1-a_{c}\right)^{1-a_{c}} a_{c}^{a_{c}}\left(\frac{e^{\frac{1}{1-a_{i}} g_{v}}}{\beta}-\left(1-\delta_{C}\right)\right)^{-\alpha_{c}}}{\left[\frac{1}{1+\lambda_{p}^{I}}\left(1-a_{i}\right)^{1-a_{i}} a_{i}^{a_{i}}\left(\frac{e^{\frac{1}{1-a_{i}} g_{v}}}{\beta}-\left(1-\delta_{I}\right)\right)^{-\alpha_{i}}\right]^{\frac{1-a_{c}}{1-a_{i}}}}
\end{aligned}
$$

Knowing $w, r_{C}^{K}$ and $r_{I}^{K}$, the expressions given in (C.17) can be used to find the steady state capital-to-labour ratios in the two sectors:

$$
\begin{aligned}
\frac{k_{C}}{L_{C}} & =\frac{w}{r_{C}^{K}} \frac{a_{c}}{1-a_{c}}, \\
\frac{k_{I}}{L_{I}} & =\frac{w}{r_{I}^{K}} \frac{a_{i}}{1-a_{c}} .
\end{aligned}
$$

The zero profit condition for intermediate goods producers in the consumption sector, $c-r_{C}^{K} k_{C}-w L_{C}=0$, and (C.13) imply:

$$
\begin{aligned}
& L_{C}^{1-a_{c}} k_{C}^{a_{c}}-F_{C}-r_{C}^{K} k_{C}-w L_{C}=0 \\
\Leftrightarrow & \frac{F_{C}}{L_{C}}=\left(\frac{k_{C}}{L_{C}}\right)^{a_{c}}-r_{C}^{K} \frac{k_{C}}{L_{C}}-w .
\end{aligned}
$$

Analogously the zero profit condition for intermediate goods producers in the investment sector, $i-r_{I}^{K} k_{I}-w L_{I}=0$, and (C.14) imply:

$$
\frac{F_{I}}{L_{I}}=\left(\frac{k_{I}}{L_{I}}\right)^{a_{i}}-r_{I}^{K} \frac{k_{I}}{L_{I}}-w
$$

These expressions pin down the steady state consumption-to-labour and investment-tolabour ratios which follow from the intermediate firms' production functions ((C.13) and (C.14)):

$$
\frac{c}{L_{C}}=\left(\frac{k_{C}}{L_{C}}\right)^{a_{c}}-\frac{F_{C}}{L_{C}}, \quad \frac{i}{L_{I}}=\left(\frac{k_{I}}{L_{I}}\right)^{a_{i}}-\frac{F_{I}}{L_{I}}
$$




$$
1+\lambda_{p}^{C}=\frac{c+F_{C}}{c} \Leftrightarrow \lambda_{p}^{C} c=F_{C}, \quad \text { and } \quad 1+\lambda_{p}^{I}=\frac{i+F_{I}}{i} \Leftrightarrow \lambda_{p}^{I} i=F_{I}
$$

This and the steady state consumption-to-labour ratio can be used to derive an expression for steady state consumption:

$$
\begin{aligned}
c & =\left(\frac{k_{C}}{L_{C}}\right)^{a_{c}} L_{C}-F_{C} \\
\Leftrightarrow c & =\left(\frac{k_{C}}{L_{C}}\right)^{a_{c}} L_{C}-\lambda_{p}^{C} c \\
\Leftrightarrow c & =\frac{1}{1+\lambda_{p}^{C}}\left(\frac{k_{C}}{L_{C}}\right)^{a_{c}} L_{C} .
\end{aligned}
$$

Analogously one can derive an expression for steady state investment:

$$
i=\frac{1}{1+\lambda_{p}^{I}}\left(\frac{k_{I}}{L_{I}}\right)^{a_{i}} L_{I} .
$$

Combining these two expressions leads to,

$$
\begin{aligned}
& p_{i} \frac{i}{c}=\frac{\frac{1}{1+\lambda_{p}^{I}}\left(\frac{k_{I}}{L_{I}}\right)^{a_{i}} L_{I}}{\frac{1}{1+\lambda_{p}^{C}}\left(\frac{k_{C}}{L_{C}}\right)^{a_{c}} L_{C}} p_{i} \\
& \Leftrightarrow \frac{L_{I}}{L_{C}}=p_{i} \frac{i \frac{1}{c} \frac{1+\lambda_{p}^{C}}{c}\left(\frac{k_{C}}{L_{C}}\right)^{a_{c}}}{1+\lambda_{p}^{I}}\left(\frac{k_{I}}{L_{I}}\right)^{a_{i}} p_{i}^{-1} .
\end{aligned}
$$

Total labour $L$ is set to unity in the steady state. However, since $a_{i}$ and $a_{c}$ are not necessarily calibrated to be equal one needs to fix another quantity in addition to $L=1$. We fix the steady state investment-to-consumption ratio, $p_{i} \frac{i}{c}$, which equals 0.399 in the data. This allows us to derive steady state expressions for labour in the two sectors. Steady state labour in the investment sector is given by

$$
L_{I}=1-L_{C},
$$

and the two equations above imply that steady state labour in the consumption sector 
can be expressed as,

$$
L_{C}=\left(1+p_{i} \frac{i \frac{1}{c} \frac{1}{1+\lambda_{p}^{C}}\left(\frac{k_{C}}{L_{C}}\right)^{a_{c}}}{1+\lambda_{p}^{I}}\left(\frac{k_{I}}{L_{I}}\right)^{a_{i}} p_{i}^{-1}\right)^{-1} .
$$

The steady state values for labour in the two sectors imply:

$$
k_{C}=\frac{k_{C}}{L_{C}} L_{C}, \quad k_{I}=\frac{k_{I}}{L_{I}} L_{I}, \quad c=\frac{c}{L_{C}} L_{C}, \quad i=\frac{i}{L_{I}} L_{I}, \quad F_{C}=\frac{F_{C}}{L_{C}} L_{C}, \quad F_{I}=\frac{F_{I}}{L_{I}} L_{I} .
$$

It follows from (C.21) that,

$$
k_{C}=\bar{k}_{C} e^{-\frac{1}{1-a_{i}} g_{v}}, \quad \text { and } \quad k_{I}=\bar{k}_{I} e^{-\frac{1}{1-a_{i}} g_{v}} .
$$

The accumulation equation of available capital (C.24) can be used to solve for investment in the two sectors:

$$
\begin{aligned}
i_{C} & =k_{C}\left(e^{\frac{1}{1-a_{i}} g_{v}}-\left(1-\delta_{C}\right)\right), \\
i_{I} & =k_{I}\left(e^{\frac{1}{1-a_{i}} g_{v}}-\left(1-\delta_{I}\right)\right) .
\end{aligned}
$$

From the definition of GDP (C.26):

$$
y=c+p_{i} i+\left(1-\frac{1}{g}\right) y
$$

From the marginal utility of income (C.20):

$$
\lambda=\frac{1}{c-h c e^{-g_{a}-\frac{a_{c}}{1-a_{i}} g_{v}}}-\frac{\beta h}{c e^{g_{a}+\frac{a_{c}}{1-a_{i}} g_{v}}-h c} .
$$

From the household's wage setting (C.25)

$$
\sum_{s=0}^{\infty} \beta^{s} \xi_{w}^{s} \lambda L\left[w-\left(1+\lambda_{w}\right) \varphi \frac{L^{\nu}}{\lambda}\right]=0
$$

follows the expression for $L$ :

$$
w-\left(1-\lambda_{w}\right) \varphi \frac{L^{\nu}}{\lambda}=0 \Rightarrow L=\left[\frac{w \lambda}{\left(1+\lambda_{w}\right) \varphi}\right]^{\frac{1}{\nu}}
$$


This expression can be solved for $\varphi$ to be consistent with $L=1$ :

$$
\begin{aligned}
1 & =\left[\frac{w \lambda}{\left(1+\lambda_{w}\right) \varphi}\right]^{\frac{1}{\nu}} \\
\Leftrightarrow \varphi & =\frac{\lambda w}{1+\lambda_{w}} .
\end{aligned}
$$

It further holds from equation (C.19) that,

$$
\frac{\pi_{I}}{\pi_{C}}=e^{g_{a}-\frac{1-a_{c}}{1-a_{i}} g_{v}}
$$

A system of 10 equations (C.27, C.28, C.30, C.32, C.33, C.34, C.35, C.36, C.37, C.38) can be solved for the 10 steady state variables $k_{C}, k_{I}, w, i_{C}, i_{I}, r_{C}^{K}, r_{I}^{K}, L_{C}, L_{I}$ and $p_{i}$. The steady state values for the remaining variables follow from the expressions above.

Given these steady state variables, the remaining steady state values which are mainly related to financial intermediaries can be derived as follows.

The nominal interest rate is given from the Euler equation as,

$$
R=\frac{1}{\beta} e^{g_{a}+\frac{a_{c}}{1-a_{i}} g_{v}} \pi_{C}
$$

The bank's stationary stochastic discount factor can be expressed in the steady state as

$$
\lambda^{B}=1
$$

The steady state borrow in advance constraint implies that

$$
\bar{k}_{x}=s_{x} .
$$

The steady state price of capital is given by

$$
q_{x, t}=p_{i, t}
$$

The steady state leverage equation is set equal to it's average value in the data over the sample period.

$$
\frac{q_{x} s_{x}}{n_{x}}=\varrho_{x}=5.47
$$

The parameters $\varpi$ and $\lambda_{B}$ help to align the value of the leverage ratio and the corpo- 
rate bond spread with their empirical counterparts. Using the calibrated value for $\theta_{B}$, the average value for the leverage ratio (5.47) and the weighted quarterly average of the corporate spreads $\left(R_{x}^{B}-R=0.5 \%\right)$ allows calibrating $\varpi$ using the bank's wealth accumulation equation,

$$
\varpi=\left[1-\theta_{B}\left[\left(R_{x}^{B} \pi_{C}-R\right) \varrho_{x}+R\right] e^{-g_{a}-\frac{a_{c}}{1-a_{i}} g_{v}} \frac{1}{\pi_{C}}\right]\left(\frac{q_{x} s_{x}}{n_{x}}\right)^{-1} .
$$

Given the non-linearity in the leverage ratio, we solve numerically for the steady state expressions for $\eta$ and $\nu$ using,

$$
\begin{aligned}
& \nu_{x}=\left(1-\theta_{B}\right) \lambda^{B} e^{-g_{a}-\frac{a_{c}}{1-a_{i}} g_{v}}\left(R_{x}^{B} \pi_{C}-R\right)+\theta_{B} \beta z_{1}^{x} \nu_{x}, \\
& \eta_{x}=\left(1-\theta_{B}\right) \lambda^{B} e^{-g_{a}-\frac{a_{c}}{1-a_{i}} g_{v}} R+\theta_{B} \beta z_{2}^{x} \eta_{x},
\end{aligned}
$$

with

$$
z_{2}^{x}=\left[\left(R_{x}^{B} \pi_{C}-R\right) \varrho_{x}+R\right] \frac{1}{\pi_{C}}, \quad \text { and } \quad z_{1}^{x}=z_{2}^{x},
$$

and the steady state leverage ratio,

$$
\varrho_{x}=\frac{\eta_{x}}{\lambda_{B}-\nu_{x}}
$$

\section{C.6 Log-linearized Economy}

This section collects the log-linearized model equations. The log-linear deviations of all variables are defined as

$$
\hat{\varsigma}_{t} \equiv \log \varsigma_{t}-\log \varsigma,
$$

except for

$$
\begin{aligned}
\hat{z}_{t} & \equiv z_{t}-g_{a}, \\
\hat{v}_{t} & \equiv v_{t}-g_{v}, \\
\hat{\lambda}_{p, t}^{C} & \equiv \log \left(1+\lambda_{p, t}^{C}\right)-\log \left(1+\lambda_{p}^{C}\right), \\
\hat{\lambda}_{p, t}^{I} & \equiv \log \left(1+\lambda_{p, t}^{I}\right)-\log \left(1+\lambda_{p}^{I}\right), \\
\hat{\lambda}_{w, t} & \equiv \log \left(1+\lambda_{w, t}\right)-\log \left(1+\lambda_{w}\right) .
\end{aligned}
$$




\section{C.6.1 Firm's production function and cost minimization}

Production function for the intermediate good producing firm $(i)$ in the consumption sector:

$$
\hat{c}_{t}=\frac{c+F_{I}}{c}\left[a_{c} \hat{k}_{C, t}+\left(1-a_{c}\right) \hat{L}_{C, t}\right]
$$

Production function for the intermediate good producing firm $(i)$ in the investment sector:

$$
\hat{i}_{t}=\frac{i+F_{I}}{i}\left[a_{i} \hat{k}_{I, t}+\left(1-a_{i}\right) \hat{L}_{I, t}\right]
$$

Capital-to-labour ratios for the two sectors:

$$
\hat{r}_{C, t}^{K}-\hat{w}_{t}=\hat{L}_{C, t}-\hat{k}_{C, t}, \quad \hat{r}_{I, t}^{K}-\hat{w}_{t}=\hat{L}_{I, t}-\hat{k}_{I, t} .
$$

Marginal cost in both sectors:

$$
\hat{m} c_{C, t}=a_{c} \hat{r}_{C, t}^{K}+\left(1-a_{c}\right) \hat{w}_{t}, \quad \hat{m} c_{I, t}=a_{i} \hat{r}_{I, t}^{K}+\left(1-a_{i}\right) \hat{w}_{t}-\hat{p}_{i, t} .
$$

\section{C.6.2 Firm's prices}

Price setting equation for firms that change their price in sector $x=C, I$ :

$$
0=E_{t}\left\{\sum_{s=0}^{\infty} \xi_{p, x}^{s} \beta^{s}\left[\hat{\tilde{p}}_{x, t} \hat{\tilde{\Pi}}_{t, t+s}-\hat{\lambda}_{p, t+s}^{x}-\hat{m} c_{x, t+s}\right]\right\}
$$

with

$$
\hat{\tilde{\Pi}}_{t, t+s}=\sum_{k=1}^{s}\left[\iota_{p_{x}} \hat{\pi}_{t+k-1}-\hat{\pi}_{t+k}\right]
$$

Solving for the summation

$$
\begin{aligned}
\frac{1}{1-\xi_{p, x} \beta} \hat{\tilde{p}}_{x, t}= & E_{t}\left\{\sum_{s=0}^{\infty} \xi_{p, x}^{s} \beta^{s}\left[-\hat{\Pi}_{t, t+s}+\hat{\lambda}_{p, t+s}^{x}+\hat{m} c_{x, t+s}\right]\right\} \\
= & -\hat{\Pi}_{t, t}+\hat{\lambda}_{p, t}^{x}+\hat{m} c_{x, t}-\frac{\xi_{p, x} \beta}{1-\xi_{p, x} \beta} \hat{\Pi}_{t, t+1} \\
& +\xi_{p, x} \beta E_{t}\left\{\sum_{s=1}^{\infty} \xi_{p, x}^{s-1} \beta^{s-1}\left[-\hat{\Pi}_{t+1, t+s}+\hat{\lambda}_{p, t+s}^{x}+\hat{m} c_{x, t+s}\right]\right\} \\
= & \hat{\lambda}_{p, t}^{x}+\hat{m} c_{x, t}+\frac{\xi_{p, x} \beta}{1-\xi_{p, x} \beta} E_{t}\left[\hat{\tilde{p}}_{x, t+1}-\hat{\Pi}_{t, t+1}\right],
\end{aligned}
$$


where we used $\hat{\Pi}_{t, t}=0$.

Prices evolve as

$$
0=\left(1-\xi_{p, x}\right) \hat{\tilde{p}}_{x, t}+\xi_{p, x}\left(\iota_{p_{x}} \hat{\pi}_{t-1}-\hat{\pi}\right),
$$

from which we obtain the Phillips curve in sector $x=C, I$ :

$$
\begin{aligned}
& \hat{\pi}_{x, t}=\frac{\beta}{1+\iota_{p_{x}} \beta} E_{t} \hat{\pi}_{x, t+1}+\frac{\iota_{p_{x}}}{1+\iota_{p_{x}} \beta} \hat{\pi}_{x, t-1}+\kappa_{x} \hat{m} c_{x, t}+\kappa_{x} \hat{\lambda}_{p, t}^{x}, \\
& \text { with } \quad \kappa_{x}=\frac{\left(1-\xi_{p, x} \beta\right)\left(1-\xi_{p, x}\right)}{\xi_{p, x}\left(1+\iota_{p_{x}} \beta\right)} .
\end{aligned}
$$

From equation (C.19) it follows that

$$
\hat{\pi}_{I, t}-\hat{\pi}_{C, t}=\hat{p}_{I, t}-\hat{p}_{I, t-1} .
$$

\section{C.6.3 Households}

Marginal utility:

$$
\begin{aligned}
\hat{\lambda}_{t}= & \frac{e^{G}}{e^{G}-h \beta}\left[\hat{b}_{t}+\left(\hat{z}_{t}+\frac{a_{c}}{1-a_{i}} \hat{v}_{t}\right)-\left(\frac{e^{G}}{e^{G}-h}\left(\hat{c}_{t}+\hat{z}_{t}+\frac{a_{c}}{1-a_{i}} \hat{v}_{t}\right)-\frac{h}{e^{G}-h} \hat{c}_{t-1}\right)\right] \\
& -\frac{h \beta}{e^{G}-h \beta} E_{t}\left[\hat{b}_{t+1}-\left(\frac{e^{G}}{e^{G}-h}\left(\hat{c}_{t+1}+\hat{z}_{t+1}+\frac{a_{c}}{1-a_{i}} \hat{v}_{t+1}\right)-\frac{h}{e^{G}-h} \hat{c}_{t}\right)\right] \\
\Leftrightarrow \hat{\lambda}_{t}= & \alpha_{1} E_{t} \hat{c}_{t+1}-\alpha_{2} \hat{c}_{t}+\alpha_{3} \hat{c}_{t-1}+\alpha_{4} \hat{z}_{t}+\alpha_{5} \hat{b}_{t}+\alpha_{6} \hat{v}_{t}, \\
& \text { with } \\
& \alpha_{1}=\frac{h \beta e^{G}}{\left(e^{G}-h \beta\right)\left(e^{G}-h\right)}, \quad \alpha_{2}=\frac{e^{2 G}+h^{2} \beta}{\left(e^{G}-h \beta\right)\left(e^{G}-h\right)}, \quad \alpha_{3}=\frac{h e^{G}}{\left(e^{G}-h \beta\right)\left(e^{G}-h\right)}, \\
& \alpha_{4}=\frac{h \beta e^{G} \rho_{z}-h e^{G}}{\left(e^{G}-h \beta\right)\left(e^{G}-h\right)}, \quad \alpha_{5}=\frac{e^{G}-h \beta \rho_{b}}{e^{G}-h \beta}, \quad \alpha_{6}=\frac{\left(h \beta e^{G} \rho_{v}-h e^{G}\right) \frac{a_{c}}{1-a_{i}}}{\left(e^{G}-h \beta\right)\left(e^{G}-h\right)}, \\
& e^{G}=e^{g_{a}+\frac{a_{c}}{1-a_{i}} g_{v}} .
\end{aligned}
$$

This assumes the shock processes (4) and (1). 
Euler equation:

$$
\hat{\lambda}_{t}=\hat{R}_{t}+E_{t}\left(\hat{\lambda}_{t+1}-\hat{z}_{t+1}-\hat{v}_{t+1} \frac{a_{c}}{1-a_{i}}-\hat{\pi}_{C, t+1}\right) .
$$

\section{C.6.4 Investment and Capital}

Capital utilization in both sectors:

$$
\hat{r}_{C, t}^{K}=\chi_{C} \hat{u}_{C, t}, \quad \hat{r}_{I, t}^{K}=\chi_{I} \hat{u}_{I, t}, \quad \text { where } \quad \chi_{x}=\frac{a_{x}^{\prime \prime}(1)}{a_{x}^{\prime}(1)} .
$$

Choice of investment for the consumption sector:

$$
\begin{aligned}
\hat{q}_{C, t}= & e^{2\left(\frac{1}{1-a_{i}} g_{v}\right)} \kappa\left(\hat{i}_{C, t}-\hat{i}_{C, t-1}+\frac{1}{1-a_{i}} \hat{v}_{t}\right)-\beta e^{2\left(\frac{1}{1-a_{i}} g_{v}\right)} \kappa E_{t}\left(\hat{i}_{C, t+1}-\hat{i}_{C, t}+\frac{1}{1-a_{i}} \hat{v}_{t+1}\right) \\
& +\hat{p}_{i, t}
\end{aligned}
$$

with $\hat{q}_{C, t}=\hat{\phi}_{C, t}-\hat{\lambda}_{t}$.

Choice of investment for the investment sector:

$$
\begin{aligned}
\hat{q}_{I, t}= & e^{2\left(\frac{1}{1-a_{i}} g_{v}\right)} \kappa\left(\hat{i}_{I, t}-\hat{i}_{I, t-1}+\frac{1}{1-a_{i}} \hat{v}_{t}\right)-\beta e^{2\left(\frac{1}{1-a_{i}} g_{v}\right)} \kappa E_{t}\left(\hat{i}_{I, t+1}-\hat{i}_{I, t}+\frac{1}{1-a_{i}} \hat{v}_{t+1}\right) \\
& +\hat{p}_{i, t}
\end{aligned}
$$

with $\hat{q}_{I, t}=\hat{\phi}_{I, t}-\hat{\lambda}_{t}$.

Capital services input in both sectors:

$$
\hat{k}_{C, t}=\hat{u}_{C, t}+\xi_{C, t}^{K}+\hat{\bar{k}}_{C, t-1}-\frac{1}{1-a_{i}} \hat{v}_{t}, \quad \hat{k}_{I, t}=\hat{u}_{I, t}+\xi_{I, t}^{K}+\hat{\bar{k}}_{I, t-1}-\frac{1}{1-a_{i}} \hat{v}_{t} .
$$

Capital accumulation in the consumption and investment sector:

$$
\begin{aligned}
& \hat{\bar{k}}_{C, t}=\left(1-\delta_{C}\right) e^{-\frac{1}{1-a_{i}} g_{v}}\left(\hat{\bar{k}}_{C, t-1}+\xi_{C, t}^{K}-\frac{1}{1-a_{i}} \hat{v}_{t}\right)+\left(1-\left(1-\delta_{C}\right) e^{-\frac{1}{1-a_{i}} g_{v}}\right) \hat{i}_{C, t}, \\
& \hat{\bar{k}}_{I, t}=\left(1-\delta_{I}\right) e^{-\frac{1}{1-a_{i}} g_{v}}\left(\hat{\bar{k}}_{I, t-1}+\xi_{I, t}^{K}-\frac{1}{1-a_{i}} \hat{v}_{t}\right)+\left(1-\left(1-\delta_{I}\right) e^{-\frac{1}{1-a_{i}} g_{v}}\right) \hat{i}_{I, t} .
\end{aligned}
$$




\section{C.6.5 Wages}

The wage setting equation for workers renegotiating their salary:

$$
\begin{aligned}
0= & E_{t}\left\{\sum_{s=0}^{\infty} \xi_{w}^{s} \beta^{s}\left[\hat{\tilde{w}}_{t}+\hat{\tilde{\Pi}}_{t, t+s}^{w}-\hat{\lambda}_{w, t+s}-\hat{b}_{t+s}-\nu \hat{\tilde{L}}_{t+s}+\hat{\lambda}_{t+s}\right]\right\}, \\
& \text { with } \\
\hat{\tilde{\Pi}}_{t, t+s}^{w}= & \sum_{k=1}^{s}\left[\iota_{w}\left(\hat{\pi}_{c, t+k-1}+\hat{z}_{t+k-1}+\frac{a_{c}}{1-a_{i}} \hat{v}_{t+k-1}\right)-\left(\hat{\pi}_{c, t+k}+\hat{z}_{t+k}+\frac{a_{c}}{1-a_{i}} \hat{v}_{t+k}\right)\right], \\
& \text { and } \\
\hat{\tilde{L}}_{t+s}= & \hat{L}_{t+s}-\left(1+\frac{1}{\lambda_{w}}\right)\left(\hat{\tilde{w}}_{t}+\hat{\tilde{\Pi}}_{t, t+s}^{w}-\hat{w}_{t+s}\right) .
\end{aligned}
$$

Then using the labor demand function,

$$
\begin{aligned}
0= & E_{t}\left\{\sum _ { s = 0 } ^ { \infty } \xi _ { w } ^ { s } \beta ^ { s } \left[\hat{\tilde{w}}_{t}+\hat{\tilde{\Pi}}_{t, t+s}^{w}-\hat{\lambda}_{w, t+s}-\hat{b}_{t+s}\right.\right. \\
& \left.\left.-\nu\left(\hat{L}_{t+s}-\left(1+\frac{1}{\lambda_{w}}\right)\left(\hat{\tilde{w}}_{t}+\hat{\tilde{\Pi}}_{t, t+s}^{w}-\hat{w}_{t+s}\right)\right)+\hat{\lambda}_{t+s}\right]\right\} \\
\Leftrightarrow 0= & E_{t}\left\{\sum _ { s = 0 } ^ { \infty } \xi _ { w } ^ { s } \beta ^ { s } \left[\hat{\tilde{w}}_{t}\left(1+\nu\left(1+\frac{1}{\lambda_{w}}\right)\right)+\hat{\tilde{\Pi}}_{t, t+s}^{w}-\hat{\lambda}_{w, t+s}-\hat{b}_{t+s}\right.\right. \\
& \left.\left.-\nu\left(\hat{L}_{t+s}-\left(1+\frac{1}{\lambda_{w}}\right)\left(\hat{\tilde{\Pi}}_{t, t+s}^{w}-\hat{w}_{t+s}\right)\right)+\hat{\lambda}_{t+s}\right]\right\} .
\end{aligned}
$$

Solving for the summation,

$$
\begin{aligned}
\frac{\nu_{w}}{1-\xi_{w} \beta} \hat{\tilde{w}}_{t} & =E_{t}\left\{\sum_{s=0}^{\infty} \xi_{w}^{s} \beta^{s}\left[-\left(1+\nu\left(1+\frac{1}{\lambda_{w}}\right)\right) \hat{\tilde{\Pi}}_{t, t+s}^{w}+\hat{\psi}_{t+s}\right]\right\} \\
& =-\nu_{w} \hat{\tilde{\Pi}}_{t, t}^{w}+\hat{\psi}_{t}+E_{t}\left\{\sum_{s=0}^{\infty} \xi_{w}^{s} \beta^{s}\left[-\nu_{w} \hat{\tilde{\Pi}}_{t, t+s}^{w}+\hat{\psi}_{t+s}\right]\right\} \\
& =\hat{\psi}_{t}-\frac{\xi_{w} \beta}{1-\xi_{w} \beta} \nu_{w} \hat{\Pi}_{t, t+1}^{w}+\xi_{w} \beta E_{t}\left\{\sum_{s=0}^{\infty} \xi_{w}^{s} \beta^{s}\left[-\nu_{w} \hat{\Pi}_{t+1, t+1+s}^{w}+\hat{\psi}_{t+1+s}\right]\right\} \\
& =\hat{\psi}_{t}+\frac{\xi_{w} \beta}{1-\xi_{w} \beta} \nu_{w} E_{t}\left[\hat{\tilde{w}}_{t+1}-\hat{\tilde{\Pi}}_{t, t+1}^{w}\right] .
\end{aligned}
$$

where

$$
\begin{aligned}
\hat{\psi}_{t} & \equiv \hat{\lambda}_{w, t}+\hat{b}_{t}+\nu \hat{L}_{t}+\nu\left(1+\frac{1}{\lambda_{w}}\right) \hat{w}_{t}-\hat{\lambda}_{t}, \\
\nu_{w} & \equiv 1+\nu\left(1+\frac{1}{\lambda_{w}}\right)
\end{aligned}
$$


and recall that $\hat{\tilde{\Pi}}_{t, t}^{w}=0$.

Wages evolve as,

$$
\begin{aligned}
\hat{w}_{t} & =\left(1-\xi_{w}\right) \hat{\tilde{w}}_{t}+\xi_{w}\left(\hat{w}_{t-1}+\iota_{w} \hat{\pi}_{c, t-1}+\iota_{w}\left(\hat{z}_{t-1}+\frac{a_{c}}{1-a_{i}} \hat{v}_{t-1}\right)-\hat{\pi}_{c, t}-\hat{z}_{t}-\frac{a_{c}}{1-a_{i}} \hat{v}_{t}\right) \\
\Leftrightarrow & \hat{w}_{t}=\left(1-\xi_{w}\right) \hat{\tilde{w}}_{t}+\xi_{w}\left(\hat{w}_{t-1}+\hat{\tilde{\Pi}}_{t, t-1}^{w}\right) .
\end{aligned}
$$

Equation (C.52) can be solved for $\hat{\tilde{w}}_{t}$. This expression, as well as the formulation for $\hat{\psi}_{t}$ given in (C.51) can be plugged into equation (C.50). After rearranging this yields the wage Phillips curve,

$$
\begin{aligned}
\hat{w}_{t}= & \frac{1}{1+\beta} \hat{w}_{t-1}+\frac{\beta}{1+\beta} E_{t} \hat{w}_{t+1}-\kappa_{w} \hat{g}_{w, t}+\frac{\iota_{w}}{1+\beta} \hat{\pi}_{c, t-1}-\frac{1+\beta \iota_{w}}{1+\beta} \hat{\pi}_{c, t} \\
& +\frac{\beta}{1+\beta} E_{t} \hat{\pi}_{c, t+1}+\kappa_{w} \hat{\lambda}_{w, t}+\frac{\iota_{w}}{1+\beta}\left(\hat{z}_{t-1}+\frac{a_{c}}{1-a_{i}} \hat{v}_{t-1}\right) \\
& -\frac{1+\beta \iota_{w}-\rho_{z} \beta}{1+\beta} \hat{z}_{t}-\frac{1+\beta \iota_{w}-\rho_{v} \beta}{1+\beta} \frac{a_{c}}{1-a_{i}} \hat{v}_{t} .
\end{aligned}
$$

where

$$
\begin{aligned}
\kappa_{w} & \equiv \frac{\left(1-\xi_{w} \beta\right)\left(1-\xi_{w}\right)}{\xi_{w}(1+\beta)\left(1+\nu\left(1+\frac{1}{\lambda_{w}}\right)\right)}, \\
\hat{g}_{w, t} & \equiv \hat{w}_{t}-\left(\nu \hat{L}_{t}+\hat{b}_{t}-\hat{\lambda}_{t}\right) .
\end{aligned}
$$

\section{C.6.6 Financial sector}

The part of the economy concerned with the banking sector is described by the following equations:

The stochastic discount factor:

$$
\hat{\lambda}_{t}^{B}=\hat{\lambda}_{t}-\hat{\lambda}_{t-1}
$$

Definition of $\nu$ for $x=C, I$ :

$$
\begin{aligned}
\hat{\nu}_{x, t}= & \left(1-\theta_{B} \beta z_{1}^{x}\right)\left[\hat{\lambda}_{t+1}^{B}-\hat{z}_{t+1}-\frac{a_{c}}{1-a_{i}} \hat{v}_{t+1}\right] \\
& +\frac{1-\theta_{B} \beta z_{1}^{x}}{R_{x}^{B} \pi_{C}-R}\left[R_{x}^{B} \pi_{C} \hat{R}_{x, t+1}^{B}+R_{x}^{B} \pi_{C} \hat{\pi}_{C, t+1}-R \hat{R}_{t}\right]+\theta_{B} \beta z_{1}^{x}\left[\hat{z}_{1, t+1}^{x}+\hat{\nu}_{x, t+1}\right] .
\end{aligned}
$$


Definition of $\eta$ :

$$
\begin{aligned}
\hat{\eta}_{x, t}= & \left(1-\theta_{B} \beta z_{2}^{x}\right)\left[\hat{\lambda}_{t+1}^{B}-\hat{z}_{t+1}-\frac{a_{c}}{1-a_{i}} \hat{v}_{t+1}+\hat{R}_{t}\right] \\
& +\theta_{B} \beta z_{2}^{x}\left[\hat{z}_{2, t+1}^{x}+\hat{\eta}_{t+1}\right], \quad x=C, I .
\end{aligned}
$$

Definition of $z_{1}$ :

$$
\hat{z}_{1, t}^{x}=\hat{\varrho}_{x, t}-\hat{\varrho}_{x, t-1}+\hat{z}_{2, t}^{x}, \quad x=C, I .
$$

Definition of $z_{2}$ for $x=C, I$ :

$$
\hat{z}_{2, t}^{x}=\frac{\pi_{C}}{\left(R_{x}^{B}-R\right) \varrho_{x}+R}\left[R_{x}^{B} \varrho_{x}\left[\hat{R}_{x, t}^{B}+\hat{\pi}_{C, t}\right]+\frac{R}{\pi_{C}}\left(1-\varrho_{x}\right) \hat{R}_{t-1}+\left(R_{x}^{B} \pi_{C}-R\right) \frac{\varrho_{x}}{\pi_{C}} \hat{\varrho}_{x, t-1}\right]-\hat{\pi}_{C, t} .
$$

The leverage ratio:

$$
\hat{\varrho}_{x, t}=\hat{\eta}_{x, t}+\frac{\nu}{\lambda_{B}-\nu} \hat{\nu}_{x, t}, \quad x=C, I
$$

The leverage equation:

$$
\hat{q}_{x, t}+\hat{s}_{x, t}=\hat{\varrho}_{x, t}+\hat{n}_{x, t} .
$$

The bank's wealth accumulation equation

$$
\begin{aligned}
\hat{n}_{x, t}= & \theta_{B} \frac{\varrho_{x}}{\pi_{C}} e^{-g_{a}-\frac{a_{c}}{1-a_{i}} g_{v}}\left[R_{x}^{B} \pi_{C}\left[\hat{R}_{x, t}^{B}+\hat{\pi}_{C, t}\right]+\left(\frac{1}{\varrho_{x}}-1\right) R \hat{R}_{t-1}+\left(R_{x}^{B} \pi_{C}-R\right) \hat{\varrho}_{x, t-1}\right] \\
& +\frac{\theta_{B}}{\pi_{C}} e^{-g_{a}-\frac{a_{c}}{1-a_{i}} g_{v}}\left[\left(R_{x}^{B} \pi_{C}-R\right) \varrho_{x}+R\right]\left[-\hat{z}_{t}-\frac{a_{c}}{1-a_{i}} \hat{v}_{t}+\hat{n}_{x, t-1}-\hat{\pi}_{C, t}\right] \\
& +\left(1-\frac{\theta_{B}}{\pi_{C}} e^{-g_{a}-\frac{a_{c}}{1-a_{i}} g_{v}}\left[\left(R_{x}^{B} \pi_{C}-R\right) \varrho_{x}+R\right]\right)\left[\hat{q}_{x, t}+\hat{s}_{x, t}\right], \quad x=C, I .
\end{aligned}
$$

The borrow in advance constraint:

$$
\hat{\bar{k}}_{x, t+1}=\hat{s}_{x, t}, \quad x=C, I .
$$

The bank's stochastic return on assets in sector $x=C, I$ :

$$
\hat{R}_{x, t}^{B}=\frac{1}{r_{x}^{K}+q_{x}\left(1-\delta_{x}\right)}\left[r_{x}^{K}\left(\hat{r}_{x, t}^{K}+\hat{u}_{x, t}\right)+q_{x}\left(1-\delta_{x}\right) \hat{q}_{x, t}\right]-\hat{q}_{x, t-1}+\xi_{x, t}^{K}+\hat{z}_{t}-\frac{1-a_{c}}{1-a_{i}} \hat{v}_{t} .
$$


Excess (nominal) return:

$$
\hat{R}_{x, t}^{S}=\frac{R_{x}^{B} \pi_{C}}{R_{x}^{B} \pi_{C}-R}\left(\hat{R}_{x, t+1}^{B}+\hat{\pi}_{C, t+1}\right)-\frac{R}{R_{x}^{B} \pi_{C}-R} \hat{R}_{t}, \quad x=C, I .
$$

\section{C.6.7 Monetary policy and market clearing}

Monetary policy rule:

$$
\hat{R}_{t}=\rho_{R} \hat{R}_{t-1}+\left(1-\rho_{R}\right)\left[\phi_{\pi} \hat{\pi}_{c, t}+\phi_{\Delta Y}\left(\hat{y}_{t}-\hat{y}_{t-1}\right)\right]+\hat{\eta}_{m p, t}
$$

Resource constraint in the consumption sector:

$$
\hat{c}_{t}+\left(r_{C}^{K} \frac{\bar{k}_{C}}{c} \hat{u}_{C, t}+r_{I}^{K} \frac{\bar{k}_{I}}{c} \hat{u}_{I, t}\right) e^{-\frac{1}{1-a_{i}} g_{v}}=\frac{c+F_{c}}{c}\left[a_{c} \hat{k}_{C, t}+\left(1-a_{c}\right) \hat{L}_{C, t}\right]
$$

Resource constraint in the investment sector:

$$
\hat{i}_{t}=\frac{i+F_{I}}{i}\left[a_{i} \hat{k}_{I, t}+\left(1-a_{i}\right) \hat{L}_{I, t}\right]
$$

Definition of GDP:

$$
\hat{y}_{t}=\frac{c}{c+p_{i} i} \hat{c}_{t}+\frac{p_{i} i}{c+p_{i} i}\left(\hat{i}_{t}+\hat{p}_{i, t}\right)+\hat{e}_{t}
$$

Market clearing:

$$
\frac{L_{C}}{L} \hat{L}_{C, t}+\frac{L_{I}}{L} \hat{L}_{I, t}=\hat{L}_{t}, \quad \frac{i_{C}}{i} \hat{i}_{i, t}+\frac{i_{I}}{i} \hat{i}_{i, t}=\hat{i}_{t}
$$

\section{C.6.8 Exogenous processes}

The 10 exogenous processes of the model can be written in log-linearized form as follows: Price markup in sector $x=C, I$ :

$$
\hat{\lambda}_{p, t}^{x}=\rho_{\lambda_{p}^{x}} \hat{\lambda}_{p, t-1}^{x}+\varepsilon_{p, t}^{x}
$$

The TFP growth (consumption sector):

$$
\hat{z}_{t}=\rho_{z} \hat{z}_{t-1}+\varepsilon_{t}^{z}
$$


The TFP growth (investment sector):

$$
\hat{v}_{t}=\rho_{v} \hat{v}_{t-1}+\varepsilon_{t}^{v} .
$$

Wage markup:

$$
\hat{\lambda}_{w, t}=\rho_{w} \hat{\lambda}_{w, t-1}+\varepsilon_{w, t} .
$$

Preference:

$$
\hat{b}_{t}=\rho_{b} \hat{b}_{t-1}+\varepsilon_{t}^{b}
$$

Monetary policy:

$$
\hat{\eta}_{m p, t}=\varepsilon_{t}^{m p} .
$$

GDP measurement error:

$$
\hat{e}_{t}=\rho_{e} \hat{e}_{t-1}+\varepsilon_{t}^{e}
$$

Capital quality in sector $x=C, I$ :

$$
\hat{\xi}_{x, t}^{K}=\rho_{\xi^{K}, x} \hat{\xi}_{x, t-1}^{K}+\varepsilon_{x, t}^{\xi^{K}}
$$

The entire log-linear model is summarized by equations (C.39) - (C.49) and (C.53) (C.69) as well as the shock processes (C.70) - (C.77).

\section{C.7 Measurement equations}

For estimation model variables are linked with observables using measurement equations. Letting a superscript "d" denote observable series, then the model's measurement equations are as follows:

Real consumption growth,

$$
\Delta C_{t}^{d} \equiv \log \left(\frac{C_{t}}{C_{t-1}}\right)=\log \left(\frac{c_{t}}{c_{t-1}}\right)+\hat{z}_{t}+\frac{a_{c}}{1-a_{i}} \hat{v}_{t}
$$

Real investment growth,

$$
\Delta I_{t}^{d} \equiv \log \left(\frac{I_{t}}{I_{t-1}}\right)=\log \left(\frac{i_{t}}{i_{t-1}}\right)+\frac{1}{1-a_{i}} \hat{v}_{t}
$$


Real wage growth,

$$
\Delta W_{t}^{d} \equiv \log \left(\frac{W_{t}}{W_{t-1}}\right)=\log \left(\frac{w_{t}}{w_{t-1}}\right)+\hat{z}_{t}+\frac{a_{c}}{1-a_{i}} \hat{v}_{t}
$$

Real output growth,

$$
\Delta Y_{t}^{d} \equiv \log \left(\frac{Y_{t}}{Y_{t-1}}\right)=\log \left(\frac{y_{t}}{y_{t-1}}\right)+\hat{z}_{t}+\frac{a_{c}}{1-a_{i}} \hat{v}_{t},
$$

Consumption sector inflation,

$$
\pi_{C, t}^{d} \equiv \pi_{C, t}=\hat{\pi}_{C, t} \quad \text { and } \quad \hat{\pi}_{C, t}=\log \left(\pi_{C, t}\right)-\log \left(\pi_{C}\right),
$$

Investment sector inflation,

$$
\pi_{I, t}^{d} \equiv \pi_{I, t}=\hat{\pi}_{I, t} \quad \text { and } \quad \hat{\pi}_{I, t}=\log \left(\pi_{I, t}\right)-\log \left(\pi_{I}\right),
$$

Total hours worked,

$$
L_{t}^{d} \equiv \log L_{t}=\hat{L}_{t}
$$

Nominal interest rate (federal funds rate),

$$
R_{t}^{d} \equiv \log R_{t}=\log \hat{R}_{t}
$$

Consumption sector corporate spread,

$$
R_{C, t}^{\Delta, d} \equiv \log R_{C, t}^{\Delta}=\frac{R_{x}^{B} \pi_{C}}{R_{x}^{B} \pi_{C}-R}\left(\log \hat{R}_{C, t+1}^{B}+\log \hat{\pi}_{C, t+1}\right)-\frac{R}{R_{x}^{B} \pi_{C}-R} \log \hat{R}_{t}
$$

Investment sector corporate spread,

$$
R_{I, t}^{\Delta, d} \equiv \log R_{I, t}^{\Delta}=\frac{R_{x}^{B} \pi_{C}}{R_{x}^{B} \pi_{C}-R}\left(\log \hat{R}_{I, t+1}^{B}+\log \hat{\pi}_{C, t+1}\right)-\frac{R}{R_{x}^{B} \pi_{C}-R} \log \hat{R}_{t},
$$

Real total equity capital growth,

$$
\begin{aligned}
\Delta N_{t}^{d} & \equiv \log \left(\frac{N_{t}}{N_{t-1}}\right) \\
& =e^{g_{a}+\frac{a_{c}}{1-a_{i}} g_{v}}\left(\frac{n_{C}}{n_{C}+n_{I}}\left(\hat{n}_{C, t}-\hat{n}_{C, t-1}\right)+\frac{n_{I}}{n_{C}+n_{I}}\left(\hat{n}_{I, t}-\hat{n}_{I, t-1}\right)+\hat{z}_{t}+\frac{a_{c}}{1-a_{i}} \hat{v}_{t}\right) .
\end{aligned}
$$

